Raciocínio de agentes musicais composição algorítmica, vida artificial e interatividade em sistemas multiagentes musicais

\author{
Santiago David Dávila Benavides
}

DisSERTAÇÃO APRESENTADA

$\mathrm{AO}$

Instituto DE MATEMÁticA E Estatística

DA

Universidade DE SÃO PAUlo

PARA

OBTENÇÃO DO TÍTULO

DE

Mestre EM CiênCIAS

Programa: Ciência da Computação

Orientador: Prof. Dr. Marcelo Gomes de Queiroz 


\title{
Raciocínio de agentes musicais composição algorítmica, vida artificial \\ e interatividade em sistemas multiagentes musicais
}

\author{
Esta dissertação contém as correções e alterações \\ sugeridas pela Comissão Julgadora durante a defesa \\ realizada por Santiago David Dávila Benavides em 03/09/2012. \\ O original encontra-se disponível no Instituto de \\ Matemática e Estatística da Universidade de São Paulo.
}

Comissão Julgadora:

- Prof. Dr. Marcelo Gomes de Queiroz (Orientador) - IME-USP

- Prof. Dr. Rogério Luiz Moraes Costa - ECA-USP

- Prof. Dr. Flávio Soares Corrêa da Silva - IME-USP 


\section{Resumo}

\section{Raciocínio de agentes musicais composição algorítmica, vida artificial e interativi- dade em sistemas multiagentes musicais}

Os múltiplos trabalhos de sistemas multiagentes musicais realizados nos últimos anos demonstram o interesse crescente na pesquisa de sistemas de composição e de performance musical que utilizem a tecnologia de agentes computacionais, sendo que apresentam um interesse maior por aqueles sistemas que integram técnicas de composição algorítmica, componentes de vida artificial e interatividade. Observamos também que a maioria dos trabalhos existentes apresentam muitas limitações em termos de escopo e flexibilidade, normalmente apresentando codificação musical simbólica e a resolução de um único problema, sendo que a motivação é mais técnica do que musical. Nesse contexto, surgem arcabouços voltados à criação de sistemas multiagentes musicais, como o Ensemble e o Interactive Swarm Orchestra, oferecendo flexibilidade para a modelagem e implementação de sistemas desse tipo, diversificando tanto os tipos de aplicação, tendo um propósito composicional ou performático, como os tipos de codificação musical que podem ser utilizados. Partimos da aparição dessas ferramentas para estudar o agente musical a partir de uma perspectiva interna, focando nos seus raciocínios, que são processos que definem o comportamento do agente no ambiente virtual do sistema e que são fundamentais para determinar e melhorar o seu valor composicional. Os arcabouços estudados se diferenciam por permitir a utilização de áudio como possível formato de codificação musical, o aproveitamento da espacialização sonora e a exploração da interatividade nos aplicativos, seja esta apenas entre agentes computacionais ou entre agentes e usuários humanos. Pretendemos portanto, nessa pesquisa, abordar sistemas com essas características. Através de extensões nos arcabouços e estudos de caso com motivação estética pretendemos dar continuidade a esses projetos e ao mesmo tempo validar e divulgar a sua utilização entre os potenciais usuários das ferramentas, como compositores, músicos interessados em performance e outros entusiastas dos sistemas musicais interativos.

Palavras-chave: sistemas multiagentes, raciocínio do agente, composição algorítmica, computação musical. 


\section{Abstract}

\section{Musical agents reasoning, algorithmic composition, artificial life and interactivity in multiagent musical systems}

Multiple musical multiagent systems have been developed in the last years proving the increasing interest in composition and musical performance systems that exploit intelligent agents technology. There's an special focus on systems that integrate algorithmic composition techniques, artificial life and interactivity. We can also observe that most of these existing projects show many flexibility and scope limitations, as they normally use symbolic musical notation and they solve a single issue or scenario, as well as they have a technical motivation rather than a musical one. In that context, some musical multiagent systems frameworks as Ensemble and Interactive Swarm Orchestra emerge, trying to help the modeling and development of this kind of musical systems, diversifying the applications' types, as they can be composition problems or musical performances, and allowing the inclusion of other kind of musical content communication. Through these new tools we study the musical agent from an internal perspective, focusing on its reasoning components, processes that define the behavior of an agent on its system's virtual environment and that are essential to determine and improve its compositional value. The studied frameworks show unique features as they support audio as a possible musical notation format; they exploit sound spatialization and they work with interactivity in their applications, including agent-to-agent or human-to-agent interaction. We will explore this type of systems on this research. Through framework extensions and aesthetics-oriented study cases we pretend to continue these projects and validate them at same time. We also will contact potential users for these tools, as composers and musicians interested in performances or other musical interactive systems enthusiasts.

Keywords: multiagent systems, agent reasoning, algorithmic composition, computer music. 


\section{Sumário}

Lista de Abreviaturas vii

$\begin{array}{lc}\text { Lista de Figuras } & \text { ix }\end{array}$

Lista de Tabelas $\quad$ xi

1 Introdução $\quad 1$

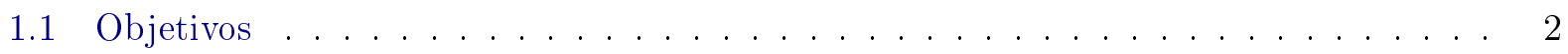

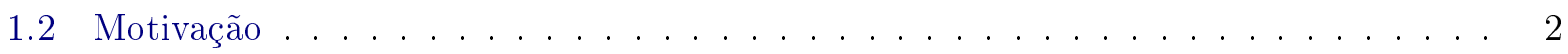

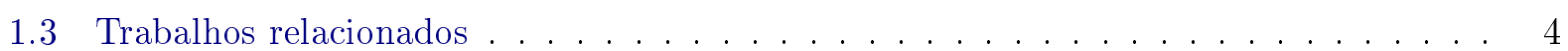

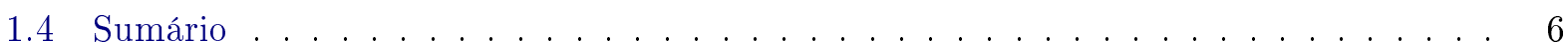

$\begin{array}{lll}2 & \text { Fundamentação Teórica } & 7\end{array}$

2.1 Sistemas Multiagentes Musicais . . . . . . . . . . . . . . . . . . 7

2.1 .1 Agentes Musicais Inteligentes _ . . . . . . . . . . . . . . 8

2.1.2 Ambiente Acústico e Ecológico . . . . . . . . . . . . . . . . . . . 11

2.1 .3 Interações . . . . . . . . . . . . . . . . . . . . . . . . . . 13

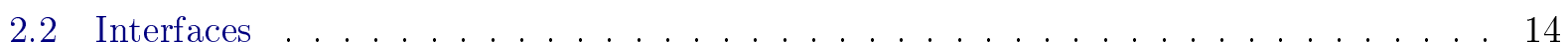

2.2.1 Interfaces com Sistemas Externos . . . . . . . . . . . . . . . . . . . 14

2.2 .2 Interfaces com bibliotecas . . . . . . . . . . . . . . . . 15

2.2 .3 Interface de usuário . . . . . . . . . . . . . . . . . . . . . 15

2.2 .4 Linguagens de Interface . . . . . . . . . . . . . . . . . . . . . . . . . . . . . . . . . . . . . . . 15

2.2.5 Linguagem para operação de Agentes . . . . . . . . . . . . . . . . . . . . 17

2.3 Desenho de uma Aplicação Musical . . . . . . . . . . . . . . . . . . . . . . . . . . . . . . . . . . . . . . . . . . . .

2.3 .1 Decisões composicionais . . . . . . . . . . . . . . . 18

2.3 .2 Raciocínio do agente . . . . . . . . . . . . . . . . . . . . . . . . . . . . . . . . . . 22

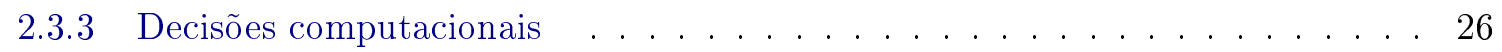

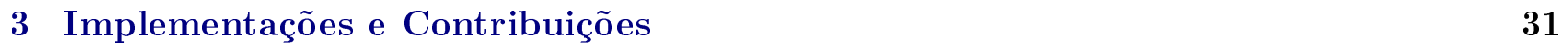

3.1 Extensões dos Arcabouços de SMA Musicais . . . . . . . . . . . . . . . . . . . . . . . . . . . . 31

3.1.1 Servidor de eventos de mensagens . . . . . . . . . . . . . . . . 32

3.1 .2 Integração com interfaces OSC . . . . . . . . . . . . . . . . . . . . . . . . . .

3.1 .3 Integração com Swarms . . . . . . . . . . . . . . . . . . . . . 40

3.1 .4 Processamento de áudio . . . . . . . . . . . . . . . . . . 43

3.2 Linguagem descritiva no Ensemble (EARScript) . . . . . . . . . . . . . . . . 47

3.2 .1 Motivação . . . . . . . . . . . . . . . . . . 47 
$3.2 .2 \quad$ Escopo . . . . . . . . . . . . . . . . . . . . . . . 49

3.2 .3 Princípios do STEP aplicados ao EARScript . . . . . . . . . . . . . . 49

3.2 .4 Estrutura da linguagem . . . . . . . . . . . . . . . . . . 52

3.2 .5 Integração com o Arcabouço . . . . . . . . . . . . . . . . . . 54

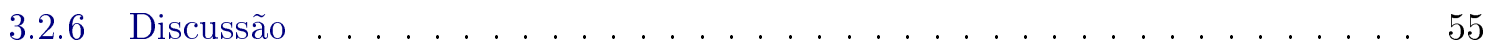

4 Aplicações e estudos de caso $\quad 57$

4.1 Gerador de material eletroacústico . . . . . . . . . . . . . . . . 57

4.1 .1 Contexto composicional . . . . . . . . . . . . . . . . . 58

4.1 .2 Agente Musical . . . . . . . . . . . . . . . . . . . . . . . . . . 59

4.1 .3 Ambiente virtual . . . . . . . . . . . . . . . . . . . 59

4.1 .4 Raciocínio . . . . . . . . . . . . . . . . . 60

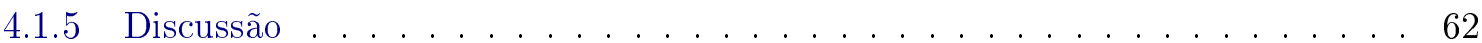

4.2 Espacialização de músicos com avatares no espaço virtual . . . . . . . . . . . . . 62

4.2 .1 Interesse performático . . . . . . . . . . . . . . . . . 63

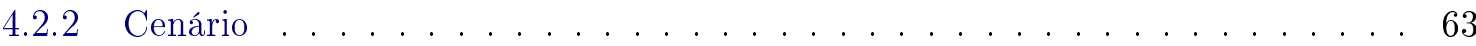

4.2 .3 Agente Musical . . . . . . . . . . . . . . . . . . . . . . . 64

4.2 .4 Ambiente virtual . . . . . . . . . . . . . . . . . . . 65

4.2 .5 Raciocínio . . . . . . . . . . . . . . . . . . . 65

4.3 Aplicação de Piano preparado . . . . . . . . . . . . . . . . . . . 67

4.3.1 Contexto composicional . . . . . . . . . . . . . . . . . 67

4.3 .2 Cenário . . . . . . . . . . . . . . . . . . . 67

4.3 .3 Agente Musical . . . . . . . . . . . . . . . . . . . . . . . . 68

4.3 .4 Raciocínio . . . . . . . . . . . . . . . . . . . 69

4.3.5 Considerações Técnicas . . . . . . . . . . . . . . . . . . 70

4.3 .6 Gravação . . . . . . . . . . . . . . . . . . . . . . . 72

5 Conclusões e trabalhos futuros $\quad \mathbf{7 9}$

5.1 Considerações . . . . . . . . . . . . . . . . . . . . . . 80

5.2 Limitações do Java para o Processamento de Áudio e Portabilidade . . . . . . . . . . 81

5.3 Trabalhos Futuros . . . . . . . . . . . . . . . . . . . 82

A Código da Interface do Piano Preparado - ControlOsC $\quad 83$

$\begin{array}{ll}\text { B Esquema de Gravação } & 87\end{array}$

$\begin{array}{ll}\text { C Manual de Uso da Aplicação } & 91\end{array}$

$\begin{array}{ll}\text { Referências Bibliográficas } & 95\end{array}$ 


\section{Lista de Abreviaturas}

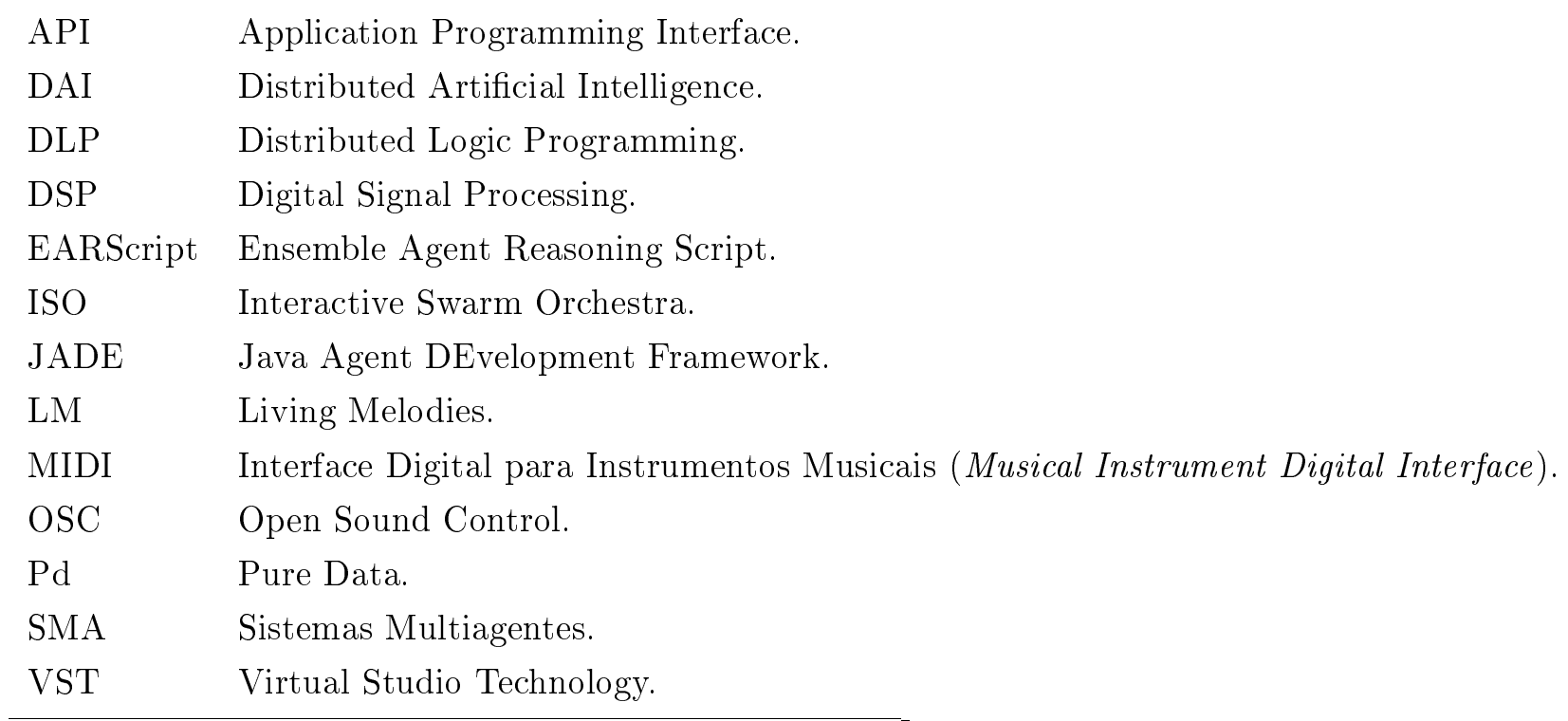




\section{Lista de Figuras}

2.1 Tela do Sniffer do ENSEMBLE . . . . . . . . . . . . . . . . . . . . 16

2.2 Alternativas baseadas na estrutura . . . . . . . . . . . . . . . . . . 19

2.3 Alternativas baseadas no processo . . . . . . . . . . . . . . . . . . . . 20

2.4 Operador Genético de Crossover . . . . . . . . . . . . . . . . . . . . . 24

2.5 Operador Genético de Mutação . . . . . . . . . . . . . . . . . . . . . 24

2.6 Ciclo resumido do Algoritmo Genético Clássico . . . . . . . . . . . . . . . . 25

3.1 Exemplo da filtragem no roteamento de comandos - RouterAgent . . . . . . . . . . 33

3.2 Método de formatação processAndOsc . . . . . . . . . . . . . . . . . . 33

3.3 Diagrama de classe do Servidor de Eventos de Mensagens . . . . . . . . . . . . . . 34

3.4 Exemplo de inclusão do servidor de Eventos de Mensagens . . . . . . . . . . . . . . 35

3.5 Exemplo de inclusão de Atuador e Sensor de Mensagens . . . . . . . . . . . . . . 35

3.6 Tela Principal do aplicativo AndOSC . . . . . . . . . . . . . . . 37

3.7 Tela de Configuração do aplicativo AndOSC . . . . . . . . . . . . . . . 38

3.8 Tela da Interface Monome - ControlOSC . . . . . . . . . . . . . . . . . . . . . . . 39

3.9 Tela da Interface Prepared Piano - ControlOSC . . . . . . . . . . . . . . . . . . 40

3.10 Diagrama de comunicação com o ENSEMBLE via OSC . . . . . . . . . . . . . . 41

3.11 Tela da Configuração de Envio OSC - CocoaFlock . . . . . . . . . . . . . . . . 42

3.12 Inicialização da classe Router Agent de roteamento de comandos . . . . . . . . . . . . 43

3.13 Patch de Roteamento de Mensagens OSC - ISO Swarm . . . . . . . . . . . . . . . 44

3.14 Exemplo da carga e configuração de um plug-in VST . . . . . . . . . . . . . . . . . 45

3.15 Exemplo do uso de um filtro - FilterProcessing . . . . . . . . . . . . . . . 46

3.16 Diagrama de Processamentos de áudio com o ENSEMBLE . . . . . . . . . . . . . . 47

3.17 Exemplo da Definição de um Valor em linguagem natural no EARScript . . . . . . . 49

3.18 Exemplo de sequência de instruções no EARScript . . . . . . . . . . . . . . . . 50

3.19 Exemplo de instruções em paralelo no EARScript . . . . . . . . . . . . . . . . 50

3.20 Exemplo de escolha aleatória de instruções no EARScript . . . . . . . . . . . . . . 50

3.21 Exemplo de repetição simples de instruções no EARScript . . . . . . . . . . . . . . 50

3.22 Exemplo de Redefinição de instruções no EARScript . . . . . . . . . . . . . . . . . 51

3.23 Exemplo de Definição de parâmetros no EARScript . . . . . . . . . . . . . . . . 51

3.24 Exemplo do Operador TEST no EARScript . . . . . . . . . . . . . . . . . . . 52

3.25 Exemplo do Operador SET no EARScript . . . . . . . . . . . . . . . . . 52

3.26 Exemplo do Operador IF no EARScript . . . . . . . . . . . . . . . . . . . 52

3.27 Exemplo de Definição de variável do Mundo Virtual . . . . . . . . . . . . . . . . 52 
3.28 Exemplo de Definição da posição Atual de um Agente . . . . . . . . . . . . . . . 53

3.29 Exemplo da Seção de um parâmetro de Agente . . . . . . . . . . . . . . . . . . . . . . . . . . . 53

3.30 Exemplo da Seção de Ações básicas de um Servidor de Evento . . . . . . . . . . . . . 54

3.31 Exemplo da Seção de Script no EARScript . . . . . . . . . . . . . . . . . . . 54

4.1 Diagrama de Objetos do Agente Gerador . . . . . . . . . . . . . . . . . . . . 59

4.2 Diagrama de Objetos do Agente Ouvinte . . . . . . . . . . . . . . . . . . 60

4.3 Diagrama de Objetos de um Agente Ambiente com Movimentação e Troca de Áudio 60

4.4 Imagem da execução do cenário de Delay Espacializado . . . . . . . . . . . . . . . . . 64

4.5 Diagrama de Objetos do Agente Avatar . . . . . . . . . . . . . . . . . . 65

4.6 Diagrama de Objetos do Agente Alto-falante . . . . . . . . . . . . . . . . 65

4.7 Definição do Agente Avatar no Delay Espacializado . . . . . . . . . . . . . . . . 66

4.8 Diagrama de Objetos de um Agente Instrumentista . . . . . . . . . . . . . . . . . 69

4.9 Diagrama da divisão por Quadrantes no Mundo Virtual da aplicação com Piano Preparado . . . . . . . . . . . . . . . . . 70

4.10 Diagrama de Interação com o Piano Preparado e Interfaces OSC - Cenário de Agentes Multi-instrumentistas . . . . . . . . . . . . . . . . . 71

4.11 Definição do Agente Multi-intrumentista no cenário do Piano Preparado . . . . . . . 71

4.12 Esquema da Gravação dos cenários ENSEMBLE com o Piano Preparado . . . . . . . 72

4.13 Preparação do Piano usada na Gravação . . . . . . . . . . . . . . . . . . 73 


\section{Lista de Tabelas}

2.1 Características simplificadas dos agentes $\ldots \ldots \ldots \ldots \ldots \ldots$

2.2 Atores da Arquitetura Ensemble . . . . . . . . . . . . . . . . . . 28

2.3 Bibliotecas de Áudio . . . . . . . . . . . . . . . . . . . . . . . 29

3.1 Estrutura da Classe Command . . . . . . . . . . . . . . . . . . . . . . 34

3.2 Parâmetros inclusos nos comandos internos . . . . . . . . . . . . . 36

3.3 Tipos de Mensagens OSC do aplicativo AndOSC . . . . . . . . . . . . . . 37

3.4 Comandos na interface Monome Emulation - ControlOSC . . . . . . . . . . . . . 39

3.5 Comandos na interface Prepared Piano - ControlOSC . . . . . . . . . . . . . . . . 40

3.6 Estímulos no raciocínio de Peak Tracking . . . . . . . . . . . . . . . . . 46

4.1 Características no Desenho do Gerador de material eletroacústico . . . . . . . . . . 74

4.2 Características no Desenho do Sistema de Espacialização com Avatares . . . . . . . . 75

4.3 Paramêtros de Controle na aplicação Delay Espacializado . . . . . . . . . . . . 76

4.4 Condições de controle na aplicação Piano Preparado . . . . . . . . . . . . . . . . 76

4.5 Paramêtros de Controle na aplicação Piano Preparado - ControlOSC . . . . . . . . . 76

4.6 Configuração do Notebook utilizado na Gravação dos cenários . . . . . . . . . . . . 76

4.7 Características no Desenho do Piano Preparado . . . . . . . . . . . . . . . 77 


\section{Capítulo 1}

\section{Introdução}

O computador tem sido utilizado por compositores para vários fins tais como a análise de peças, o estudo de estilos composicionais e a produção de sistemas de notação. Porém, se focarmos nas tarefas intrínsecas da composição, o computador tem sido principalmente usado para dois propósitos: como uma ajuda para cálculos pré-composicionais ou para produzir material sonoro, o que pode ocorrer tanto antes de uma eventual performance quanto durante a performance.

A composição algorítmica tem como propósito combinar elementos ou abstrações musicais a partir de regras ou operações; as múltiplas técnicas existentes oferecem ao compositor a possibilidade de controlar parâmetros musicais gerais como textura, harmonicidade e densidade de acontecimentos simultâneos [Tho11]. Há mais de meio século, desde as primeiras experimentações de Xenakis com processos estocásticos manuais, ou da pioneira Illiac Suite de Hiller [HI58], muitas técnicas e ferramentas têm sido desenvolvidas e aperfeiçoadas.

Durante os últimos anos, novos objetivos e novos paradigmas computacionais têm chamado a atenção dos pesquisadores da área. Um desses objetivos é a interatividade nos sistemas musicais, que permite a humanos interagir de várias formas com sistemas musicais, seja guiando a criação de acompanhamentos musicais automáticos, definindo os parâmetros de criação de material sonoro ou como intermediários entre vários usuários músicos.

Nesse contexto surgem os sistemas multiagentes musicais (SMAs), que combinando a tecnologia de agentes computacionais e outras técnicas como a vida artificial à composição algorítmica definem um novo paradigma interativo de criação sonora e performance musical. Seja com processos estocásticos ou determinísticos, com participação direta ou indireta da contraparte humana, muitos trabalhos definem sistemas e os experimentam na criação musical, mas continua sendo questionável o valor estético de grande parte dessas abordagens.

Whalley [Wha05] descreve como um problema o interesse que tanto técnicos como artistas têm em se concentrar apenas nas suas próprias áreas de conhecimento, sendo que as melhores soluções podem vir apenas de uma perspectiva multidisciplinar. Assim, enquanto um artista se perde no aprendizado de mecanismos tecnológicos, o técnico prioriza sistemas intelectualmente desafiadores que possuem um limitado valor estético.

Uma das possíveis alternativas a esse problema são ferramentas que permitam que artistas possam transpor suas idéias criativas em sistemas computacionais sem curvas de aprendizagem desgastantes, ou através da intermediação de técnicos que adotem os objetivos estéticos como primordiais para o sucesso dos sistemas musicais. Nessa linha temos a aparição de arcabouços como o ENSEMBLE [TQ09] que permite a criação de aplicações multiagentes musicais abstraindo a complexidade da programação, contrastando assim com a maioria de trabalhos relacionados, que normalmente apresentam implementações não-reaproveitáveis. Igualmente o arcabouço ISO [BNF07] disponibiliza 
bibliotecas para o desenvolvimento de aplicações musicais multiagentes, focando na movimentação dos agentes num ambiente virtual. Uma das características interessantes desse arcabouço é a diversidade de produções artísticas já criadas que envolvem música e outras atividades artísticas, especialmente a dança.

Partimos da aparição dessas ferramentas para estudar o agente musical a partir de uma perspectiva interna, focando nos seus raciocínios, que são os processos que definem o comportamento do agente no ambiente virtual do sistema e que são fundamentais para concretizar as idéias composicionais dos usuários, tanto para a emissão de som como para outras funções do agente musical, ajudando assim a alcançar os objetivos estéticos da aplicação musical.

Os arcabouços estudados se diferenciam dos demais sistemas multiagentes por permitir a utilização de áudio como possível formato de codificação musical, o aproveitamento da espacialização sonora e a exploração da interatividade nos aplicativos. Pretendemos, portanto, nessa pesquisa, abordar sistemas com essas características.

\subsection{Objetivos}

A diretiva primária dessa pesquisa é dar continuidade ao arcabouço de criação de sistemas multiagentes musicais ENSEMBLE, a partir de uma perspectiva mais interdisciplinar e crítica, focando nos processos internos, ou raciocínios, do agente musical. Podemos destacar os seguintes objetivos:

- Estudar a problemática dos sistemas multiagentes musicais a partir de uma perspectiva interna do agente e definir o papel dos raciocínios no desenho de uma aplicação musical.

- Dar continuidade aos focos da pesquisa anterior [Tho11], tais como a interatividade, espacialidade e utilização de áudio como formato de codificação musical.

- Levantar, propôr e implementar raciocínios de agente reutilizáveis, com interesse composicional, adaptadas à troca de áudio.

- Fazer a mediação entre o arcabouço e músicos interessados em formular aplicações com finalidade estética que tenham uma visão composicional ou performática definida. Consequentemente o propósito também é divulgar e validar a ferramenta.

- Aproximar os usuários-alvo do arcabouço ENSEMBLE, através de mecanismos que facilitem a formulação de comportamentos do agente.

- Propor formas de integração para o arcabouço ENSEMBLE, principalmente com o projeto ISO, para agregar valor ao projeto.

\subsection{Motivação}

A tecnologia de agentes computacionais tem sido aplicada com sucesso em diversas áreas, e existem vários fatores que justificam o seu uso no contexto musical. Se fizermos uma analogia com problemas de busca ou otimização, na criação musical confrontamos um problema com "espaços de 
busca" composicionais muito extensos; e algumas abordagens musicais impõem uma divisão funcional, seja quando um integrante de um grupo de música eletroacústica se encarrega de controlar os parâmetros de patches em $\mathrm{Pd}$, mudando o resultado sonoro de outros músicos, ou quando por escolha composicional se separam as tarefas de criação musical em componentes como ritmo, melodia e harmonia [CVM08]. Essas características encaixam perfeitamente no escopo dos sistemas multiagentes.

Whalley [Wha09] afirma que alguns métodos encontrados nos sistemas musicais multiagentes podem ser implementados com outras tecnologias de Inteligência artificial, mas perder-se-ia a vantagem que os agentes computacionais proporcionam em termos de adaptação em tempo real.

Com essas observações constatamos a importância de prosseguir com a pesquisa de sistemas multiagentes musicais que consigam integrar técnicas e funcionalidades ao serviço dos artistas interessados. No entanto, numa época em que ferramentas voltadas para a criação de áudio como Pure Data [Puc96] e o CSound [VE90] já são parte do dia-a-dia do compositor, o acesso à criação com sistemas multiagentes musicais continua sendo difícil, requer habilidades específicas e muitas vezes é necessário começar uma implementação do zero.

Uma ferramenta como o arcabouço ENSEMBLE [TQ09], mais versátil e direcionada para usuários com um perfil menos técnico, oferece algumas soluções e ao mesmo tempo gera a necessidade de aprofundamento neste tema, a fim de expandir funcionalidades relevantes, fornecer interfaces mais amigáveis para os usuários e principalmente validar essas iniciativas como plataformas úteis para a expressão artística.

Esses mesmos SMA musicais se apresentam como o nicho ideal para aplicar e desenvolver técnicas de composição algorítmica, sejam aquelas recolhidas na literatura ou novas abordagens que agreguem valor e potencial aos agentes musicais. Outros âmbitos de desenvolvimento para esse tipo de sistemas são os games, que podem usufruir da experiência de espacialização do som, na perspectiva de um indivíduo dentro de um mundo virtual; tais sistemas também poderiam ser úteis para usuários de estúdio de gravação que poderiam mixar manipulando agentes da forma que manipulam canais de áudio. Outras aplicações possíveis estariam voltadas para uso da plateia e não necessariamente do compositor ou intérprete, por exemplo, individualizando a experiência espacial do som produzido por músicos numa determinada apresentação ao vivo.

Tratando uma outra diretiva desse trabalho, observamos que o uso do formato de áudio em pesquisas de sistemas multiagentes musicais é pouco comum, sendo que muitas vezes a escolha de um formato de codificação simbólica se deve exclusivamente à baixa exigência computacional, ou seja, a um requisito técnico e não estético. Disso vem a importância de trabalhar em aplicações que utilizem áudio, mais próximas da realidade musical contemporânea. Especificamente no caso dos agentes, isso exige a definição de componentes e raciocínios reutilizáveis que tenham como entrada e como resultado sinais de áudio.

As formas de interação com sistemas musicais podem ser desenvolvidas a partir de novas ferramentas, com mais funcionalidades disponíveis e de mais fácil acesso; aproveitando a crescente popularidade de ferramentas voltadas ao processamento sonoro, surge a possibilidade de integrar diferentes plataformas e agregar valor aos ambientes computacionais de produção musical já existentes.

Seguindo a linha proposta no arcabouço ENSEMBLE, a espacialidade constitui outro foco importante nessa pesquisa, que além de ter uma importância marcada na composição musical contemporânea é um dos pontos fortes do arcabouço, e como diferencial, precisa de uma atenção especial, através da exploração de sua utilização em expressões artísticas com características espaciais preponderantes como são as instalações e performances musicais interativas. 


\subsection{Trabalhos relacionados}

Existem vários trabalhos vinculados com computação musical e sistemas multiagentes musicais, que apresentam abordagens com um escopo limitado [Tho11], seja para descrever ecossistemas de agentes com emissão sonora [McC01][DN01] [Mir02][Mir03b] [Mir03a] [GMJ06], criação de peças musicais completas, sem edição ou intervenção posterior [DFMS09] [EP09] ou geração de acompanhamentos [WNV03] [MMH99] [MMZG00], entre outros propósitos. Alguns desses trabalhos, como por exemplo, o sistema Living Melodies [DN01] e a arquitetura MAMA [MRSE06], foram referências para a criação do arcabouço ENSEMBLE [Tho11], que levanta pontos em comum para permitir uma versatilidade na construção de aplicações SMA de intuito musical.

O sistema Living Melodies de Dahlstedt e Nordahl [DN01] trata a simulação de um ecossistema de agentes, num mundo discreto bidimensional. O comportamento individual segue regras de vida artificial, usando algoritmos genéticos para determinar as ações do agente. Os agentes têm como objetivo se alimentar e procriar assim como manter o sentido do prazer de cantar; o ambiente virtual, que usa uma abstração da transmissão do som, apresenta um resultado sonoro externo do mundo e permite que o usuário modifique alguns parâmetros de escuta como o mapeamento dos valores sonoros produzidos pelos agentes em notas fixas ou em intervalos, assim como a parametrização de limiares que determinam em que situações o som produzido por um agente será escutado pelo usuário. Nesse sistema os processos internos dos indivíduos se dão por regras simples e fixas de vida artificial que determinam desde a movimentação e a alimentação até o fato mesmo de cantar. O comportamento do indivíduo está determinado até mesmo na hora da reprodução, embora o resultado desta última tenha um componente aleatório.

Na mesma linha de trabalho, encontramos o sistema Eden [McC01], que possui semelhanças marcadas com o Living Melodies; a diferença está em que os indivíduos não têm a obrigação de cantar, e os comportamentos sonoros, quando mantidos, devem ser produto de estratégias que favoreçam a sobrevivência do indivíduo, seja para a reprodução ou na procura de recursos que mantenham sua energia.

É interessante observar nesses trabalhos a combinação da tecnologia de agentes com vida artificial, porém os comportamentos dos indivíduos, ou mesmo o valor estético do resultado sonoro, não são o foco no desenho da aplicação; no caso do Living Melodies, um indivíduo de uma espécie apenas pode emitir uma nota ou intervalo determinado, enquanto no Eden uma simulação poderia simplesmente não ter nenhum som produzido, se os agentes conseguirem sobreviver sem a característica de emissão sonora.

Em outro projeto que propõe um ecossistema sonoro, Eigenfeldt [EP11] aplica técnicas de vida artificial sem recorrer à reprodução ou evolução. A ênfase é dada aos relacionamentos entre os agentes e à comunicação, nesse sentido a proposta se aproxima de características oferecidas pelo arcabouço ENSEMBLE. Este projeto também define a figura de redes sociais para a interação entre agentes, que podem solicitar serem amigos de agentes adjacentes e determinar assim uma emissão sonora parametrizada pelo conjunto da rede. Utilizando síntese granular como método de geração sonora sobre áudio em tempo real criam-se unidades, elementos sonoros de $242 \mathrm{~ms}$ de duração que são espalhados no mundo virtual. Essas unidades são o alimento dos agentes que vivem e interagem no ambiente, e ao se alimentar eles processam o áudio da unidade. Partindo de parâmetros aleatórios para a movimentação e a emissão de áudio os agentes interagem e intercambiam esses valores durante a execução do sistema.

Uma diferença evidente nessa abordagem é que a informação sobre a posição dos agentes está 
armazenada em cada um deles, sem a existência de um ambiente centralizado como no caso do arcabouço ENSEMBLE. Por outro lado é interessante ressaltar que este é um dos poucos sistemas que consideram áudio como formato de codificação musical.

Em outro trabalho que prioriza os vínculos entre agentes, Beyls [Bey07] trata um ambiente distribuído com agentes que interagem socialmente seguindo o principio biológico da autopoiesis e um sistema de afinidades, considerando que a auto-organização permite que com o tempo surjam vínculos fortes e satisfatórios entre agentes, sejam ou não humanos, e o sistema. Clusters temporais são criados que permitem o intercâmbio de informação e parâmetros com os vizinhos. A complexidade da articulação musical resultante se deve aos processos internos nos agentes, que além de parâmetros próprios para determinar melodias também dependem de eventos grupais.

$\mathrm{Na}$ área da criação musical encontramos o projeto Inmamusys [DFMS09] que utiliza sistemas especialistas e princípios de sistemas baseados em regras na criação de um sistema multiagentes modular de composição. Dividido em camadas, primeiramente a partir de um grupo de agentes compositores especializados em vários estilos se escolhe o mais adequado à entrada do usuário. $\mathrm{O}$ agente compositor selecionado posteriormente escolhe numa segunda camada os agentes colaborativos que definem ritmo, número de vozes e instrumentos para completar uma solução. Recolhe-se a preferência do usuário que indica uma determinada emoção, como tristeza, felicidade ou medo, que será mapeada para determinar se o compositor usado será do estilo muzak (que simula música ambiental ou de "elevador"), ou escuro (que utiliza dissonâncias e intervalos de quintas diminutas) ou aleatório. Esse sistema, como muitos outros, representa a música de forma simbólica, e a participação do usuário se resume a informar alguns poucos parâmetros.

Também temos a abordagem de Wulfhorst, Nakayama e Vicari [WNV03] que apresentam um sistema multiagentes para a geração de acompanhamentos que simula um grupo instrumental. $\mathrm{O}$ trabalho tem foco nas interações entre os indivíduos para gerar e organizar resultados sonoros, os agentes conseguem perceber relações harmônicas e o ritmo do ambiente para se adaptar aos outros num contexto de música tonal. Definem-se características específicas nos agentes como a tendência ao improviso, o nível de flexibilidade para adaptação ou a liderança. É interessante observar nesse trabalho a capacidade de adaptação dos agentes em tempo real e a divisão funcional entre agentes.

Com uma abordagem diferente para a criação musical e principalmente com objetivo de experimentação, o sistema de Todd e Werner [TW99] tenta combinar técnicas de evolução, regras e aprendizado. Num contexto de vida artificial que tem como propósito a geração de material musical para uso posterior, são definidos indivíduos machos encarregados de cantar uma sequência de notas determinada na sua base de conhecimento, normalmente um processo interno simples e sem mudança, e fêmeas que decidem com que indivíduo acasalar seguindo critérios fixados, como a comparação direta ou indireta com uma tabela interna de transições. Essa utilização de críticos, ou juízes automatizados, acelera o processo de evolução em comparação à interação com uma contraparte humana. Os resultados se vêem condicionados pelas decisões estéticas das fêmeas.

Outras iniciativas interessantes abordam problemas como a inclusão de componentes expressivas, afetivas ou emocionais nos sistemas musicais, seja para modificar música em tempo real [LMBL07] ou criar automaticamente arranjos baseados em dados coletados pelo usuário [NTN02]. O interesse desses trabalhos está na possibilidade de agregar uma dimensão diferente aos SMA musicais e aos seus raciocínios de agentes.

Numa dessas iniciativas, Livingstone [LMBL07] propõe uma arquitetura de computação afetiva para modificar música em tempo real visando uma indução previsível de emoções musicais. Utiliza um sistema baseado em regras e define dois níveis de características musicais, de partitura e de performance para chegar a esse objetivo. Justifica a indução no ouvinte pelo modelo de transmissão 
da emoção, enquanto o modelo bidimensional do espaço emocional, o 2DES [Sch99], que considera os eixos de excitação e valência, é utilizado para mapear as emoções dos usuários, inferidas pelo feedback de sensores na pele e outros mecanismos como controles manipulados pelos usuários. As mudanças que o sistema realiza nas características performáticas têm como propósito humanizar o resultado musical simbólico do protótipo desenvolvido.

Num outro exemplo, o sistema criado por Numao [NTN02] tenta localizar as relações entre a partitura musical e o sentimento produzido num ouvinte, partindo da estrutura musical e princípios da teoria musical tonal. Primeiro, e em várias instâncias, são coletados dados vinculados com os sentimentos percebidos pelo usuários para peças específicas. Usando seis pares de adjetivos contrastantes e programação lógica indutiva, o sistema tenta automaticamente criar um arranjo de uma peça conhecida ou uma nova composição a partir de algoritmos genéticos que cause o mesmo efeito emocional através de sua estrutura musical. Para isso a partitura é representada através de predicados PROLOG.

Como uma iniciativa relacionada à interação em tempo real com algum uso de áudio encontramos o OMAX, que é um sistema musical interativo voltado à improvisação com usuários humanos; ele captura regras estilísticas superficiais de uma entrada simbólica e gera uma resposta MIDI a partir dessa análise, tendo como objetivo uma interação homem-máquina musicalmente mais rica. Foi implementado nos ambientes de composição e performance MAX e OpenMusic e baseia-se num modelo estatístico de aprendizado que usa cadeias variáveis de Markov (VMM) e parsing incremental (IP) [AD02]. A análise das entradas musicais se divide em duas escalas de tempo diferentes; O OpenMusic se encarrega da arquitetura do modelo estatístico enquanto o MAX permite a interação em tempo real, a captura instrumental e o controle de MIDI e áudio. Uma variante do OMAX, o OFON foi posteriormente desenvolvida acrescentando uma camada que converte áudio monofônico em MIDI usando pitchtracking, e disponibiliza essa informação simbólica para o tratamento do OMAX. O sistema armazena os vínculos temporais entre o áudio e o MIDI, reproduzindo posteriormente os trechos do áudio original. É interessante a utilização de áudio em tempo real com instrumentistas (flauta, voz), apesar da dependência de uma estrutura simbólica que permite a reprodução desses trechos cronologicamente catalogados. Sendo as regras estilísticas o foco desse trabalho, não existe um processamento dinâmico que modifique o áudio que será reproduzido.

\subsection{Sumário}

Os próximos capítulos do texto de qualificação estão organizados da seguinte forma:

- Capítulo 2 - expõe uma fundamentação teórica que apresenta a tecnologia de agentes e como ela se relaciona com o contexto musical. Também apresenta o processo de desenho de uma aplicação musical multiagentes, desde a tomada de decisões composicionais relevantes até a apresentação da arquitetura do arcabouço ENSEMBLE e suas interfaces;

- Capítulo 3 - descreve as implementações propostas para alcançar os objetivos do trabalho; incluem-se aqui as extensões ao arcabouço, a proposta de uma nova linguagem de script para os raciocínios e a integração com o sistema ISO

- Capítulo 4 - encerra o texto, apresentando as três aplicações musicais que ilustram o interesse composicional e performático da ferramenta, a produção artística vinculada a esse trabalho, conclusões e as perspectivas de continuidade na área tratada; 


\section{Capítulo 2}

\section{Fundamentação Teórica}

\subsection{Sistemas Multiagentes Musicais}

A programação como disciplina tem evoluído consideravelmente desde a aparição dos primeiros computadores e das primeiras linguagens com esse propósito. Vários paradigmas têm ocupado a preferência dos profissionais da área, responsáveis também por criar novos esquemas que satisfaçam necessidades especiais e forneçam novas capacidades. Nos primórdios da programação as tarefas e ações dos programas computacionais eram explicitamente planejadas e determinadas; careciam de adaptabilidade e qualquer cenário inesperado resultava num erro que o sistema não conseguia contornar. Para um grupo de temáticas e problemas, como por exemplo, o controle de tráfego aéreo, administração de redes, recuperação de informação, mineração de dados, administração de agendas, entre muitos outros, existe a necessidade de programas computacionais mais autônomos e capazes de tomar decisões, se adaptando a situações diferentes. A Música, em particular na composição e na realização de performances, se encaixa nesse perfil de áreas que precisam de adaptação e tomada de decisões em tempo real.

A pesquisa no campo dos Sistemas Multiagentes começou nos anos 80, porém, estes ganharam notoriedade digna de destaque apenas em meados dos anos 90 [Woo02], e portanto este é um campo relativamente novo nas ciências da computação que tem visto um claro crescimento em diversas áreas de aplicação como nos sistemas de defesa, logística, sistemas de informação geográfica, sistemas de computação gráfica e também na área da computação musical. Um Sistema Multiagentes é um sistema em que dois ou mais agentes interagem ou trabalham em conjunto realizando determinadas tarefas ou cumprindo grupos de objetivos; neles os agentes apresentam duas características principais: serem capazes de agir de forma autônoma, tomando decisões, levando a realização dos seus objetivos, e serem capazes de interagir com outros agentes utilizando protocolos de interação social inspirados ou não nos protocolos humanos, e incluindo características como a coordenação, cooperação, competição e negociação.

Um dos pontos essenciais para permitir a construção de sociedades de agentes consiste em conseguir gerir as interações e as dependências das atividades dos diferentes agentes. A coordenação tem um papel essencial nos Sistemas Multiagentes já que estes sistemas são por natureza, distribuídos. Seguindo essa linha a motivação principal dos sistemas multiagentes é o tratamento de problemas inerentemente distribuídos. Esse ponto essencial se encaixa em vários cenários relacionados com a área da computação musical, seja para composição algorítmica ou para performance interativa.

Outras motivações próprias desse tipo de sistemas são [Rei03]:

- Resolver problemas de dimensão grande demais para poder ser tratados por um único agente monolítico; 
- Alcançar a interconexão e interoperação de vários sistemas e paradigmas diferentes;

- Providenciar uma solução mais natural para problemas geograficamente distribuídos, ou funcionalmente distribuídos, como no caso de atores com papéis diferenciados, o piloto de um barco tem funções diferentes dos outros integrantes da tripulação;

- Permitir uma interface cooperativa homem-máquina mais natural em que ambos funcionam como agentes no sistema;

- Oferecer uma maior clareza e simplicidade conceitual de projeto.

Essas características podem se relacionar com a área da computação musical e permitir que se desenvolvam projetos específicos que usufruam dos benefícios dos sistemas multiagentes.

Podemos assim:

- Permitir que sistemas e paradigmas diferentes de representação musical e sonora convivam e interajam num mesmo ambiente.

- Focar na interatividade e cooperação entre um usuário e o sistema no contexto de uma performance musical.

- Utilizar a clareza proposta na formulação de interfaces amigáveis, aproximando o público alvo dos sistemas musicais.

Os Sistemas Multiagentes incluem agentes homogêneos ou heterogêneos. Cada agente é um elemento capaz de resolução autônoma de problemas e opera assincronamente com respeito aos outros agentes. Para garantir que o agente opere como parte do sistema é necessário que exista uma infraestrutura de comunicação e/ou iteração entre os agentes do sistema [Rei03].

Uma das áreas de interesse para a aplicação dos sistemas multiagentes é a computação musical e existem vários trabalhos sobre aplicações musicais que utilizam sistemas multiagentes [DN01][McC01][DFMS09]. Esses sistemas se compõem de agentes musicais inteligentes e do ambiente virtual, sendo que esse ambiente define as características acústicas ou ecológicas no sistema.

\subsubsection{Agentes Musicais Inteligentes}

\section{Agentes computacionais}

Embora existam varias categorizações de tipos de agentes e arquiteturas diferentes de sistemas multiagentes, não existe um consenso quanto às características que definem um agente, além da autonomia. Dentro dessa diversidade de perspectivas sobre o que é um agente podemos achar elementos importantes e relevantes, como na seguinte definição de Reis [Rei03]:

Um Agente é um sistema computacional, situado num dado ambiente, que tem a percepção desse ambiente através de sensores, tem capacidade de decisão, age de forma autônoma nesse ambiente através de atuadores, e possui capacidade de comunicação com outros agentes e/ou humanos, de forma a desempenhar uma dada função para a qual foi projetado. 


\section{Agentes Inteligentes}

Os agentes inteligentes se diferenciam já que são aqueles que conseguem realizar decisões autônomas flexíveis para alcançar seus objetivos.

Whalley [Wha05], introduzindo os agentes no contexto dos sistemas multiagentes musicais, ressalta que eles podem apresentar vários níveis de persistência, independência, comunicação e colaboração com outros agentes ou pessoas. Os agentes inteligentes podem incluir habilidades de tomada de decisão, aprendizado no ambiente e mobilidade nas redes, enquanto agentes mais inteligentes podem monitorar ambientes, decidir se devem reagir ou não em um dado contexto, coletar informação e modificar os seus comportamentos de acordo com as informações recebidas.

Jennings [Jen00] propõe uma definição menos rigorosa desse tipo particular de agentes com as seguintes características:

\begin{tabular}{|c|l|}
\hline Autonomia & $\begin{array}{l}\text { Consegue operar sem a intervenção de humanos ou outros } \\
\text { sistemas, possui um status interno e controle sobre as suas } \\
\text { ações. }\end{array}$ \\
\hline Habilidade Social & $\begin{array}{l}\text { Consegue interagir com outros agentes e humanos utilizando } \\
\text { algum tipo de linguagem. }\end{array}$ \\
\hline Reatividade & Percebe o ambiente, seja ele real ou virtual. \\
\hline Pro - atividade & $\begin{array}{l}\text { Os agentes não atuam simplesmente em resposta ao ambi- } \\
\text { ente, mas podem desenvolver comportamentos próprios para } \\
\text { alcançar seus objetivos, por iniciativa própria. }\end{array}$ \\
\hline
\end{tabular}

Tabela 2.1: Características simplificadas dos agentes

Além dessas características, numa definição mais rigorosa para esse tipo de agentes, menciona-se a necessidade de aproximar essas características utilizadas nos agentes a comportamentos e características humanas, como intenção, obrigação e crença [Sho93], ou agentes emocionais [BS94].

\section{Agente Musical}

O presente trabalho tem como um dos seus objetivos analisar a utilização de agentes musicais no arcabouço de sistemas multiagentes musicais proposto por Thomaz [TQ09], que define um agente musical como um agente computacional especializado em processar informações musicais e sonoras. Ele é capaz de perceber e analisar o som do seu ambiente, executar processos internos ou raciocínios, usando essa informação para gerar uma resposta sonora, seja com síntese simbólica, síntese de áudio ou outras técnicas [TQ09].

Esse tipo de agente computacional também pode possuir outros sensores e atuadores que permitem incluir aspectos não-musicais como seriam, por exemplo, outros sentidos humanos (visão, tato, olfato) e movimentação, bem como outras características relacionadas à vida artificial (energia, estado de ânimo).

Base de Conhecimento A base de conhecimento de um agente constitui o repositório onde são armazenados os dados que o agente internamente dispõe para conhecer seu próprio estado, o de outros agentes e do ambiente. Assim esse banco de dados pode se alimentar de informação da inicialização, de dados percebidos por sensores do agente ou dados derivados de processos internos ou raciocínios. 
Além dos fatos que uma base de conhecimento pode conter tais como teorias musicais, códigos genéticos, regras internas e outros atributos do agente, no contexto de um agente musical existe a necessidade de considerar como a informação musical será codificada dentro da base. Ela pode ser codificada em formato de áudio ou em alguma notação simbólica como no caso da notação MIDI, MusicXML ou alguma notação específica da aplicação.

A base de conhecimento também pode funcionar como uma base de dados inteligente, capaz não apenas de armazenar fatos, mas também de efetuar processamentos de dados, ou armazenar técnicas de transformação do sinais [Tho11].

Raciocínio Um agente musical possui uma representação interna, explícita ou implícita, do seu ambiente, além de conhecimento e capacidade de raciocinar baseada no seu conhecimento, de forma a decidir em cada instante qual a melhor ação a executar.

Um raciocínio constitui um mecanismo interno do agente, que pode utilizar e manipular informações percebidas através de sensores, sejam estas sonoras ou não, para decidir as suas ações, seja para responder sonoramente a um evento ou para tomar uma iniciativa que implique em ações não-musicais como a movimentação no ambiente ou alguma operação de vida artificial. A modelagem do raciocínio dos agentes é a base que permite ao músico tomar decisões composicionais e estéticas sobre os elementos sonoros e musicais e também sobre outras características nas aplicações.

Estes mecanismos que utilizam tanto os dados perceptuais recentes quanto as informações contidas na base de conhecimento podem ser ferramentas de análise, técnicas de síntese ou diversas técnicas de composição algorítmica [TQ09]. Pela importância desses raciocínios na integração da parte técnica com a parte artística e estética daremos a ênfase maior na definição deles no contexto do arcabouço ENSEMBLE, e como eles podem ser desenvolvidos nas implementações apresentadas posteriormente.

Analisamos alguns exemplos de raciocínios internos em aplicações relacionadas com os sistemas multiagentes musicais. No sistema de Todd e Werner [TW99] os agentes fêmeas agem como avaliadoras do canto dos indivíduos machos, para o que elas implementam internamente uma rede neural ou cadeia de Markov para poder definir que cantos consideram mais inovadores ou surpreendentes. Esse raciocínio ajuda a tomada de decisões e a escolha do rumo na evolução do resultado sonoro. No Living Melodies [DN01] os agentes tem que executar diferentes tarefas, seja para a movimentação dos mesmos no mundo virtual, ou para emitir o canto que poderá ser escutado no ambiente. Isso é resumido no contexto de um conjunto básico de operações: Caminhar, Girar, Descansar e Cantar; além dessas operações existe a possibilidade de criar condições (IF) e repetições das sequências de comandos (LOOP). Nessas condições podem ser comparados os valores recebidos pelos três tentáculos com sensores de cada indivíduo, assim como a idade, quantidade de energia, o nível de prazer na escuta e a direção na qual estão escutando. Implicitamente temos outros raciocínios internos que serão responsáveis por determinar o nível de prazer a partir dos sons que a criatura escuta, assim como um processo para determinar as mudanças no nível de energia do indivíduo a partir das atividades executadas e os elementos do ambiente que afetam essa característica. Na descrição do sistema alguns detalhes não estão explicitados, porém fica claro que algumas das tarefas de vida artificial são executadas pelo ambiente, que possui um conhecimento completo das características das criaturas a todo momento.

No Eden [McC01], sistema que possui semelhanças com o LM [DN01], o conjunto de ações que uma criatura pode executar inclui Caminhar, Girar, Descansar, Cantar e também outras como Comer, Bater em outra criatura e se Reproduzir. Nesse sistema as ações são controladas por mensagens que são processadas por um sistema interno de regras. As regras, contidas numa tabela, 
também contam com um processo de apostas para determinar qual regra determinará a ação para uma mensagem compatível; isso é feito por um sistema de créditos que garante que as regras mais úteis para a criatura sejam as mais usadas. Outro processo interno calcula o nível de dor da criatura quando é agredida ou tem fome, assim decisões podem ser tomadas com a motivação da dor. Algumas intenções da criatura que não são viáveis fisicamente, como caminhar sobre uma pedra, serão controladas pelo ambiente. Internamente as criaturas do sistema têm conhecimento das suas características físicas, como massa, velocidade, nível de energia e cor. A cor determina o tipo de criatura ou objeto no mundo em quanto que a massa da criatura determina a quantidade de energia para tarefas como a movimentação.

No sistema descrito em Eigenfeldt e Pasquier [EP11] os agentes se movimentam no espaço e reproduzem áudio a partir de parâmetros internos determinados aleatoriamente na inicialização do indivíduo. No ambiente encontram-se unidades granulares de áudio que representam a comida para os agentes; quando um agente enxerga comida ele se dirige automaticamente para ela, e caso não exista comida no campo visual dele ele escolhe uma direção aleatoriamente para se movimentar.

Sensores Os sensores são os componentes do agente musical que permitem a percepção do mundo virtual; o agente consegue reagir através da informação que eles providenciam, assim como um humano percebe seu ambiente através dos seus olhos, ouvidos, do olfato, do gosto e do tato. Essa informação recebida pode ser armazenada, repassada para raciocínios internos e processada.

No caso dos agentes musicais o principal sensor é o auditivo [Tho11] já que diferencia esse tipo de agentes de outros menos específicos. Esse tipo de sensor recebe informações sonoras presentes no ambiente.

Temos também sensores que permitem a locomoção dentro do ambiente, como sensores de posição em alguns sistemas com ambiente virtual, ou sensores infravermelhos ou câmeras no caso de agentes robóticos no mundo real. O tato ou controle de colisão precisa também de sensores que determinem a proximidade com outro objeto ou agente, como no caso dos tentáculos presentes no agente do Living Melodies [DN01].

Outros tipos de sensores podem ser incluídos no sistema como, por exemplo, sensores para visualizar cores dos objetos no mundo [McC01], ou para enxergar o estado emocional de outros agentes [Sch04].

Atuadores Os atuadores são os componentes do agente que permitem a execução de ações no ambiente virtual; eles recebem as instruções geradas em raciocínios internos e interagem com os outros atores do sistema, permitindo mecanismos de locomoção, mecanismos de vida artificial que impliquem interação física e outros como a expressão do estado emocional. No caso do agente musical, os atuadores musicais permitem emitir o som gerado pelos múltiplos mecanismos internos, como raciocínios musicais que incluem técnicas de composição algorítmica, processamento ou síntese sonora. A natureza do atuador musical vai depender do tipo de codificação utilizado.

\subsubsection{Ambiente Acústico e Ecológico}

\section{Ambiente Virtual}

Um agente computacional existe num ambiente determinado, percebendo-o e agindo nesse ambiente. As características do ambiente em que o agente "vive" são determinantes na definição da estrutura do agente e da sua forma de operação [Rei03]. Assim é através do ambiente, e por meio 
de sensores e atuadores, que o agente consegue interagir com outras entidades do sistema.

O mesmo acontece, no contexto dos sistemas multiagentes musicais, aonde um ambiente virtual vai determinar uma série de características como atributos físicos, formas de comunicação e interação. É interessante observar que um ambiente virtual para agentes muitas vezes se mostra mais versátil e possui um conjunto de percepções e ações maior do que um mundo físico como no caso de agentes robóticos destinados a atuar em um ambiente real [Rei03].

Esses ambientes virtuais podem representar mundos hipotéticos, possuir $n$ dimensões ou simular características do mundo real com diversos níveis de precisão. Existem descrições mais detalhadas dessas categorias de ambientes para agentes $\left[\mathrm{RNC}^{+} 95\right]$. No contexto dos sistemas multiagentes musicais encontramos vários exemplos que implementam um ambiente bidimensional em forma de tabuleiro com posições discretas [McC01][Bey07][DN01].

É vantajoso manter uma flexibilidade para definir essas características de um ambiente virtual. Thomaz [Tho11] no seu arcabouço define o ambiente virtual pela sua representação física e pela sua representação Ecológica. Essa categorização abrange muitos ambientes encontrados nos trabalhos de sistemas multiagentes musicais relacionados (ver seção 1.3).

Representação Física O mundo virtual é regido por leis físicas definidas como, por exemplo, a propagação de som, enquanto a representação do espaço determina o número de dimensões utilizadas para representar uma posição, a estrutura de adjacências de posições nesse espaço e a forma geométrica que limita o ambiente.

Um ponto muito importante em sistemas multiagentes musicais, principalmente num contexto interativo, é a representação sonora do ambiente, que muitas vezes constitui a base para determinar como o som vai ser transmitido entre os agentes, como vai ser codificado e muitas vezes também define como o resultado vai ser escutado e com que características de qualidade. Assim muitos trabalhos utilizam uma representação simbólica do som, como no caso do MIDI [DFMS09][DN01][Bey07]. Isso traz a vantagem de diminuir o número de eventos a serem processados, o que é computacionalmente vantajoso, porém, o fenômeno acústico é sacrificado, limitando o controle do resultado [Tho11].

Representação Ecológica Essa representação considera as características de um agente que se vinculam a técnicas de vida artificial. Pode-se definir o ciclo de vida dos agentes, as leis que determinam nascimento, reprodução, morte e outras interações biológicas com o ambiente e com outros indivíduos. Assim controla-se o número de indivíduos vivos no sistema, as interações sociais entre agentes de mesmo tipo e de tipos diferentes. Muitas vezes um conjunto de parâmetros globais do sistema controla limites biológicos, como no caso do LM que determina o número máximo de indivíduos na simulação ou os requisitos de energia, prazer auditivo e atividade para se reproduzir. No sistema Eden [McC01] se determina um raio de interação com outros agentes, assim como no caso do sistema Kinetic Engine [EP11].

É muito relevante que essa representação permita a modelagem dos diferentes tipos de interação entre agentes e usuários, características sociais e interativas. A vida artificial e o vínculo dessa disciplina com os sistemas multiagentes musicais são tratados na seção 2.1.2.

\section{Vida artificial}

Um ponto em comum de muitos trabalhos relacionados com sistemas multiagentes e arte sonora é justamente a utilização de técnicas de vida artificial [McC01] [EP11] [Bey07]. A Vida Artificial 
é uma disciplina que estuda sistemas de vida natural pela simulação em computadores de alguns aspectos biológicos [Lan97]. Provou ser um mecanismo viável para obter um melhor entendimento teórico de organismos vivos e permite a aplicação prática de princípios biológicos nos âmbitos da medicina e da tecnologia como, por exemplo, nas áreas da robótica e da nanotecnologia, entre outras. Pela capacidade dessa disciplina de tratar problemas de alta complexidade, especificamente utilizando agentes, surge um interesse em outras áreas menos relacionadas com a biologia como as ciências sociais, a linguística e a computação musical [MT03].

A vida artificial oferece novos paradigmas de composição no contexto da computação musical, através de características como a auto-organização e os comportamentos emergentes [EP11]. Um diferencial em relação a outras técnicas computacionais voltadas ao desenvolvimento musical é o uso da dinâmica social em agentes interativos. Temos três modelos de aplicação levantados por Miranda e Todd [MT03]:

- Renderizar em áudio comportamentos extra-musicais; quando os agentes realizam tarefas ou ações, o sistema mapeia interações sociais em resultado sonoro. Assim, essas interações modificam o resultado que o usuário escuta, mas não interferem no comportamento da sociedade de agentes.

- Outra alternativa é a associação direta para que cada indivíduo produza sua própria música e usar essa música ou resultado sonoro como um elemento que determine a sobrevivência e a reprodução do agente. Utilizam-se algoritmos genéticos para recombinar as músicas geradas e o processo pretende levar a resultados mais complexos e/ou interessantes. Temos nesse enfoque a figura do crítico (seja humano, automático, ou de outro tipo), que determina que melodia ou som está mais apto para sobreviver e se manter em novas gerações. Mais uma vez o som não é escutado pelos outros agentes nem interfere nas interações sociais.

- Como terceiro modelo existe uma abordagem "cultural", na qual os agentes escutam os sons emitidos por outros e reagem a esses eventos, influenciando as músicas que o agente produz e a tendência de acasalar ou proteger um território, por exemplo. Alguns dos elementos apresentados nesse modelo estão presentes no sistema Living Melodies [DN01], já adaptado anteriormente para o arcabouço ENSEMBLE [TQ09].

A capacidade de interação social é muito relevante para o desenvolvimento dessa pesquisa; e pretende-se aplicar um modelo social de agentes musicais, utilizando áudio além da representação simbólica na interação dos agentes, como ilustrado em outras aplicações.

Além dessa classificação de modelos sociais existem vários usos para essas técnicas no contexto da computação musical com agentes; inicialmente as técnicas de vida artificial ajudam a definir indivíduos que emitem sons diretamente [DN01]; além disso, podem ajudar na evolução de críticos que determinam quais indivíduos e melodias são interessantes para uma próxima geração de agentes [TW99], e também temos trabalhos que omitem o lado evolutivo nos agentes e montam apenas um ecossistema fechado para criar vínculos mais complexos entre os indivíduos [EP11]. Através das técnicas de vida artificial também pode-se desenvolver os parâmetros musicais que vão ser controlados por um performer na hora de usar o sistema [MH03].

\subsubsection{Interações}

Um dos benefícios dos sistemas multiagentes musicais é justamente a capacidade de dar suporte a diversos tipos de interações. As interações podem acontecer entre os agentes de um sistema, considerando que usuários podem ser representados como agentes em sistemas interativos. Essas interações podem acontecer de forma predominantemente física ou ecológica [Tho11]. Fisicamente um agente não pode, por exemplo, estar no lugar ocupado por outro individuo, o que implica um tipo 
de interação. Além das colisões temos, por exemplo o caso do sistema Eden [McC01] que permite que um agente bata, mate e se alimente de outro agente. Os diferentes tipos de comunicação entre os agentes também representam interações, seja essa comunicação sonora, através de mensagens ou visual, quando agentes conseguem por exemplo determinar a proximidade de outros.

\subsection{Interfaces}

O arcabouço ENSEMBLE conta com várias interfaces com os diferentes atores de uma aplicação musical, sejam estes sistemas externos, usuários ou bibliotecas de processamento de áudio. Ele oferece a possibilidade de integração com sistemas externos permitindo delegar algumas tarefas como, por exemplo, a representação gráfica de um mundo virtual do ENSEMBLE ou direcionar as saídas de áudio da aplicação a outra ferramenta relacionada. Uma aplicação disto é aproveitar recursos já existentes em outros projetos, sejam de processamento de áudio ou de geração de comportamentos de agentes, como no caso do ISO [BNF07], para enriquecer o repertório de operações disponíveis para o usuário interessado no desenvolvimento de sistemas multiagentes musicais com o ENSEMBLE.

O ENSEMBLE já tem suporte para vários tipos de comunicação; veremos brevemente o estado atual das interfaces do arcabouço, tanto para interagir com outros sistemas como para acessar bibliotecas externas. Depois trataremos os mecanismos que permitem essa interação e as interfaces de usuário.

\subsubsection{Interfaces com Sistemas Externos}

Durante o processo de criação do ENSEMBLE foram consideradas algumas alternativas para a troca de áudio com o arcabouço, considerando a importância de ter múltiplos canais de entrada e saída. Nesse contexto o ENSEMBLE usa a API do Jack Connection Kit [DH03] para criar canais de áudio e interagir com eles.

Jack Connection Kit é um servidor de áudio multi-plataforma que permite conectar diversos aplicativos e compartilhar áudio ou MIDI em tempo real com uma baixa latência. Esse projeto conta com uma biblioteca de base, a API do Jack que define as estruturas de dados, protocolos e métodos usados pelo Jack. Uma implementação dessa API para Java, usando Java Native Interface (JNI)[Gor98], foi desenvolvida especificamente para uso com o ENSEMBLE, o JJack, que permite que os diferentes atuadores ou sensores de áudio se vinculem diretamente com um canal de entrada ou saída, seja virtual para troca de áudio entre aplicações ou físico na placa de som. O Jack gerencia essas entradas e saídas, direcionando o fluxo do áudio e sincronizando várias aplicações que estejam sendo executadas simultaneamente. Uma grande vantagem dessa estrutura é a capacidade de utilizar mais de dois canais de entrada e de saída, tarefa problemática com a API JavaSound. O servidor Jack deve estar rodando antes de executar tarefas de áudio vinculadas ao ENSEMBLE, e constitui o principal mecanismo de interação com a placa de som e outras ferramentas de áudio.

Outra aplicação externa que faz parte do ecossistema do ENSEMBLE é o PureData (Pd), que, através de uma comunicação padrão do ENSEMBLE, recebe as posições dos agentes de um mundo virtual como mensagens OSC (Open Source Control)[WF97] e plota as mesmas num external do Open Audience [FTS ${ }^{+}$05], desenhado para apresentar visualmente a disposição espacial de fontes sonoras. Essa configuração é usada tanto para acompanhar a situação do mundo virtual como para determinar posições de agentes no ENSEMBLE. Assim, arrastando um determinado icone de agente no external, o Pd emite uma mensagem de posicionamento para o ENSEMBLE. 


\subsubsection{Interfaces com bibliotecas}

O arcabouço ENSEMBLE possui a capacidade de interagir com bibliotecas externas. Esse mecanismo permite a reutilização de código no contexto do arcabouço, assim como a possibilidade de escolher outra linguagem ou ambiente para o desenvolvimento de alguma parte da aplicação musical.

Se precisarmos integrar bibliotecas externas, podemos fazer isso através do uso do padrão de programação AbstractFactory. Atualmente foram incorporadas ao arcabouço ENSEMBLE, usando esse padrão, a biblioteca Aubio [Bro06], que contém funções de processamento de sinais, e a biblioteca LibXtract, focada na extração de características do som. Quando necessário, um servidor de eventos utiliza a fábrica de objetos ProcessFactory para acessar as funções das bibliotecas externas através do método createProcessor(), informando o tipo de função e os parâmetros necessários. Um processador (Processor) é criado para a biblioteca em questão acessar a função de processamento através do método process(), passando como argumento os parâmetros para a execução da função e um objeto com o conjunto de dados de entrada, recebendo depois um objeto diferente com o conjunto de dados processados [Tho11].

Outra integração presente no ENSEMBLE é a utilização de plugins VST, a partir de código intermediário do projeto VST Interface for $\mathrm{Java}^{1}$, que consegue carregar bibliotecas VST e executar transformações de acordo com os parâmetros de entrada definidos pelo plugin. Lamentavelmente, pela ausência de um padrão de entrada e saída nessas bibliotecas de processamento de áudio, é necessário verificar para cada plugin VST se os parâmetros necessários são enviados, se os domínios das entradas são respeitados e se as saídas respeitam uma ordem específica. Outra dificuldade é prever o tipo de GUI que o plugin usa, já que às vezes os parâmetros ou configurações se encontram em arquivos externos e não nas variáveis de parâmetros padrão; além disso algumas saídas do processamento, especificamente aquelas de análise, são apresentadas apenas como informação visual no GUI, sendo que o código intermediário não pode capturar automaticamente esses resultados do plug-in.

\subsubsection{Interface de usuário}

O arcabouço ENSEMBLE possui uma Interface Gráfica de Usuário, o Sniffer, como ilustrado na figura 2.1, que permite controlar um sistema desenvolvido no arcabouço e monitorar seu estado [Tho11]. A interface é baseada no agente Sniffer disponível no middleware JADE e é muito útil para poder testar aplicações.

O Sniffer apresenta a estrutura de agentes existentes no ambiente, permitindo adicionar componentes como sensores, atuadores, raciocínios e outros, seguindo a mesma lógica apresentada no arquivo XML de configuração inicial.

O usuário do ENSEMBLE conta com a alternativa do external de Pd mencionado na seção 2.2.1 para interagir com o ambiente virtual em tempo de execução, especificamente observar e controlar a posição dos agentes no mundo virtual.

\subsubsection{Linguagens de Interface}

Os mecanismos para integrar o ENSEMBLE com outros sistemas ou bibliotecas são relevantes para o entendimento da arquitetura do arcabouço e essenciais para determinar o rumo que podemos tomar para melhorar os recursos e fomentar o interesse no projeto. Com isso em mente vamos descrever o JNI [Gor98] e principalmente o protocolo OSC [WFM03], que será adotado nas expansões

\footnotetext{
${ }^{1}$ http://jvst.sourceforge.net
} 


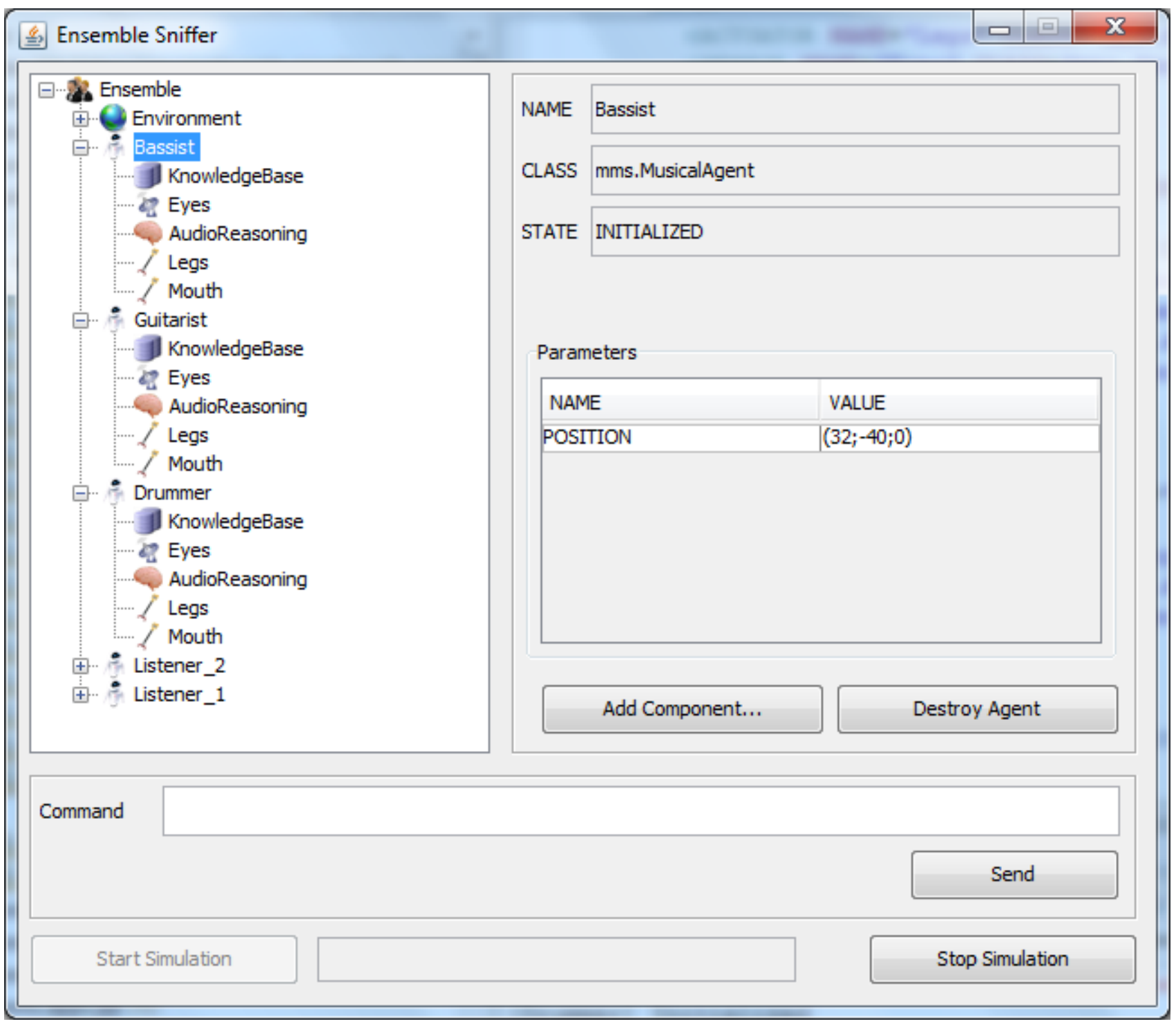

Figura 2.1: Tela do Sniffer do ENSEMBLE

da presente pesquisa.

Com o propósito de integrar programas em Java com outras APIs, serviços e aplicativos escritos em outras linguagens, a plataforma Java disponibiliza o JNI (Java Native Interface) para ajudar nesse tipo de integração. No ENSEMBLE o JNI é utilizado para incorporar as bibliotecas externas anteriormente mencionadas. Essa técnica exige que as bibliotecas sejam compiladas para cada plataforma na qual o ENSEMBLE vai ser utilizado.

Define-se assim uma nomenclatura padrão e uma convenção para as chamadas, de modo que a máquina virtual do Java pode localizar e invocar os métodos nativos, podendo assim obter entradas e saídas, recuperar gráficos, operações de rede ou executar operações em threads no sistema operacional host da máquina virtual.

O outro mecanismo relevante para dar suporte às integrações é o Open SoundControl (OSC), um protocolo aberto baseado em mensagens, desenhado para a comunicação de dados musicais como gestos, parâmetros e seqüências de notas entre computadores, sintetizadores e outros dispositivos multimídia, com foco na otimização da comunicação por rede. Com esse protocolo os nós ou sistemas referenciados na rede são identificados por uma organização flexível, no estilo de URLs, e 
inclui uma linguagem robusta de identificação de padrões que permite ter múltiplos destinatários numa única mensagem.

O OSC nasce como uma alternativa ao MIDI, com o propósito de eliminar as limitações e problemas desse formato e aproveitar as vantagens da tecnologia atual de redes. O formato dos dados em OSC independe da camada de transporte da rede, e assim pode ser transmitido por diferentes tecnologias, como PCI, USB, Ethernet, Fast Ethernet, entre outras. Em contraste com o MIDI, o protocolo OSC não se preocupa em reduzir o tamanho em bytes da informação musical; a largura de banda de referência é de pelo menos 10 Mbps., em comparação com a banda de 31.25 Kbps do MIDI que é 300 vezes mais lenta.

O modelo de mensagens do OSC é um conjunto hierárquico de objetos dinâmicos que podem representar vozes de um sintetizador, canais de saída, filtros ou algum outro nível de abstração, como comandos no caso de raciocínios ou componentes de agentes num sistema musical multiagente. A notação é semelhante a uma URL, e não existe um controle sobre a organização dessa hierarquia nem sobre o tamanho desses caminhos, eliminando-se assim as limitações de tamanhos fixos presentes em protocolos simbólicos como o MIDI.

Outra característica importante para o uso de OSC em aplicações musicais é a alta resolução temporal e a possibilidade de destacar grupos de mensagens que devem provocar efeitos simultâneos. A representação temporal em 64 bits segue o padrão usado pela Internet NTP timestamps [Mil92]; apesar disso o OSC não disponibiliza nenhum mecanismo de sincronização de relógio.

Além das vantagens técnicas do OSC, também é interessante a base de implementações que inclui tanto hardware como bibliotecas e aplicações baseadas em OSC. Algumas das ferramentas compatíveis são MAX, Pd, Ardour, CSound, Matlab, entre outras. Também existem aplicações de controle gestual para fins musicais que utilizam OSC como OSCpad, AndOSC, OSCRemote e tou$\operatorname{chOSC}^{2}$ que expandem a usabilidade do protocolo a dispositivos móveis ou interfaces tangíveis. No escopo desse trabalho é relevante mencionar o suporte do ISO para a comunicação via OSC, tanto como entrada de parâmetros como saída de informação de agentes.

\subsubsection{Linguagem para operação de Agentes}

O processo de criação de aplicações musicais no ENSEMBLE pode ser facilitado pelo desenvolvimento e melhoramento das interfaces com o usuário. Um dos pontos tratados nesse trabalho é a possibilidade de usar uma linguagem de script capaz de representar comportamentos nos agentes a partir das escolhas composicionais do autor, contando com operações já presentes no arcabouço e que tenham um nível de detalhe superior àquele do Sniffer [Tho11], que interage em alto nível com os componentes dos agentes no ENSEMBLE.

As linguagens de script representam uma forma de simplificar as tarefas de processamento e raciocínio, com a vantagem de separar roteiros de ações dos agentes da programação em Java que define a arquitetura dos agentes e sua lógica de raciocínio [HEV05].

STEP (Scripting Technology for Embodied Persona) [HEV05] é uma linguagem de operação de agentes antropomórficos, especialmente criada para expressar atos comunicativos como gestos e posturas. Possui uma fundamentação semântica robusta que usa composição de operadores e define interações em mundos de agentes. Essa linguagem de operação de agentes torna-se assim uma referência muito relevante e tomamos emprestados conceitos do STEP que garantem muitos dos nossos objetivos. Um detalhamento destes pontos é apresentado juntamente com a linguagem de

\footnotetext{
${ }^{2}$ http://hexler.net/software/touchosc
} 
script proposta para o ENSEMBLE na seção 3.2.

\subsection{Desenho de uma Aplicação Musical}

Nesta seção vamos considerar o processo de desenho de uma aplicação musical que utiliza a tecnologia de agentes computacionais voltada à área da criação musical ou arte sonora.

Tanto no contexto mais técnico, na criação de um estudo de caso para validar uma ferramenta, quanto no contexto de um processo criativo para desenhar um projeto artístico, alguns passos devem ser seguidos e decisões devem ser tomadas para se chegar a uma aplicação musical que atenda aos objetivos traçados.

As diferentes características da aplicação a ser implementada determinam as potencialidades e limitações do sistema, assim como os possíveis usuários finais, performers ou ouvintes dos resultados. A perspectiva considerada é aquela do usuário ou compositor que pretende utilizar um arcabouço de sistemas multiagentes musicais para estruturar uma aplicação, não importando se esse usuário possui um perfil mais técnico ou mais artístico. Assim pretendemos validar a ferramenta, verificando a versatilidade da mesma, determinando até que ponto ela atende às necessidades dos criadores ou artistas, e que tipo de conhecimento é exigido para sua utilização.

Nesse contexto trataremos primeiro das decisões composicionais no processo, comuns para aplicações musicais com agentes, para depois tratar de decisões de ordem computacional, em referência às técnicas e requisitos dos arcabouços multiagentes musicais analisados [BNF07][Tho11].

\subsubsection{Decisões composicionais}

Dentro das decisões composicionais para uma aplicação musical com agentes, deve-se considerar primeiramente o objetivo da aplicação, seja o propósito de gerar material musical, interagir com usuários humanos, propor uma instalação interativa ou criar uma plataforma de improvisação, entre outras possibilidades.

Tomamos, para ajudar na progressão dessas importantes decisões, o arcabouço teórico proposto por Whalley [Wha09], que explica algumas escolhas indispensáveis para esse tipo de sistema, que se realizam de forma explícita ou implícita. Entre essas opções temos a definição da metodologia técnica em relação à perspectiva artística do projeto, e outras escolhas complementares sobre a comunicação, a estrutura das bases de conhecimento e definições voltadas ao ambiente virtual e aos agentes musicais envolvidos.

Como ponto central desse trabalho tratamos em detalhe a perspectiva interna do agente musical na forma dos raciocínios. Nesse contexto trataremos de algumas técnicas de composição algorítmica que podem ser utilizadas e de outras considerações referentes ao desenho de raciocínios de um agente musical.

\section{Metodologia Técnica e Perspectiva Artística}

Em relação aos novos trabalhos e criações, Gimenes [GMJ05] aponta que cada trabalho artístico está embebido de uma herança cultural, e que as peças musicais refletem tanto as escolhas do compositor como o histórico das influências do contexto da composição. Assim o usuário compositor/criador de um sistema multiagentes musical impregna com seus objetivos e intenções o novo trabalho, de forma consciente ou não. Ele exerce também uma influência na aplicação do quesito da representação do conhecimento e das diversas técnicas utilizadas, fazendo que elas se adequem 
à formação artística e técnica do criador [Wha09].

Estrutura ou Formato do Resultado Sonoro Expandindo para os sistemas multiagentes musicais a observação de Weinberg [Wei05], proposta no contexto de sistemas musicais vinculados a redes, encontramos uma classificação em duas abordagens possíveis para o formato ou estrutura do resultado sonoro da aplicação. Uma primeira abordagem se centra na definição rigorosa de uma estrutura musical e no controle exercido pelo compositor, enquanto que a segunda alternativa promove o processo como a base do resultado musical.

Essa separação evoca a tensão de meados do século XX entre a radicalização das estruturas musicais e o controle do compositor praticados por compositores da "avant-garde" e pós-serialismo europeu como Karlheinz Stockhausen e Pierre Boulez, e a tendência de substituir uma estrutura rígida pela a busca de um processo musical dinâmico, como foi explorado por músicos como os americanos John Cage e Steve Reich. Se opondo ao controle absoluto do compositor, esse movimento acreditava que a música pode ser uma forma de arte processual e emergente.

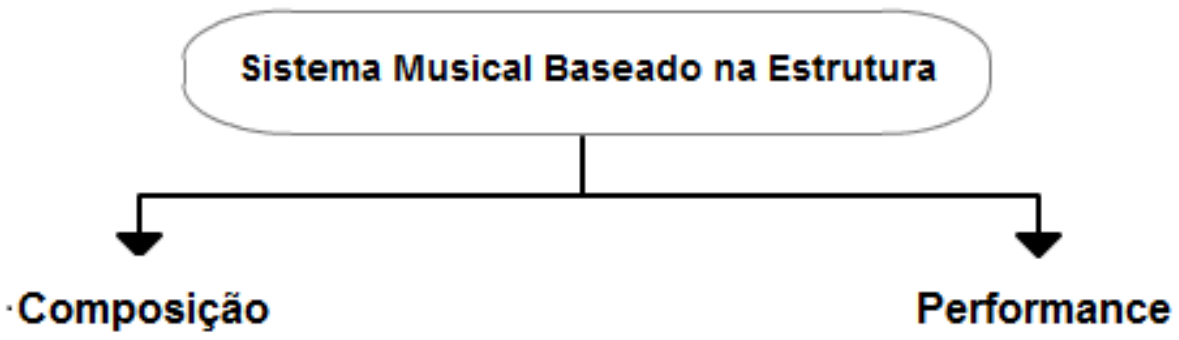

Figura 2.2: Alternativas baseadas na estrutura

No contexto de sistemas de composição algorítmica e sistemas interativos, podemos encaixar na primeira categoria uma grande quantidade de aplicações e trabalhos, desde o jogo dos dados de Mozart, passando por os diversos trabalhos que se restringem a regras da música tonal, como é o caso de sistemas de acompanhamento automatizado [CVM08]. Ilustramos com a figura 2.2 alternativas a serem exploradas com uma estrutura definida; tecnicamente, nesse tipo de sistemas os participantes, sejam humanos ou agentes computacionais, preenchem uma estrutura ou performance musical já delimitada [Wha09].

Na figura 2.3 mostramos a segunda abordagem, que se concentra em explorar possibilidades ou alcançar objetivos através da colaboração e concorrência [Wha09]. Podemos avaliar os resultados desse modelo em alguns sistemas como Living Melodies [DN01] e no sistema de Eigenfeldt e Pasquier [EP11], nos quais o compositor define o processo de interação e evolução deixando que os agentes produzam o som, ou no caso do sistema Eden [McC01], onde a emissão de som não é uma característica indispensável.

Comunicação e bases de conhecimento Seguindo com o arcabouço de Whalley [Wha09] e em relação à comunicação no sistema temos os seguintes fatores a considerar, lembrando que não são excludentes e podem se sobrepor na maioria das ocasiões:

- A codificação musical pode ser baseada em notação musical padrão, em notação simbólica simplificada, MIDI, áudio ou em uma combinação de formatos [Wha09]. 


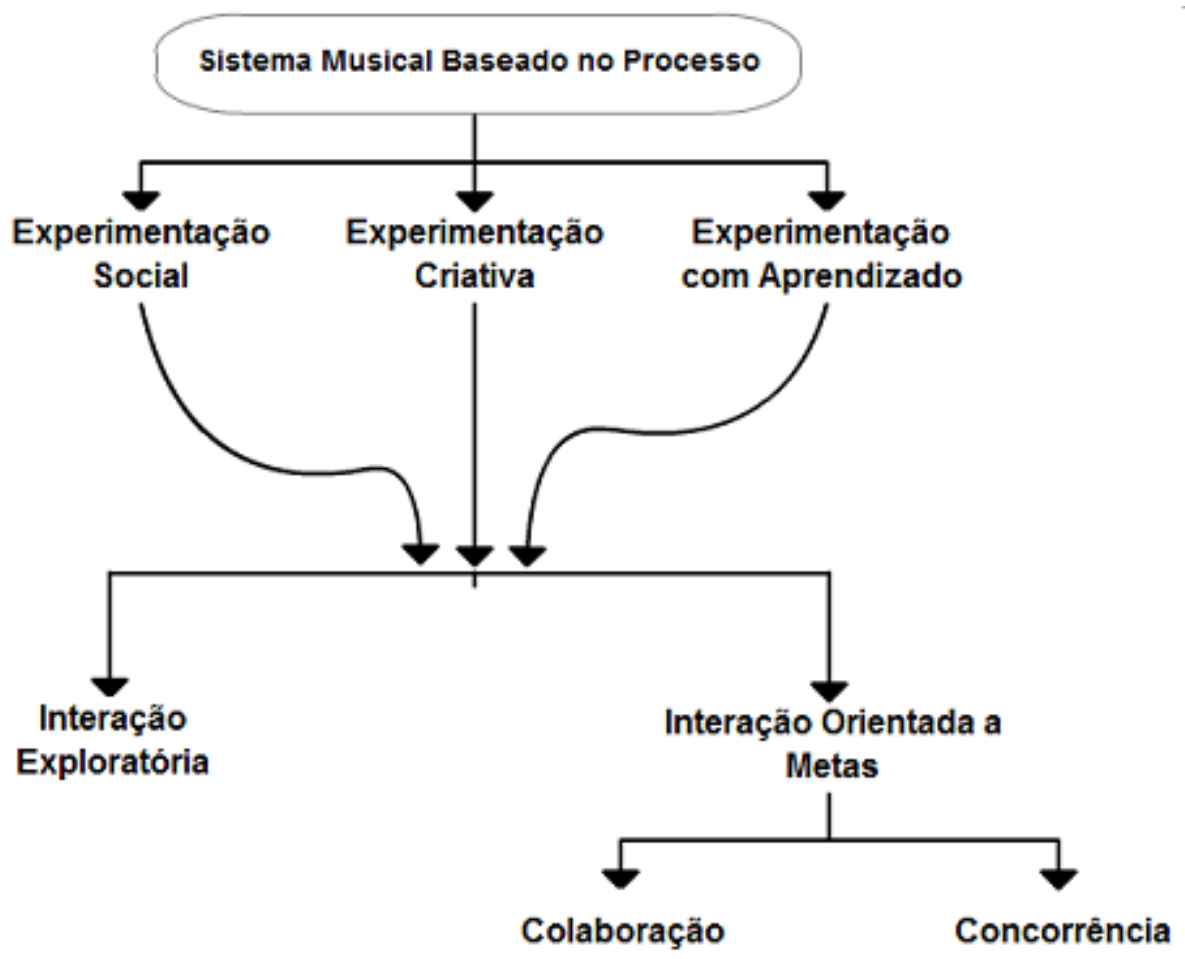

Figura 2.3: Alternativas baseadas no processo

- Deve-se determinar se a codificação, seja baseada em som ou em notação, contêm ou não atributos afetivos/emotivos como descrito em [JS01]. Distingue-se assim uma abordagem formalista de outra referenciada/afetiva.

- Podemos determinar se existirá algum elemento comunicativo com outras expressões artísticas, como a dança [HB03], definindo se a linguagem musical é independente ou não do contexto.

Considerando que em algumas ocasiões as bases de conhecimento se vinculam a metodologias aplicadas à codificação musical, podemos afirmar que essas decisões afetam o desenho das bases de conhecimento no sistema. Muitas vezes é relevante para o planejamento das bases considerar como a notação musical armazenada nas bases de conhecimento pode ser manipulada com técnicas de inteligência artificial.

\section{Ambiente Virtual}

É necessário avaliar o papel que o ambiente virtual, tratado na seção 2.1.2, vai ter no contexto da aplicação, e quais características se encaixam melhor nas intenções do usuário criador.

Dimensão Esse parâmetro refere-se ao número de coordenadas independentes utilizadas para representar uma posição. Parte do atrativo de lidar com representações virtuais é a oportunidade de explorar alternativas ao mundo real, sendo que o ambiente virtual pode exceder as três dimensões, ou pode representar posições baseadas em outro tipo de magnitudes físicas, como por exemplo frequências, cores ou intensidades. 
Estrutura Ainda no contexto da representação física, a estrutura do mundo virtual se refere à escolha entre posições contínuas ou discretas para uma dada dimensão; esta escolha independe do parâmetro físico representado pela dimensão correspondente, e pode ser diferente para cada dimensão considerada.

Forma A forma geométrica do mundo pode ser um fator relevante no âmbito composicional quando se quer explorar o fenômeno acústico de um determinado espaço. No ENSEMBLE [Tho11] o ambiente virtual pode ser limitado (como um retângulo ou paralelepípedo) ou ilimitado, e também pode ser construído em loop (como um toro).

\section{Agente Musical}

Tratamos agora de decisões composicionais mais específicas da utilização da tecnologia de agentes, sendo que elas também constituem alternativas não-excludentes. Seguindo uma tipologia simplificada baseada em Tweedale [TIS ${ }^{+} 07$ ] e Nwana [Nwa96] temos os elementos:

Mobilidade Definimos se o código computacional dos agentes é estático ou se tem mobilidade, ou seja, se eles têm a capacidade de se locomover numa rede. Temos o exemplo do projeto Andante [UK04], que permite a definição de Agentes Móveis Musicais com a capacidade de migrar seu código entre os nós de uma rede, dentro do contexto de um ambiente computacional distribuído.

Modelo do raciocínio O modelo pode ser deliberativo ou reativo. Os agentes deliberativos possuem um raciocínio interno simbólico que permite se envolver em planejamentos e negociações para coordenar ações com outros agentes. Por outro lado os agentes reativos não possuem esses modelos simbólicos específicos aos indivíduos ou do ambiente, e atuam na base de um comportamento de estímulo/resposta.

Atributos Numa perspectiva minimalista [Nwa96] consideram-se três atributos principais para os agentes: Autonomia, Aprendizado e Cooperação. Esses atributos vinculados com a proposta artística ajudam a alcançar os objetivos da aplicação.

Autonomia Como já foi mencionado no início do presente capítulo, a autonomia de um agente se refere à independência de operação de um agente em relação à participação de um humano.

Cooperação Um dos motivos da existência de múltiplos agentes é a capacidade de cooperação. Para isso é importante que o agente possua habilidades sociais, ou seja, a capacidade de interagir com outros agentes e/ou humanos.Podemos ilustrar essa escolha no contexto de um sistema multiagente musical [CVM08] que apresenta a cooperação entre agentes melódicos e agentes rítmicos para produzir uma única saída musical. É interessante observar que existem agentes que têm a capacidade de coordenar ações sem cooperação [Nwa96]. Ressaltamos que a criação musical não possui em geral o objetivo de se chegar a uma solução única ou ideal; daí é frequentemente difícil determinar uma função de avaliação ou de meta para sistemas evolutivos musicais [TW99]. 
Aprendizado A capacidade de aprender através das reações e interações com o ambiente virtual agrega inteligência ao agente. Esse aprendizado pode se refletir em melhor desempenho ao longo do tempo, característica que pode ser de interesse em aplicações musicais.

Paradigma multiagentes Além da tipologia mencionada em [Nwa96], Whalley [Wha09] inclui a classificação entre as aplicações que envolvem entradas externas e aquelas que não envolvem. As aplicações DAI (Inteligência Artificial Distribuída) aceitam entradas externas, no caso de sistemas multiagentes musicais, isso corresponderia à participação de usuários humanos. As outras aplicações sem entradas externas, denominadas por Whalley de MAS (Sistemas multiagentes), permitem a interação apenas entre agentes internos.

\subsubsection{Raciocínio do agente}

Sejam ou não musicais, os raciocínios executam a intenção composicional do agente e podem incluir mecanismos complexos e interativos, decisivos para alcançar as metas da aplicação. Nesse contexto, faremos algumas considerações básicas sobre os raciocínios numa aplicação, e uma análise mais detalhada de técnicas de composição algorítmica que têm sido utilizadas em trabalhos relacionados, e que podem ser úteis em posteriores aplicações, seja retomando abordagens já testadas ou adaptando essas técnicas a um contexto mais interativo e flexível.

Uma aplicação musical com agentes pode fazer uso de diversos tipos de raciocínios num mesmo agente ou em vários agentes de tipos diferentes. Uma classificação que contextualiza o uso de raciocínios em sistemas multiagentes musicais e mais especificamente no arcabouço ENSEMBLE pode ser encontrada em [Tho11].

Consideramos assim o interesse em levantar e propor técnicas que utilizem áudio nesses raciocínios, já que este é o formato de codificação mais utilizado na criação musical mediada por tecnologia e o menos explorado em trabalhos relacionados.

\section{Utilização de áudio}

O áudio como codificação musical e sonora tem sido pouco aproveitado nos sistemas multiagentes musicais [NOK94] [EP11], e especialmente naqueles sistemas interativos que incluem uma contraparte humana. O papel que o áudio terá no sistema é essencial para delinear os raciocínios e processamentos sonoros a serem utilizados. Essa escolha em princípio deve se basear na qualidade desejada para o resultado sonoro e nas entradas disponíveis para a interação.

Thomaz [TQ09] ilustra a viabilidade de efetuar processamentos de áudio em tempo real com ferramentas como o ENSEMBLE o estudo de caso Clapping Music [Tho11], expandido e implementado no arcabouço, ilustra uma aplicação da comunicação entre agentes exclusivamente baseada em áudio.

Pretendemos dispor de uma ampla escolha entre formatos e codificações. O objetivo é que a opção pelo áudio seja viável e que uma codificação simbólica (como MIDI) não seja escolhida exclusivamente pela vantagem técnica da sua simplicidade computacional, colocando em segundo plano outras questões estéticas e composicionais.

\section{Composição algorítmica}

A composição algorítmica pode ser descrita como a sequência ou conjunto de regras, instruções ou operações para resolver um determinado problema ou tarefa de combinar elementos ou 
abstrações musicais numa composição [Cop93]. Um contexto histórico da composição algorítmica é apresentado em alguns trabalhos como [Row99] [PW99] [Jar00].

Dentro do processo criativo e composicional deve-se modelar características e tarefas voltadas ao propósito musical de uma peça, sistema, performance ou instalação. Para definir os comportamentos musicais de um agente podem ser utilizadas muitas técnicas de composição algorítmica, que podem ter diferentes abordagens e que podem ser combinadas dentro de um ou vários raciocínios do agente.

Vários algoritmos podem ser misturados numa única peça musical, ou podem ser aplicados em diferentes parâmetros musicais, como altura, timbre e ritmo, ou para determinar os componentes da estrutura geral de uma obra. Os programas computacionais podem manipular grande número de instruções ou regras musicais num tempo curto, permitindo assim ao compositor concentrar a sua atenção em outros aspectos da obra como um todo [Jar00].

Modelos matemáticos Vários modelos matemáticos têm sido utilizados extensamente em composição algorítmica, tais como processos estocásticos [Xen92] e em especial cadeias de Markov [Ame89]. Nesses processos, números gerados aleatoriamente são utilizados pelos compositores para tomar decisões, determinando parâmetros, rotinas ou composições completas.

Um dos motivos para utilizar esses métodos de baixa complexidade computacional é a possibilidade de aplicação em tempo real [PW99], motivo pelo qual são encontrados, por exemplo, em alguns programas comerciais como o M e Jam Factory [Zic87].

Transformações simbólicas Com a popularidade do formato MIDI para aplicações musicais simbólicas surgiram outros tipos de algoritmos que transformam parâmetros com significado musical. Nesse grupo de técnicas achamos o trabalho de Zicarelli [Zic87], que utiliza processos de reordenação para permitir que o usuário mude parâmetros musicais simbólicos em formato MIDI, como o tom, o comportamento cíclico de uma frase ou a densidade de notas geradas, com a intenção de deixar que o usuário escute imediatamente o resultado da operação. No caso do programa M, a aplicação está orientada para a composição de material musical, e no caso do Jam Factory a aplicação está focada na realização de performances interativas.

Outra proposta que utiliza transformações e processos matemáticos aplicados a informação MIDI é o sistema Cypher [Row92a] [Row92b]; nele o usuário consegue interagir com uma série de parâmetros para mudar a resposta sonora do sistema. As transformações incluem mudança de oitavas, inversão de acordes e duração das notas, entre outros processos aplicados a uma entrada MIDI. O mais comum é aplicar várias transformações simples na entrada, sendo que a combinação delas produz resultados mais complicados através da sobreposição de efeitos. O sistema Cypher utiliza uma interface gráfica que permite aplicar vínculos entre vários tipos de transformação, que estão divididas por categorias e mantêm uma estrutura hierárquica.

Observamos que esse tipo de técnica teve uma importância maior na época desses sistemas pioneiros. Chama a atenção o fato que o M e o Jam Factory eram sistemas comerciais com um discreto sucesso e notoriedade [Ame89].

Algoritmos genéticos e evolutivos Os sistemas baseados em computação evolutiva mantêm uma população de soluções potenciais, aplicam processos de seleção baseados na adaptação de um indivíduo e empregam outros operadores genéticos. Existem diversas abordagens para sistemas baseados em evolução, sendo que as principais diferenças entre elas dizem respeito aos operadores genéticos empregados [VZ03]. Tomamos o exemplo dos algoritmos genéticos para ilustrar esse tipo de técnica. 
Os algoritmos genéticos foram introduzidos por Holland [Hol75] com o objetivo de formalizar matematicamente processos de adaptação em sistemas naturais e desenvolver sistemas artificiais com os mecanismos encontrados em sistemas naturais. Os algoritmos genéticos empregam os operadores de crossover e mutação.
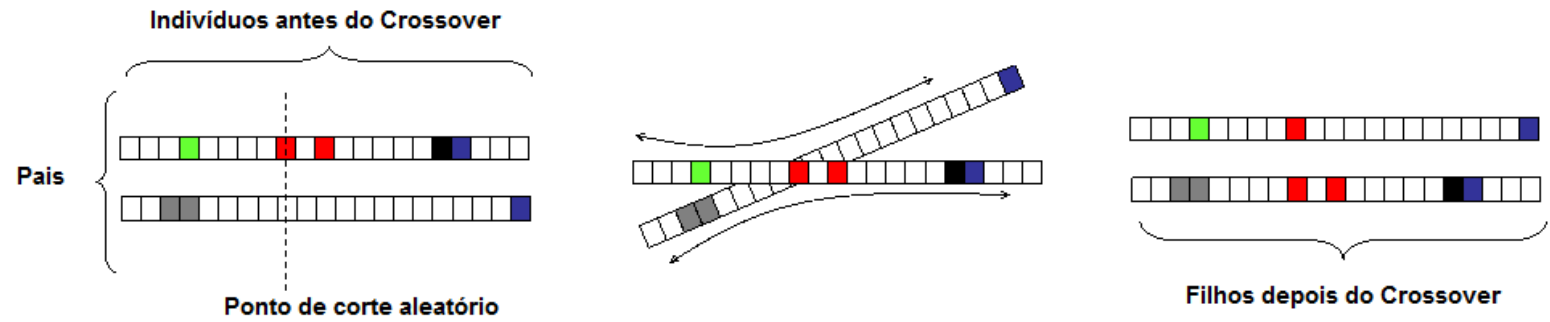

Figura 2.4: Operador Genético de Crossover

Crossover O operador de crossover ou recombinação cria novos indivíduos através da combinação de dois ou mais indivíduos como apresenta a figura 2.4. A idéia intuitiva por trás do operador de crossover no contexto da resolução de problemas é a troca de informação entre diferentes soluções candidatas [VZ03].
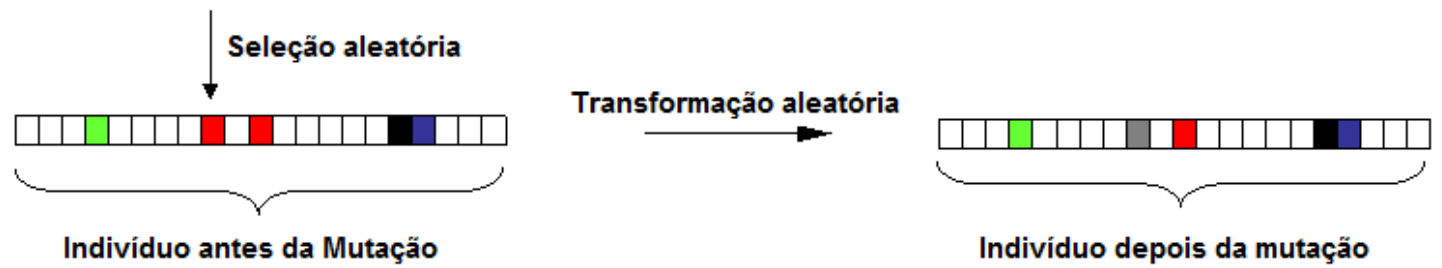

Figura 2.5: Operador Genético de Mutação

Mutação O operador de mutação modifica aleatoriamente um ou mais genes de um cromossomo como ilustrado na figura 2.5. A probabilidade de ocorrência de mutação em um gene é denominada taxa de mutação. Usualmente, são atribuídos valores pequenos para a taxa de mutação. A idéia intuitiva por trás do operador de mutação na solução de problemas é criar uma variabilidade extra na população de soluções possíveis [VZ03].

Ciclo do Algoritmo Genético O ciclo de um algoritmo genético, representado na figura 2.6, normalmente parte de uma população inicial; dois ou mais pais desse grupo participam da reprodução, que aplica operadores genéticos como o crossover e a mutação nos novos indivíduos criados. Esses filhos são avaliados para determinar se atendem às expectativas do algoritmo, que normalmente trata de buscar uma solução ou otimizar algum cenário, através de funções de avaliação ou fitness. Aqueles novos indivíduos que forem considerados aptos, junto com o restante da população anterior, reiniciam o processo para uma nova geração de soluções.

Os algoritmos genéticos têm se mostrado métodos de busca eficientes, especificamente em problemas que apresentam espaços de busca muito grandes. Também é conveniente a habilidade desses algoritmos de encontrar múltiplas soluções, ponto importante em domínios criativos como, por 


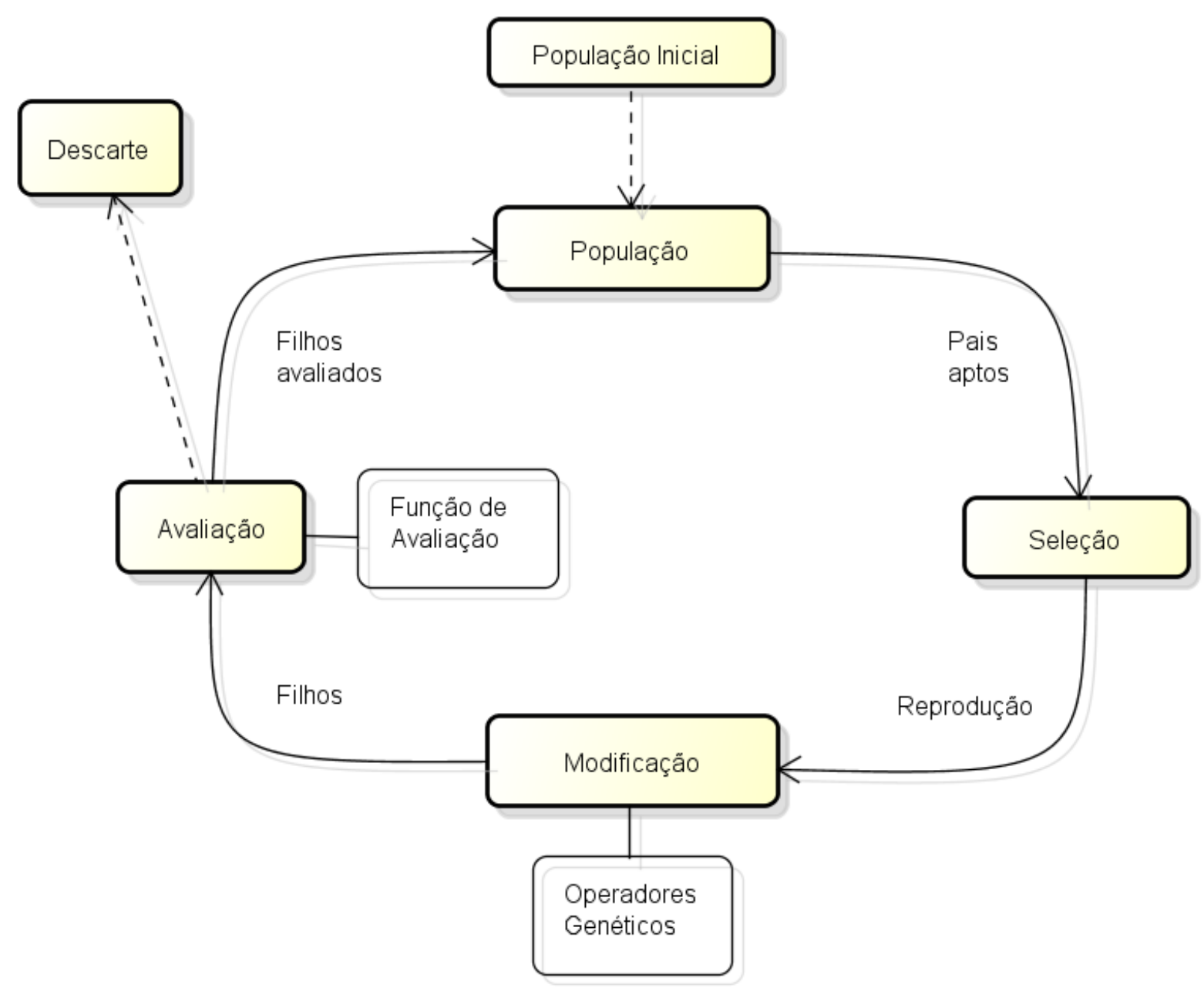

Figura 2.6: Ciclo resumido do Algoritmo Genético Clássico

exemplo, na busca de material diversificado para a saída de uma aplicação musical [PW99].

As operações genéticas podem ser aplicadas sobre diferentes parâmetros, como melodias, regras [McC01] ou elementos mais gerais que incluem tarefas musicais [DN01]. Daí temos um primeiro ponto de escolha, na forma de seleção desses valores iniciais. Outro ponto importante que divide os trabalhos vinculados a aplicações musicais é o critério de seleção, o crítico ou função de avaliação que atribui valor a um dado candidato musical, sendo que este valor pode ser determinado pela máquina ou por um juiz humano.

Na segunda categoria se encaixa o trabalho de Jacob [Jac95] na sua abordagem que combina em cromossomos musicais elementos como processos estocásticos, comprimento de frases, taxas de variação, acordes e intervalos válidos. Um agente "ouvido" determina que frases fazem sentido, e somente depois desse filtro um humano avalia o resultado.

Numa linha um pouco diferente, Biles [Bi103], no seu sistema GenJam que modela um solista de Jazz com técnicas evolutivas e operadores genéticos, utiliza a média das opiniões da platéia como critério de avaliação.

A partir de uma revisão crítica de trabalhos anteriores com técnicas evolutivas para a criação musical, Todd e Werner [TW99] propõem uma abordagem comparativa que testa diferentes tipos de críticos. 
Outras técnicas Existem outras técnicas de composição algorítmica com apelo menos interativo, entre elas as gramáticas formais. Dado que em muitos gêneros de música existe naturalmente algum tipo de hierarquia, onde elementos menores se conectam para formar frases, seções, movimentos e peças [Jar00], é intuitiva a aplicação de ideias gramaticais a elementos musicais [Ste96]. Uma gramática musical pode ser definida através de um conjunto de regras que expandem símbolos de alto nível, como movimentos, em descrições mais detalhadas de baixo nível. Expõe-se em [RW79] uma revisão completa de gramáticas no contexto musical.

Outras técnicas menos populares incluem GAT, geração e teste, que consiste em aprovar ou rejeitar totalmente o resultado ou saída de um sistema; esta técnica foi utilizada por exemplo na geração da Illiac Suite de Hiller [HI58]. Também temos a aplicação de sistemas especialistas que usam uma base de conhecimento para inferir os próximos resultados, como no caso do trabalho de Cope [Cop87], que gerava música imitando o estilo de algum compositor a partir de uma série de exemplos de obras.

Sistemas Híbridos Os sistemas híbridos no contexto da composição algorítmica são aqueles que utilizam uma combinação de técnicas de Inteligência Artificial. Eles podem combinar métodos evolutivos, conexionistas, simbólicos e sub-simbólicos. A iniciativa de combinar métodos de IA não se restringe a aplicações musicais, e é facilmente justificável já que cada método apresenta pontos fortes em aspectos específicos [Gut92].

Gibson e Byrne [GB91] criam harmonizações simples de melodias curtas de até 4 compassos usando apenas os acordes de tônica, subdominante e dominante, utilizando uma combinação de algoritmos genéticos e redes neurais cooperativas. Lewis [Lew00] na sua orquestra virtual de improvisação Voyager, combina respostas à interação de um performer com técnicas de geração própria de material sonoro. Em Todd e Werner [TW99] se combinam técnicas de evolução, regras e aprendizado num sistema que propõe a co-evolução de agentes cantores e agentes críticos que avaliam os primeiros pelo resultado de seu canto, de acordo com uma função de fitness.

Performance Interativa A participação de usuários humanos no contexto de uma performance interativa requer uma atenção especial na hora de modelar os agentes da aplicação e seus raciocínios. O suporte à entrada de informação do usuário externo deve ser garantido, e esses dados podem vir em codificação simbólica e/ou em áudio.

\subsubsection{Decisões computacionais}

Nesta subseção vamos descrever algumas características dos potenciais usuários de arcabouços voltados à implementação de sistemas multiagentes musicais, e como as aplicações podem ser formuladas para aproveitar as características dessas ferramentas.

\section{Perfil do usuário}

Um dos problemas recorrentes em sistemas computacionais é o entendimento dos requisitos do usuário e qual é o público alvo de uma determinada ferramenta computacional. Whalley [Wha09] nos lembra que, dada a abrangência e a quantidade de pesquisas na área de sistemas multiagentes musicais, é surpreendente a pouca atenção que essas ferramentas conseguem entre compositores e cientistas da computação interessados em criação musical e arte sonora. Complementando e talvez 
explicando um pouco esse cenário, Whalley [Wha05] questiona a motivação desses sistemas, já que são muitas vezes criadores da área técnica que estão mais interessados em sistemas computacionais desafiadores do que em aplicações com um valor estético.

Assim, considerando que um arcabouço como o ENSEMBLE [Tho11] pretende abranger na sua taxonomia um número representativo de sistemas existentes na literatura, consideramos que o perfil dos usuários do arcabouço coincide com aquele dos trabalhos de referência para sua construção. Podemos afirmar no entanto que essa falta de atrativo é também um problema a se resolver no contexto do ENSEMBLE.

Um primeiro tipo de usuários terá justamente um perfil mais técnico, em boa parte pessoas envolvidas com a pesquisa em computação musical. Esses usuários técnicos não terão maiores dificuldades para começar a trabalhar nos arcabouços de sistemas multiagentes, porém, dominar em detalhe todos os recursos possue uma curva de aprendizado. Gostariamos que isso não seja um obstáculo para que novas iniciativas sejam implementadas.

Outro grupo de usuários pode ter um perfil mais voltado para o âmbito artístico, como no caso de compositores e artistas entusiastas de disciplinas técnicas. Vemos por exemplo que a ferramenta ISO tem sido aplicada com sucesso na combinação de sistemas multiagentes musicais com coreografias de dança ao vivo que utilizam reconhecimento de imagens [BNF08].

Esse tipo de usuário pode ter um conhecimento técnico básico, dado que eles já têm um interesse em combinar tecnologia na criação musical e artística, porém, não podemos supor que a maioria de músicos e artistas interessados em experimentar com sistemas multiagentes tenha a capacidade de programar em uma linguagem orientada a objetos, como Java no caso do ENSEMBLE [Tho11] e $\mathrm{C}++$ no caso do ISO [BNF07].

Assim enxergamos que nem todos os recursos das ferramentas poderão ser aproveitados por todos os potenciais usuários, e daí a necessidade de analisar até que ponto as interfaces e atalhos dos arcabouços permitem que um usuário não-técnico consiga experimentar na criação de aplicações musicais com agentes.

Outro ponto relevante é propor rumos para melhorar a experiência de usuário e divulgar essas ferramentas, ao mesmo tempo em que seria útil servir de intermediário entre iniciativas artísticas e a execução de aplicações multiagentes musicais.

\section{Definição dos aplicativos}

Aqui veremos os passos que devemos dar para definir um aplicativo no contexto de um arcabouço orientado à nossa área de estudo. Consideraremos alguns cenários diferentes que surgem no contexto das possíveis aplicações.

O arcabouço ENSEMBLE, desenvolvido em Java, se apresenta como um conjunto de bibliotecas multi-plataforma para a construção de sistemas multiagentes musicais; o código pode ser baixado de um repositório ${ }^{3}$ e conta com casos de estudo que ilustram algumas modalidades de uso da ferramenta.

Arquitetura A arquitetura apresentada por Thomaz [Tho11] independe de tecnologia de implementação, porém vamos abordar as características principais da mesma já considerando a versão

\footnotetext{
${ }^{3} \mathrm{http}: / /$ code.google.com/p/musicalagents/
} 
desenvolvida em Java. Essa escolha se justifica pela busca de portabilidade, permitindo que as aplicações musicais programadas pelos usuários do ENSEMBLE possam ser executada em plataformas distintas [Tho11].

Para essa implementação foi utilizado o middleware de sistemas multiagentes JADE [BPR99], por ser um software gratuito de código aberto que, além de ser bem documentado, possui várias extensões e aplicações, demonstrando seu nível de maturidade. Entrar em detalhes do JADE não é necessário para um usuário do ENSEMBLE, já que um dos objetivos deste arcabouço é abstrair essa complexidade, porém, uma explicação sobre a utilização de JADE no arcabouço pode ser consultada no trabalho de Thomaz [Tho11].

Se voltarmos nossa atenção para um nível mais específico do arcabouço ENSEMBLE, podemos observar que existem vários componentes diferentes, tais como agentes, componentes musicais, servidores de eventos, interfaces de comunicação, entre outros. Todos eles implementam uma mesma interface Java chamada LifeCycle, uniformizando o ciclo de vida não só dos agentes mas de todos os componentes do sistema. Assim podemos iniciar, configurar, parar ou definir parâmetros para cada componente [Tho11].

Atores Para um entendimento da estrutura do arcabouço vamos começar observando os diferentes atores e suas principais características na tabela 2.2.

\begin{tabular}{|c|c|c|}
\hline Ator & Classe & Descrição \\
\hline Agente Musical & MusicalAgent & $\begin{array}{l}\text { É o encarregado de processar a informação so- } \\
\text { nora e musical e habita o mundo virtual. Está } \\
\text { composto por diversos componentes interligados } \\
\text { como a Base de Conhecimento (Classe Knowled- } \\
\text { geBase), Raciocínios (Classe Reasoning) deta- } \\
\text { lhados na seção 2.3.2, Sensores (Classe Sensor) } \\
\text { e Atuadores (Classe Actuator). }\end{array}$ \\
\hline Agente Ambiente & EnvironmentAgent & $\begin{array}{l}\text { Representa o Ambiente Virtual e controla todas } \\
\text { as interações entre os Agentes Musicais; é com- } \\
\text { posto de Servidores de Eventos (classe Event- } \\
\text { Server ) que são os responsáveis por processar } \\
\text { os eventos recebidos pelo agente Ambiente. }\end{array}$ \\
\hline Agente Externo & MusicalAgent ou Sistema Externo & $\begin{array}{l}\text { Representa qualquer sistema externo ou usuá- } \\
\text { rio que queira interagir com os agentes do arca- } \\
\text { bouço. Pode ser mapeado em um Agente Musical } \\
\text { ou então se comunicar com os agentes do sistema } \\
\text { através do envio de dados. }\end{array}$ \\
\hline
\end{tabular}

Tabela 2.2: Atores da Arquitetura Ensemble

Continuaremos essa revisão da arquitetura com os elementos que compõem um agente musical.

Base de Conhecimento Esse elemento tem como base a classe KnowledgeBase, e armazena o conjunto de informações necessárias (fatos) para representar o estado interno atual do Agente. Um fato é criado e vinculado usando o método registerFact() na inicialização, e pode ser alterado em tempo de execução com o método updateFact(). Os fatos privados podem ser vistos como o genótipo do Agente Musical, enquanto que os fatos públicos correspondem a seu fenótipo. 
Para o desenho e utilização das bases de conhecimento num contexto temporal é indispensável considerar a interface Memory. Estão disponíveis métodos para a criação (createMemory()), referência (getMemory()), escrita (writeMemory ()$)$ e leitura (readMemory()). Essa estrutura é principalmente útil para manipular áudio, usando o método readMemory(), que pode receber um instante exato no tempo ou um intervalo em segundos, recuperando as amostras solicitadas. Na prática usar uma memória para cada sensor permite ter controle bastante completo sobre o áudio ou os eventos de cada agente.

Sensores e Atuadores Os sensores e atuadores são os únicos componentes do Agente Musical que têm contato com o mundo virtual. São responsáveis pela interação do Agente com o Ambiente; enquanto os Sensores (classe Sensor) recebem eventos do ambiente, os Atuadores (classe Actuator) enviam eventos [Tho11]. Os eventos no contexto do arcabouço são estímulos ou acontecimentos com tipos diferentes, como por exemplo, eventos de movimentação, de emissão de som ou de execução de uma tarefa de vida artificial.

Servidores de evento Um Servidor de Eventos é um componente do Agente ambiente que envia e recebe os eventos através das interfaces Sensing e Acting, usando uma interface de comunicação $(C o m m)$. Essa interface de comunicação é de vital importância para obter a performance adequada num aplicativo que troque áudio ou outro tipo de dados em grandes quantidades, principalmente nas aplicações com processamento de áudio em tempo real.

Devemos considerar que, para cada tipo de evento que o Ambiente controla, deve existir um objeto da classe EventServer associado que incorpora funções análogas aos Sensores, Atuadores e Raciocínios nos Agentes Musicais. Existem no arcabouço ENSEMBLE implementações de servidores de eventos básicos, tanto para a movimentação de agentes como para a propagação sonora no ambiente.

\begin{tabular}{|c|c|c|c|c|}
\hline Biblioteca & Classe para Entrada & Classe para Saída & Suporte multicanal & Biblioteca Nativa \\
\hline JavaSound & JavaInputReasoning & JavaOutputReasoning & Não & Sim \\
\hline PortAudio & PAInputReasoning & PAOutputReasoning & Sim & Sim \\
\hline Jack & JackInputReasoning & JackOutputReasoning & Sim & Não \\
\hline
\end{tabular}

Tabela 2.3: Bibliotecas de Áudio

Iniciando uma aplicação Para compor uma aplicação no ENSEMBLE precisamos definir uma série de componentes de base como o ambiente virtual, os tipos de agentes, tipos de raciocínios e tipos de atuadores ou sensores que podem ser utilizados. Com esses pontos estabelecidos pode-se criar as instâncias dos agentes que viverão nesse ambiente.

Um arquivo de configuração em formato texto e codificado em XML é utilizado como entrada da classe Loader, e contém todos os dados necessários para a definição de uma aplicação musical e sua inicialização.

Formulação de Novos Raciocínios Para a criação de novos raciocínios temos uma série de referências e classes base que servem ao desenvolvimento dos componentes. Apesar de não existir uma integração com alguma IDE ou GUI, a estrutura dos projetos permite um entendimento dos componentes e da organização dos exemplos inclusos na API. Porém, os usuários que queiram criar novos raciocínios, sejam eles musicais ou não, terão que desenvolver código em Java, fazendo dessa 
característica uma limitação, assim como um rumo para dar continuidade ao projeto.

Em termos de técnicas implementadas de composição algorítmica, seria interessante possuir exemplos prontos para agilizar a experimentação de compositores e usuários em geral; porém, as necessidades dos usuários nesse ponto são normalmente muito específicas. Da mesma forma é útil dispor de processamentos de aúdio prontos no arcabouço ENSEMBLE, portanto é um objetivo desta pesquisa fornecer algumas implementações nesse sentido.

Formulação de Novos Servidores de evento Para a comunicação sonora no ambiente e para a movimentação existem classes de base chamadas de Servidores de eventos que são necessárias para implementar os tipos de raciocínio num ambiente virtual e nos agentes.

É necessário definir novos servidores de evento apenas no caso de se desejar programar uma modalidade nova de comunicação ou uma característica nova dos agentes, como por exemplo para incluir um sistema emocional nos agentes para representar o estado de ânimo dos mesmos. Neste exemplo, além do servidor de eventos, seria necessário também definir uma interface de comunicação do tipo Comm e implementar as interfaces Sensing e Acting desse novo tipo de atuadores e sensores. 


\section{Capítulo 3}

\section{Implementações e Contribuições}

Neste capítulo trataremos dos principais pontos das implementações que derivaram dessa pesquisa, sendo principalmente extensões dos arcabouços de SMA Musicais.Também apresentamos, como uma contribuição teórica, a definição e modelagem de uma linguagem de script para raciocínios de agentes no ambiente ENSEMBLE.

Tradicionalmente os trabalhos na área de sistemas multiagentes musicais surgiram como iniciativas isoladas, principalmente em termos de implementação. Apesar de que muitos conceitos e técnicas se compartilham entre projetos, a codificação começava do zero. Em oposição a esse precedente, queremos mostrar como podemos mudar essa tendência com o uso de ferramentas como o arcabouço ENSEMBLE e ISO; pretendemos no presente trabalho facilitar e expandir sua utilização.

Com esse propósito apresentamos um novo servidor de eventos para o ENSEMBLE que facilita a comunicação entre agentes e a integração com sistemas externos. Complementando a melhoria na comunicação no arcabouço temos a implementação de uma integração com interfaces OSC no contexto de aplicações musicais.

Apresentamos também a integração entre o ENSEMBLE e as simulações feitas no contexto do Interactive Swarm Orchestra [BNF07]. As APIs da ISO já foram utilizadas em projetos com parcerias interdisciplinares, impulsionando vários trabalhos artísticos [BNF08][BU09][BU10], contrastando com muitos outros projetos de sistemas multiagentes musicais que servem apenas como protótipos de técnicas e como experimentação na área da computação.

Trataremos também as soluções para processamento de áudio dentro dos raciocínios do agente musical e finalmente propomos uma linguagem descritiva de raciocínios no contexto do ENSEMBLE.

\subsection{Extensões dos Arcabouços de SMA Musicais}

Considerando os objetivos desta pesquisa, considera-se importante propor e implementar extensões ao ENSEMBLE que acrescentem atrativo para todos os tipos de usuários potencialmente interessados. A partir dessa premissa foram implementadas ferramentas dentro do ENSEMBLE que permitem melhorar a comunicação entre os agentes musicais e principalmente que viabilizam uma integração com diversos sistemas e interfaces de usuário. Na mesma linha, define-se um escopo de integração do ENSEMBLE com ISO para aproveitar as vantagens desses arcabouços e complementar os pontos fortes que cada uma dessas abordagens possui.

Como outro elemento no escopo desse trabalho temos as implementações que permitam o processamento de áudio em tempo real, seja visando analisar características do áudio ou a modificação do mesmo com efeitos digitais. O resultado desses processos poderá ser usado em raciocínios de 
agentes dentro das aplicações musicais.

Além da disponibilização de novos recursos, foi o nosso intuito aproximar possíveis interessados não-programadores do ENSEMBLE; esse propósito esteve presente ao longo da pesquisa e se mostrou como um ponto muito relevante. Assim, propõe-se uma linguagem de script em raciocínio que permita simplificar esta etapa no desenho de uma aplicação.

Para ilustrar o funcionamento e aplicação dos novos recursos do ENSEMBLE utilizamos referências a duas das aplicações posteriormente apresentadas no capítulo 5. Primeiro temos a aplicação de um delay espacializado para uso de uma pianista, que possui um agente avatar que aplica o efeito enquanto se movimenta pelo mundo virtual. Uma segunda aplicação é a interação entre um piano preparado e agentes multi-instrumentistas que existem num mundo virtual e podem ser manipulados pela pianista.

\subsubsection{Servidor de eventos de mensagens}

O ENSEMBLE possui servidores de evento que cuidam da movimentação dos agentes no mundo virtual e da troca e propagação de áudio no mesmo ambiente. Diferentes variantes podem oferecer distintas possibilidades ao usuário como, por exemplo, estabelecer uma movimentação discreta ou contínua no mundo virtual ou alterar a forma como se irá propagar o áudio nas simulações.

Igualmente, a arquitetura do ENSEMBLE permite acrescentar servidores de eventos para o tratamento de novos tipos de acontecimentos no mundo virtual, que serão percebidos por sensores especializados para tais operações e que conseguem agir através de atuadores também especializados. Usando essa capacidade própria do arcabouço, foi implementado um servidor de eventos para permitir uma comunicação mais direta entre agentes e o ambiente, que trate a comunicação de instruções e comandos como eventos do mundo virtual.

Para alcançar esse propósito foi aproveitado o mecanismo de roteamento de comandos do ENSEMBLE, que já estabelece a estrutura de uma instrução e que é utilizado para o repasse de algumas operações. Esses comandos no ENSEMBLE permitem executar operações de movimentação como caminhar, mudar posição ou parar. A extensão propõe fornecer uma alternativa para transmitir esses comandos, e assim formalizar um mecanismo padrão para operações de vida artificial e explorar mais possibilidades de eventos de controle, seja através de interfaces externas ou através da integração com outros sistemas. O servidor de mensagens permite que um agente receba comandos de tipos diferentes e os armazene numa memória específica vinculada a um sensor receptor de mensagens. Isso também oferece a possibilidade de manipular essa informação de diversas formas em momentos diferentes.

\section{Roteamento de Comandos}

O serviço de roteamento de mensagens realiza a troca de mensagens entre Agentes Musicais e o Agente Ambiente utilizando um mecanismo interno de troca de mensagens do middleware multiagente [Tho11]. O esquema de endereçamento baseia-se numa sequência de caracteres contendo o nome do sistema e o nome do componente interno, e o comando resultante é representado no ambiente do arcabouço através de um objeto da classe Command. Essa estrutura de dados possui um identificador que facilita a filtragem assim como um conjunto de parâmetros, cada um dos quais está composto por um identificador e um valor associado, e ambos são obrigatoriamente sequências de caracteres. 
Alguns métodos executam o envio e processamento dos comandos, como o método sendCommand(Command $\mathrm{cmd}$ ), que deve identificar o destinatário, o comando e o método processCommand(Command $\mathrm{cmd}$ ) que trata os diferentes tipos de mensagem e pode ser alterado para cada raciocínio. No caso de mensagens externas, um serviço especial de roteamento faz a interface com o mundo exterior. A classe RouterAgent se encarrega de receber e encaminhar mensagens, funcionalidade aproveitada também pelo novo servidor de eventos. As mensagens são recebidas e interpretadas pela classe RouterAgent, e mais especificamente pelas instâncias da classe interna Listener que monitoram as portas configuradas. Na figura 3.1 vemos um exemplo de como o roteamento de mensagens identifica as mensagens pela fonte, nesse caso o prefixo determina se as mensagens vieram da aplicação AndOSC e se são mensagens do sensor de tela, orientação ou acelerômetro. Tambem podemos ver como determinamos que essas mensagens serão encaminhadas para o nosso servidor de mensagens interno. O método processAndOsc detalhado na figura 3.2 formata o parâmetros do comando segundo nosso novo padrão. Primeiro conferimos o tipo de mensagem e a quantidade de parâmetros, depois acrescentamos parâmetros que indicam o domínio do comando, tipo de fonte e ação. No exemplo temos uma mensagem de domínio externo, do tipo AndOSC e que determina um toque na tela numa posição determinada.
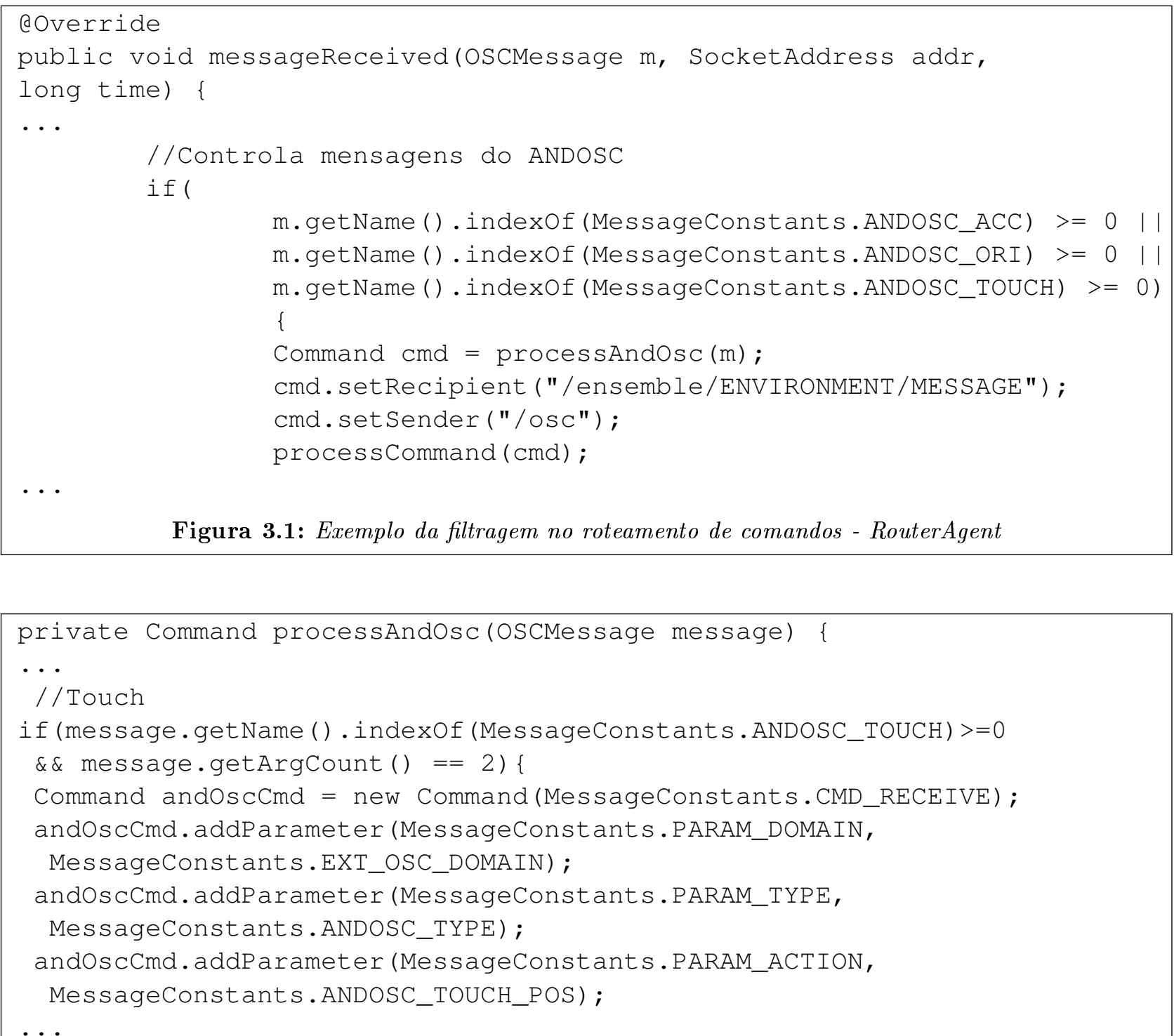

Figura 3.2: Método de formatação processAndOsc

Utilizamos a estrutura da classe Command, apresentada na tabela 3.1, para registrar eventos 
de mensagens que têm como diferença a possibilidade de serem percebidos por sensores e enviados por atuadores.

\begin{tabular}{|c|c|l|}
\hline Propriedade & Tipo & Descrição \\
\hline Command & String & Identifica o tipo de comando. \\
\hline Parameters & HashMap & $\begin{array}{l}\text { Conjunto de parâmetros de configuração próprios do co- } \\
\text { mando. }\end{array}$ \\
\hline UserParameters & HashMap & Conjunto de parâmetros definidos pelo usuário. \\
\hline
\end{tabular}

Tabela 3.1: Estrutura da Classe Command

\section{Estrutura do Servidor de eventos}

Como base para a construção de um novo servidor de eventos no ENSEMBLE definimos um novo tipo de evento Message que será identificado tanto na definição XML dos elementos da simulação como nos métodos de registro de sensores e atuadores. Dessa forma cada elemento que envie ou receba mensagens poderá acessar esses eventos pelos mesmos métodos definidos para áudio ou movimento.

Como apresentamos na figura 3.3 a nova classe MessageEventServer estende da classe EventServer e foi criada para definir a estrutura padrão do novo servidor. Assim respeitamos os mesmos princípios de configuração de período para a execução das rotinas que verificam a existência de eventos, e também criamos uma memória de eventos padrão para cada sensor registrado nesse servidor de mensagens. Para cada evento do tipo mensagem recebido o servidor estrutura um comando e notifica aos agentes registrados.

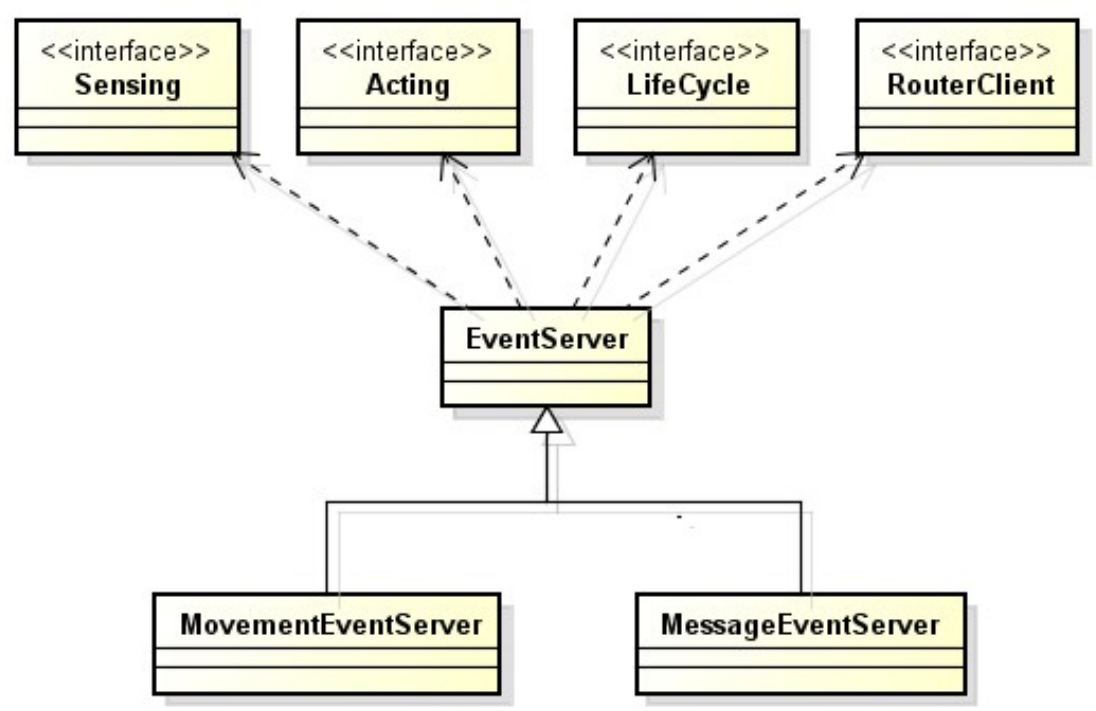

Figura 3.3: Diagrama de classe do Servidor de Eventos de Mensagens

Para utilizar esse servidor numa aplicação é necessário incluí-lo como se ilustra na figura 3.4 na configuração inicial, no arquivo XML que será usado para montar a aplicação. Os parâmetros de período e tempo de espera podem ser alterados nessa inclusão com o campo PERIOD.

Os agentes com raciocínios que utilizem mensagens precisam ter um sensor e/ou atuador com o tipo de evento de mensagem; na figura 3.5 temos o exemplo de definição no arquivo XML de 
<EVENT_SERVER CLASS="ensemble.router.MessageEventServer"
COMM="ensemble.comm.direct.CommDirect" PERIOD="100 0" />

Figura 3.4: Exemplo de inclusão do servidor de Eventos de Mensagens

configuração inicial, o atuador de nome Messenger e o sensor de nome Antenna se definem com o tipo de evento de mensagem.

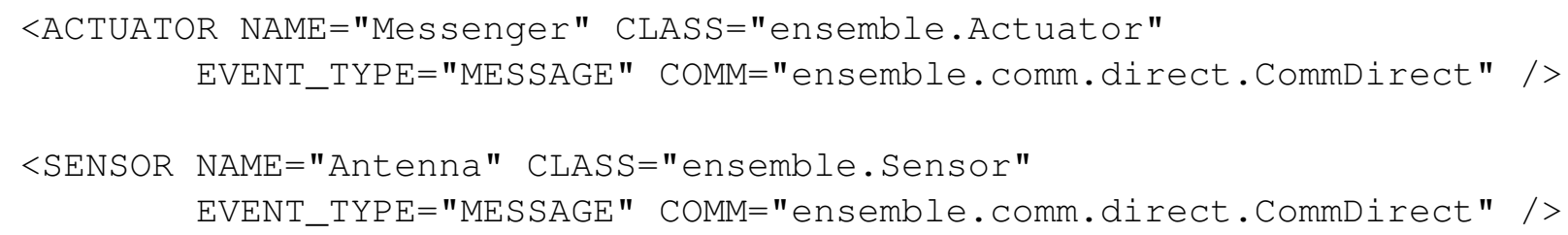

Figura 3.5: Exemplo de inclusão de Atuador e Sensor de Mensagens

Já no raciocínio devemos considerar os eventos de registro e desvinculação de atuadores e sensores de mensagem para nesse ponto identificar os componentes certos vinculados ao agente e para recolher as informações relevantes para o processamento. Assim o raciocínio consegue ter acesso, por exemplo, à memória de mensagens de um determinado atuador. Em qualquer momento que for preciso, um raciocínio pode escrever na memória do atuador um comando que logo será enviado pelo servidor. Analogamente, para cada novo evento percebido pelo sensor de mensagens do agente se executará o método "newSense" e poderá ser resgatada a mensagem que o raciocínio utilizará para compor sua lógica ou executar um determinado processamento.

Para ilustrarmos este mecanismo podemos citar a aplicação de piano preparado com agentes multi-instrumentistas; nela um raciocínio de reconhecimento de picos analisa o áudio para comparar com um determinado limiar, e caso esse nível seja ultrapassado o raciocínio escreve uma mensagem na memória de um atuador mensageiro do agente. Essa mensagem é enviada pelo servidor de mensagens e é recebida por um sensor do mesmo agente ou de outro agente. No nosso exemplo, a direção e aceleração do agente no mundo virtual se alteram a partir desse estímulo graças a um novo comando enviado para o servidor de movimentação.

Os comandos enviados através do servidor de mensagens interagem diretamente no contexto da simulação do mundo virtual, permitindo também um mecanismo alternativo para a integração com sistemas externos. Mensagens externas, no formato OSC, que podem vir a partir de linha de comando ou a partir de ambientes como o Pd ou CSound, chegam ao ENSEMBLE e são convertidos em comandos pelo mecanismo de roteamento descrito anteriormente nesta seção; a partir desse ponto eles também são considerados pelo servidor de mensagens, abrindo algumas possibilidades de interação com os agentes e principalmente como comandos de controle dos mesmos.

\subsubsection{Integração com interfaces OSC}

Seguindo o nosso objetivo de ampliar as interfaces de interação com o ENSEMBLE melhoramos a comunicação via OSC, diversificando o seu uso nas aplicações musicais e implementando integrações específicas para ferramentas existentes.

Esse tipo de comunicação via mensagens OSC, no ENSEMBLE servia originalmentepara comunicar posições dos agentes à GUI ENSEMBLE, um external de Pd que permite visualizar a posição 
dos agentes no mundo virtual. Incluímos agora uma alternativa para interagir com o ENSEMBLE a partir de dispositivos móveis com o sistema operacional Android ou IOS, sejam estes celulares ou tablets. Tomamos dois aplicativos populares e práticos (ControlOSC ${ }^{1}$ e AndOSC $^{2}$ ) e definimos um mecanismo para recepção de comandos em mensagens OSC para eles. Eles foram escolhidos por serem gratuitos, atenderem as necessidades das nossas aplicações e permitirem formular interfaces gráficas próprias.

\section{Mensagens OSC}

Usando Open Sound Control (OSC)[WF97], um protocolo de troca de mensagens especializado em aplicações musicais, podemos enviar instruções para os raciocínios do ENSEMBLE. Nesse contexto definimos uma nova estrutura de prefixos que complementa a estrutura do comando existente, com o objetivo de classificar os diferentes tipos de fonte da mensagem assim como os diferentes tipos de instruções possíveis. Com os prefixos, o mecanismo de roteamento de mensagens externos da classe RouterAgent identifica e estrutura as informações de forma adequada, formando um comando facilmente identificável nos raciocínios. Respeitamos assim os parâmetros base definidos pela classe Command que servem para identificar mensagens internas ou externas. Na tabela a seguir listamos os novos valores presentes nos comandos correspondentes a mensagens OSC.

\begin{tabular}{|c|c|l|}
\hline Nome & Valores & Descrição \\
\hline DOMAIN & EXT_OSC_DOMAIN & $\begin{array}{l}\text { Informa se o comando foi externo ou interno em relação } \\
\text { aos componentes do ENSEMBLE. }\end{array}$ \\
\hline TYPE & $\begin{array}{c}\text { ANDOSC_TYPE } \\
\text { ISO_TYPE }\end{array}$ & Determina a fonte da mensagem. \\
& CONTROL_OSC_TYPE & \\
\hline ACTION & $\begin{array}{c}\text { ISO_POSITION } \\
\text { CONTROL_OSC_POSITION } \\
\text { ANDOSC_TOUCH_POS }\end{array}$ & Instrução a ser executada. \\
\hline
\end{tabular}

Tabela 3.2: Parâmetros inclusos nos comandos internos

\section{Aplicativos em dispositivos móveis}

Outra expansão interessante no ENSEMBLE pretende fornecer uma alternativa de interface de usuário que seja mais confortável do que digitar um comando no computador ou a interação com o mouse para determinar alguma instrução. Consideramos os dispositivos móveis com os quais podemos replicar gestos numa touchscreen, e no caso de muitos destes aparelhos podemos usar a informação de acelerômetros como variáveis de controle de raciocínios no ENSEMBLE. Desta forma temos um controlador diferente do que seria tal vez uma pedaleira. Existem outros aplicativos de Android e de outras plataformas voltadas a dispositivos móveis que usam OSC com propósitos musicais, como é o caso do OSCemote ${ }^{3}$ OSCRemote $^{4}$, TouchOSC $^{5}$ e AndOSC ${ }^{6}$. Escolhemos os dois últimos para ilustrar o mecanismo de controle e fornecer uma integração pronta no arcabouço com essas aplicações simples e versáteis.

\footnotetext{
${ }^{1} \mathrm{http}: / /$ www.charlie-roberts.com/

${ }^{2}$ http://www.gotohakone.com/

${ }^{3}$ http://lux.vu/blog/oscemote/

${ }^{4}$ http://www.nr37.nl/OSCRemote/

${ }^{5}$ http://hexler.net/software/touchosc

${ }^{6} \mathrm{http}: / /$ www.gotohakone.com/
} 
AndOSC O aplicativo AndOSC permite, de forma simples, a transmissão via OSC das leituras de três sensores do dispositivo móvel: a posição na tela touchscreen, a orientação do aparelho e os dados oriundos dos acelerômetros. Este aplicativo está disponível apenas para o sistema operacional Android, mas tem a vantagem de funcionar em qualquer versão, mesmo nas versões mais antigas e por isso pode ser utilizado por qualquer dispositivo Android. O aplicativo pode ser baixado de forma gratuita do repositório de aplicativos do sistema operacional.

Para o ENSEMBLE identificamos os três tipos de mensagens por uma implementação adicional no mecanismo de roteamento e as codificamos como apresentado na tabela 3.3. A figura 3.6 mostra a interface do aplicativo, o círculo determina a última posição transmitida, e podemos conferir os valores dos outros sensores que se atualizam em tempo real. É importante lembrar que o destinatário das mensagens deve ser configurado no aplicativo assim como a porta a ser utilizada, na tela apresentada na figura 3.7.

\begin{tabular}{|c|c|c|c|}
\hline Sensor & Prefixo & Argumentos & Tipo no ENSEMBLE \\
\hline Touch & touch & X,Y & ANDOSC_TOUCH_POS \\
\hline Orientation & $/$ ori & X, Y, Z & ANDOSC_ORIENTATION \\
\hline Accelerometer & $/$ acc & XAcc, YAcc, ZAcc & ANDOSC_ACCELEROMETER \\
\hline
\end{tabular}

Tabela 3.3: Tipos de Mensagens $O S C$ do aplicativo AndOSC

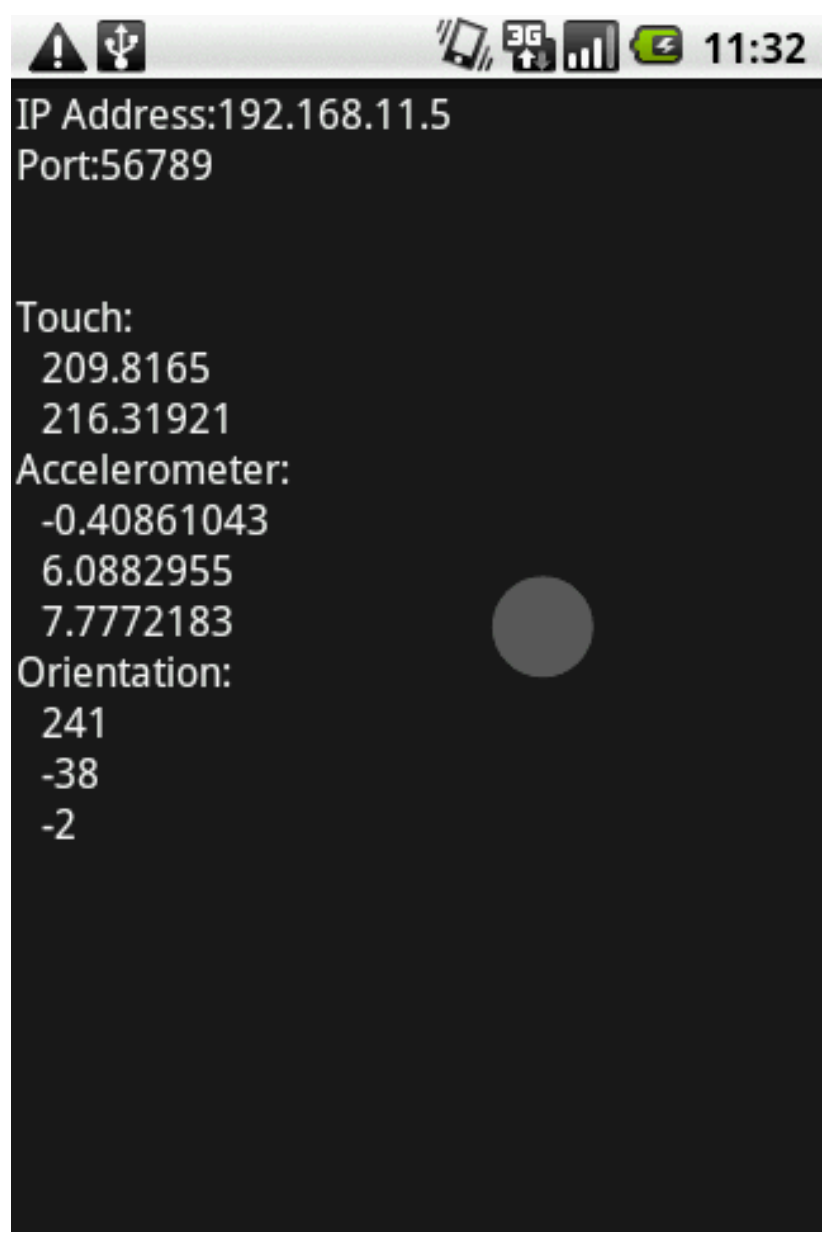

Figura 3.6: Tela Principal do aplicativo AndOSC 


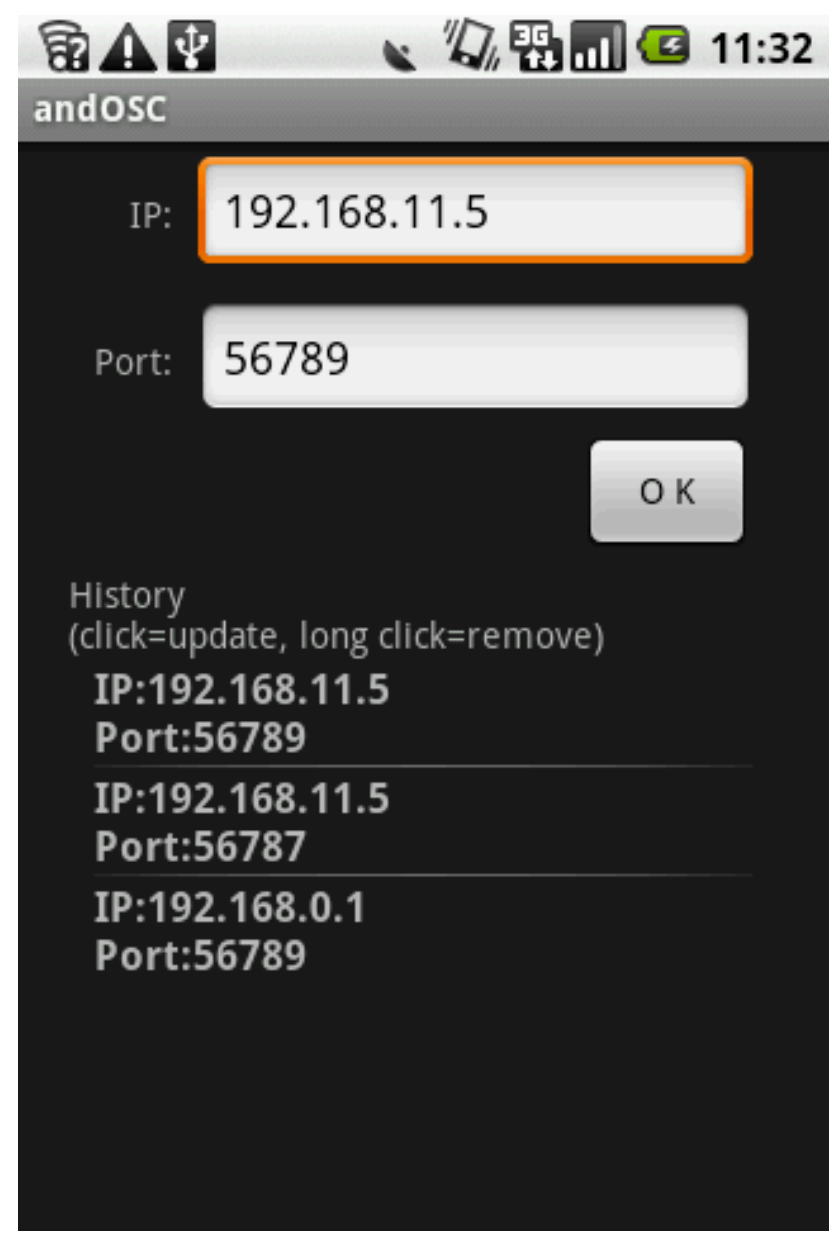

Figura 3.7: Tela de Configuração do aplicativo AndOSC

ControlOSC O ControlOSC é uma ferramenta versátil que tem como objetivo dar suporte para a criação de interfaces gráficas para aplicações musicais, artísticas e de realidade virtual a partir de uma comunicação baseada no protocolo OSC. As funcionalidades mais relevantes do aplicativo são o acesso a uma lista de interfaces a serem executadas e uma aba de configurações de destinatários, onde podemos definir e escolher com que endereço de rede e com que porta queremos nos comunicar. Conta com acesso aos principais sensores dos dispositivos móveis como giroscópio, acelerômetro e toque de tela e pode transmitir sem fio tanto no formato MIDI como em OSC. Esse aplicativo está disponível para Android e IOS, foi desenvolvido por Charlie Roberts ${ }^{7}$ usando a plataforma de PhoneGap [Chr11], que utiliza padrões web como HTML5 e CSS para dar suporte a um desenvolvimento compatível com múltiplas plataformas móveis a partir do mesmo código fonte.

Em relação às interfaces gráficas, vemos que existe um conjunto predefinido de interfaces que são carregadas no aplicativo na primeira execução, porém, podem ser implementadas interfaces personalizadas na linguagem JavaScript, utilizando o padrão JavaScript Object Notation (JSON) [Cro].

A carga dessas novas interfaces é feita via internet ou intranet, referenciando um arquivo de script com extensão 'js' que deve estar publicado em algum servidor web que o dispositivo móvel possa acessar. A estrutura dessas interfaces permite um nível de programação de eventos como inicialização e eventos de ação de componentes da interface, como o acionamento de um botão ou a mudança de valor num slider. A programação se facilita a partir de exemplos prontos que servem de tutorial; nesses exemplos podemos destacar o código para incluir prefixos nas mensagens de saída, alternativas para executar a atualização da definição de uma interface (via Internet) ou a inclusão

\footnotetext{
${ }^{7}$ http://www.charlie-roberts.com/
} 
de botões que interagem com as outras abas do aplicativo, como no caso de precisar voltar à lista de interfaces ou para trocar de destinatário.

Pela versatilidade do aplicativo ControlOSC escolhemos uma interface padrão, como o nome de Monome Emulator e apresentada na figura 3.8, justamente fazendo referencia ao hardware controlador multiuso criado para envio de MIDI e OSC. Como no caso dos dispositivos Monome ${ }^{8}$ trata se de uma matriz de botões que não têm funções fixas. A saída dessa interface controla no exemplo do delay espacializado o tipo de movimentação que o avatar vai apresentar no mundo virtual e também o ganho da saída do agente e o tempo de delay a ser aplicado na execução. Esses comandos, representados na tabela 3.4, podem ser utilizados por raciocínios de agentes no ENSEMBLE; para isso incluímos um filtro de mensagens do tipo ControlOSC, e devemos garantir que o agente possua pelo menos um sensor para receber estas mensagens.

\begin{tabular}{|c|c|c|l|}
\hline Componente & Prefixo & Argumentos & \\
\hline Slider 1 & slider1 & {$[0$ a 1$]$} & Valor contínuo entre 0 e 1 \\
\hline Slider 2 & $/$ slider2 & {$[0$ a 1$]$} & Valor contínuo entre 0 e 1 \\
\hline Monome & $/$ mlr & X, Y, Pressed & $\begin{array}{l}\text { Valor discreto de fila e coluna entre 0 } \\
\text { e 7, Pressionado 1, 0 caso contrário. }\end{array}$ \\
\hline
\end{tabular}

Tabela 3.4: Comandos na interface Monome Emulation - ControlOSC

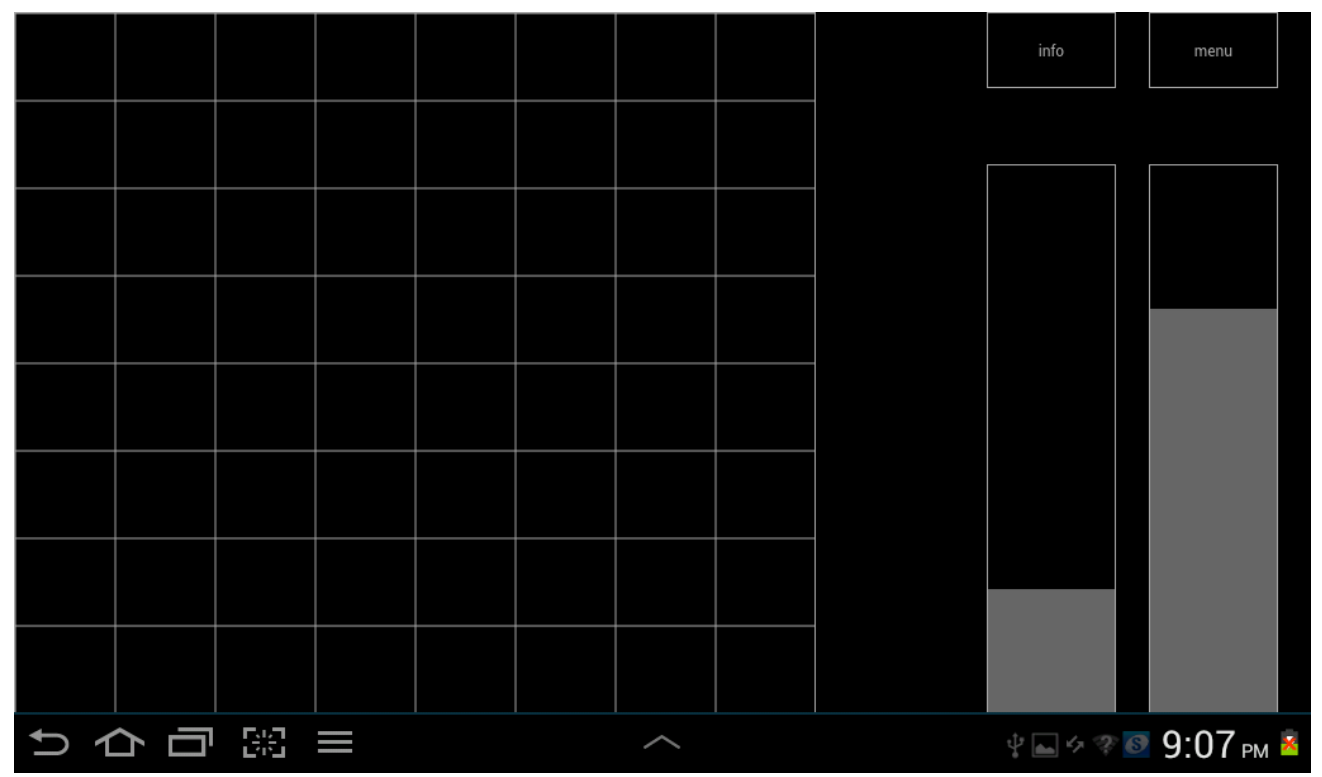

Figura 3.8: Tela da Interface Monome - ControlOSC

Esse aplicativo foi útil no ENSEMBLE como controlador no cenário da aplicação com o piano preparado e agentes instrumentistas. Para essa aplicação foi criada uma interface específica que contém arranjos de botões, switches e sliders como mostra a figura 3.9. O código script da interface se apresenta no apêndice A, esse arquivo foi publicado num servidor web para podermos realizar testes e atualizações. Os tipos de mensagens enviados estão listados na tabela 3.5.

Padrão Ensemble Considerando o potencial das mensagens OSC em aplicações musicais e interativas propomos uma nomenclatura genérica de mensagens para interação com o ENSEMBLE. Para isso já existem filtros que entendem essas nomenclaturas no mecanismo de roteamento do

\footnotetext{
${ }^{8}$ http://monome.org/
} 


\begin{tabular}{|c|c|c|c|}
\hline Componente & Prefixo & Argumentos & Comando no ENSEMBLE \\
\hline Botões A1, A2 e A3 & $/ \mathrm{pp} / \mathrm{M}$ & Id, Pressionado & PP_OSC_SWITCH \\
\hline Lista de Botões & $/ \mathrm{pp} / \mathrm{ISO}$ & Movimento & PP_OSC_ISO \\
\hline Slider Low Pass & $/ \mathrm{pp} / \mathrm{LP}$ & Id, Frequência & PP_OSC_LP \\
\hline Slider Hogh Pass & $/ \mathrm{pp} / \mathrm{HP}$ & Id, Frequência & PP_OSC_HP \\
\hline
\end{tabular}

Tabela 3.5: Comandos na interface Prepared Piano - ControlOSC

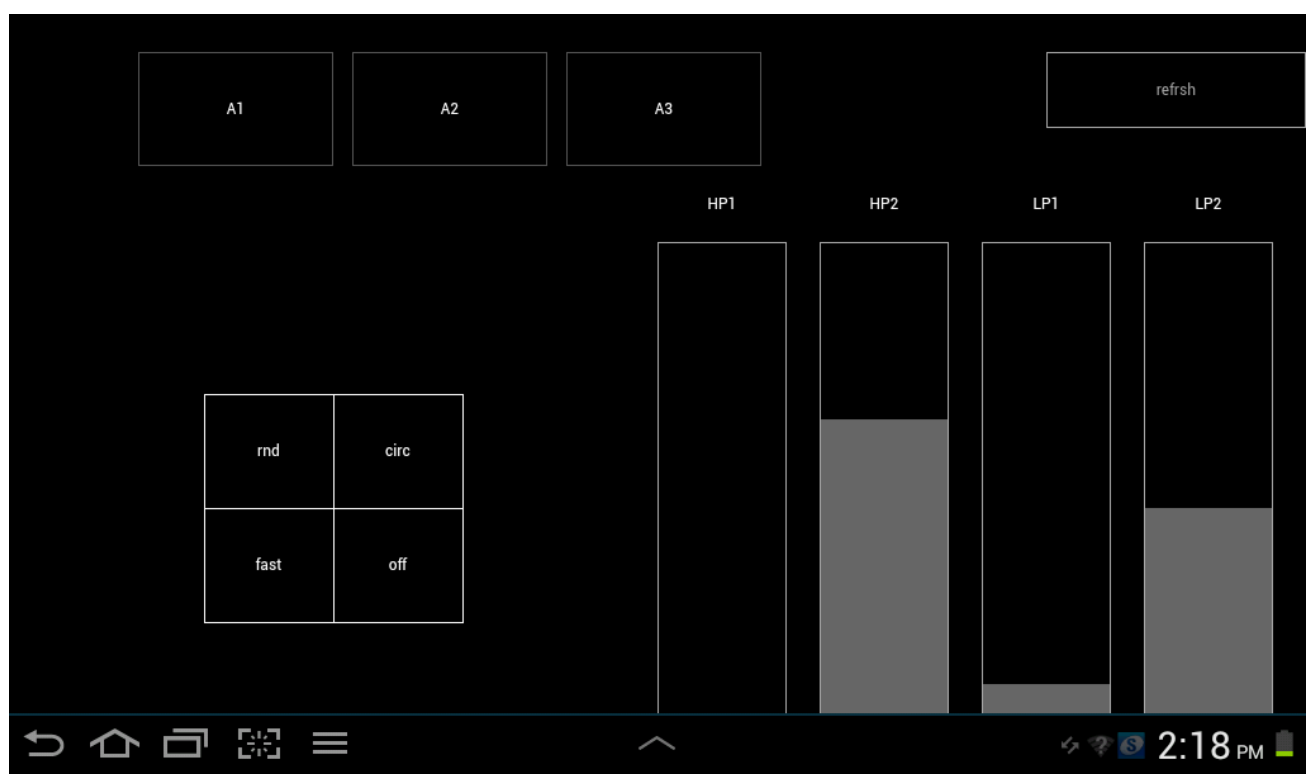

Figura 3.9: Tela da Interface Prepared Piano - ControlOSC

ENSEMBLE e que constróem os comandos específicos a partir dos parâmetros transmitidos. Primeiro consideramos os âmbitos mais frequentemente usados nas aplicações, como a movimentação e a troca de áudio. Para o primeiro caso consideramos um comando para determinar a posição dos agentes no mundo virtual, assim qualquer dispositivo ou sistema que envie uma mensagem compatível com o ENSEMBLE poderá determinar a posição atual do agente ou a movimentação do mesmo quando determinamos a informação de direção e aceleração. No caso do áudio consideramos a possibilidade de parar a emissão de áudio de um determinado agente assim como o ganho que se aplica ao áudio trafegado. Mostramos na tabela os comandos genéricos criados.

Resumindo os mecanismos citados nas últimas seções, na figura 3.10 podemos ver as diferentes formas de comunicação com o ENSEMBLE utilizando o protocolo OSC.

\subsubsection{Integração com Swarms}

\section{Motivação}

O projeto ISO, Interactive Swarm Orchestra, possui várias APIs para o uso de agentes em aplicações musicais, com ênfase em alguns comportamentos já implementados e experimentados em aplicações artísticas, principalmente para a movimentação de agentes no mundo virtual.

O conceito de swarm, neste contexto de agentes computacionais, implica simular comportamentos inspirados no fenômeno biológico dos enxames; por isso a maioria dos cenários na ferramenta ISO contam com grandes quantidades de agentes agrupados em enxames e a movimentação é um dos focos principais, tanto no caso da movimentação do enxame como um todo, quanto do indivíduo em relação aos outros agentes do mesmo enxame. 


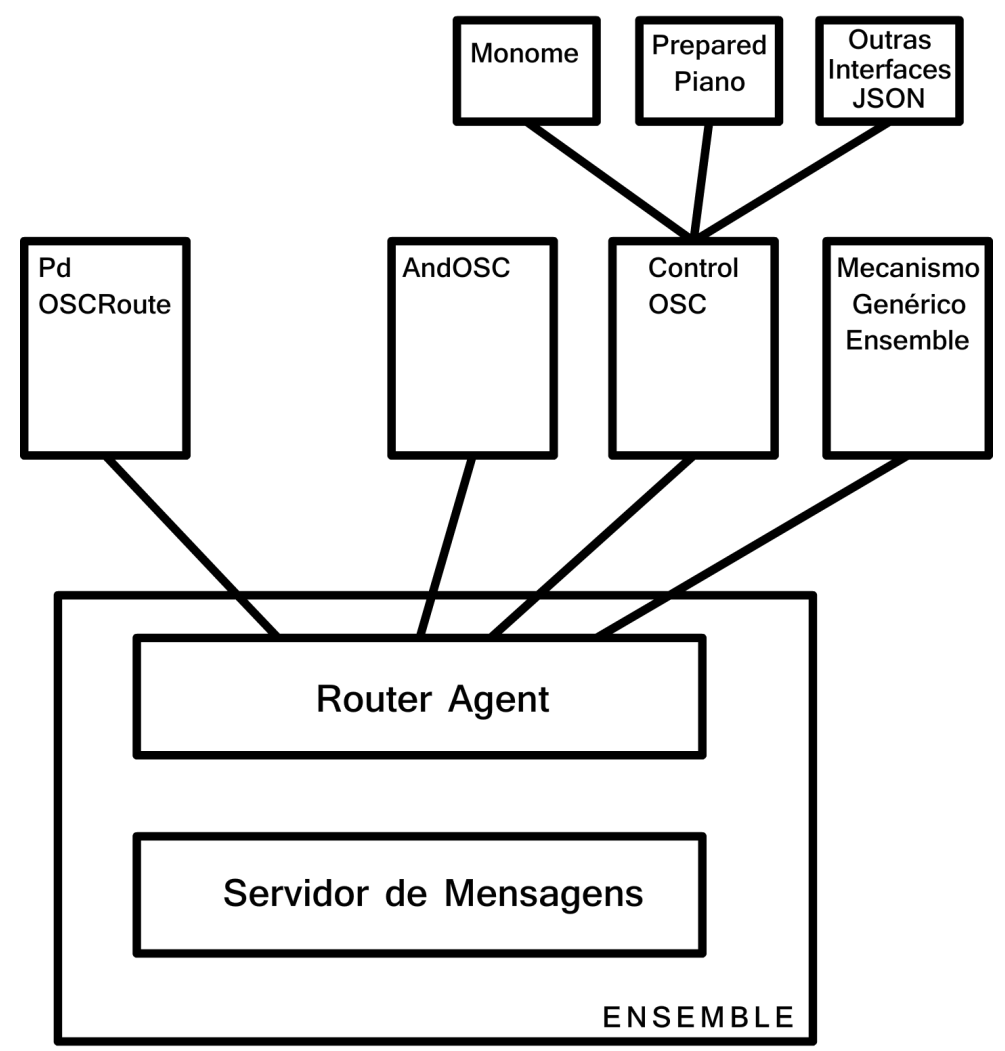

Figura 3.10: Diagrama de comunicação com o ENSEMBLE via OSC

O projeto ISO conta igualmente com recursos visuais que permitem acompanhar de forma parametrizada os agentes gerados nas aplicações. Os raciocínios (chamados no ISO de behaviours) possuem técnicas para movimentação interessantes, como movimentação em espiral e impedimento de colisões, entre muitas outras, o que forneceria exemplos interessantes de aplicação integrada com a proposta do ENSEMBLE.

As ferramentas ISO Swarm existem apenas para o ambiente Mac, já que uma versão para Linux foi descontinuada faz mais de dois anos e o autor confirmou que não existirá um suporte para outra plataforma.

\section{Integração ISO-ENSEMBLE}

Considerando que existe um mecanismo de comunicação externa utilizando OSC, podendo capturar as posições e movimentações dos agentes numa simulação do ISO, fornecendo um caminho de integração com o arcabouço ENSEMBLE. O foco dos agentes musicais do ENSEMBLE está na troca de áudio, interatividade, aspectos sociais e espacialidade do som, portanto em elementos diferentes do ISO, ou pelo menos com uma abordagem bem diferente em relação à movimentação. Propomos então combinar as características do ENSEMBLE com o trabalho já desenvolvido no projeto ISO para integrar esses comportamentos numa aplicação que processe o som no arcabouço a partir das posições vindas do outro sistema.

CocoaFlock CocoaFlock é a aplicação de testes standalone disponível no site do projeto ISO Swarms ${ }^{9}$, e consideramos que seria a utilização mais direta dessa API, não apenas para desenvolver

\footnotetext{
${ }^{9}$ http://swarms.cc/downloads/
} 
a integração com o ENSEMBLE, mas também como aplicação de controle para disponibilizar entre possíveis usuários que queiram usar o ENSEMBLE com o ISO. Eles contariam dessa forma com uma interface gráfica para configurar uma simulação de enxame, salvar essas configurações e alterá-las em tempo de execução.

Mapeamento das Posições ISO A aplicação CocoaFlock apresenta uma interface para a configuração das mensagens enviadas via OSC; o padrão definido corresponde às capacidades da API, incluindo posição, direção e velocidade, como mostra a figura 3.11. As posições são informadas no formato padrão da API, assim o mecanismo de roteamento do ENSEMBLE recebe e interpreta esta mensagem. Identificamos o agente vinculado à posição assim como as coordenadas tridimensionais; nas nossas simulações consideramos apenas duas dimensões para os mundos virtuais.

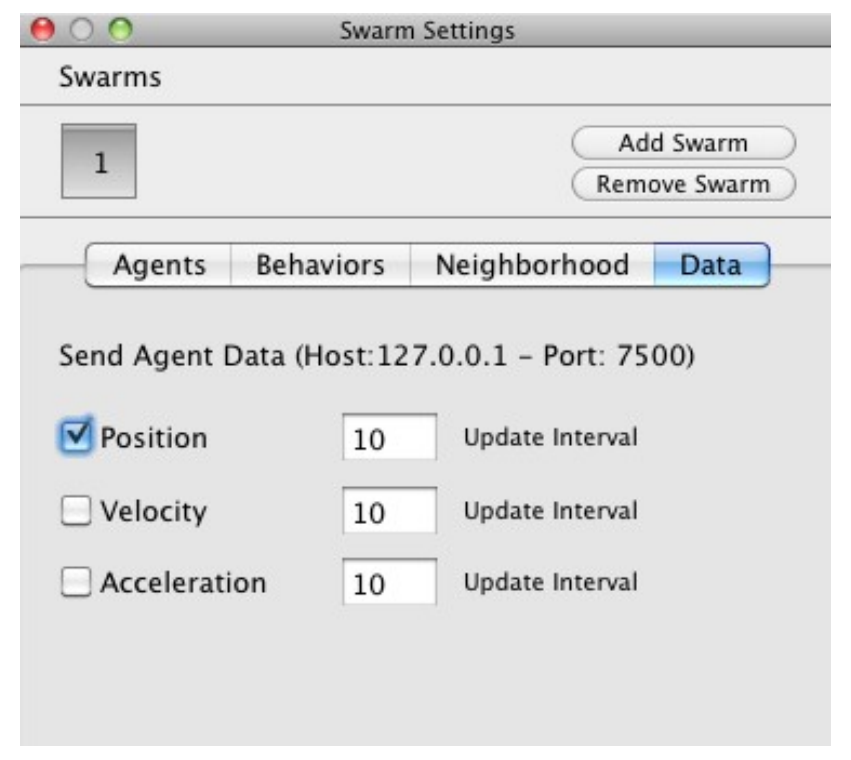

Figura 3.11: Tela da Configuração de Envio OSC - CocoaFlock

O CocoaFlock possui como limitações a incapacidade de redirecionar as mensagens OSC para outras portas ou IPs de destino. Com a intenção de fornecer um cenário de testes em outras plataformas foi montado um patch roteador que direciona as mensagens vindas da aplicação de teste CocoaFlock a outros destinatários como mostramos na figura 3.13. Seja de forma direta ou utilizando o patch roteador, a simulação de ISO Swarms consegue enviar uma mensagem OSC, usando a porta 7500 no primeiro caso ou pela porta 57111, que estão sendo escutadas pelo ENSEMBLE. Para conseguir escutar na porta de comunicação default do ISO Swarms alteramos a nossa classe RouterAgent, acrescentando uma nova instância da classe Listener, um monitor de mensagens, no nosso cliente OSC dentro do ENSEMBLE, na figura 3.12 mostramos o novo código de inicialização de roteamento de comandos. A mensagem é identificada e monta-se um comando que depois será enviado para o componente destinatário dentro do arcabouço.

Para executar os movimentos propostos pela integração com a API ISO, o comando é recebido pelo raciocínio e traduzido para o servidor de movimento, respeitando o vetor de posição inicial, direção e a aceleração. Essa tradução é necessária para garantir o funcionamento da propagação de áudio no ENSEMBLE. Uma alternativa para esse mecanismo foi o uso da tele-transportação, mecanismo incluso no servidor de movimento padrão que coloca o agente diretamente em outro lugar do mundo virtual; com esse tipo de instrução o agente se desloca diretamente entre as posições informadas pelo sistema ISO e a taxa de amostragem das posições se converte em um paramêtro importante para obter o efeito de trajetória desejado. 


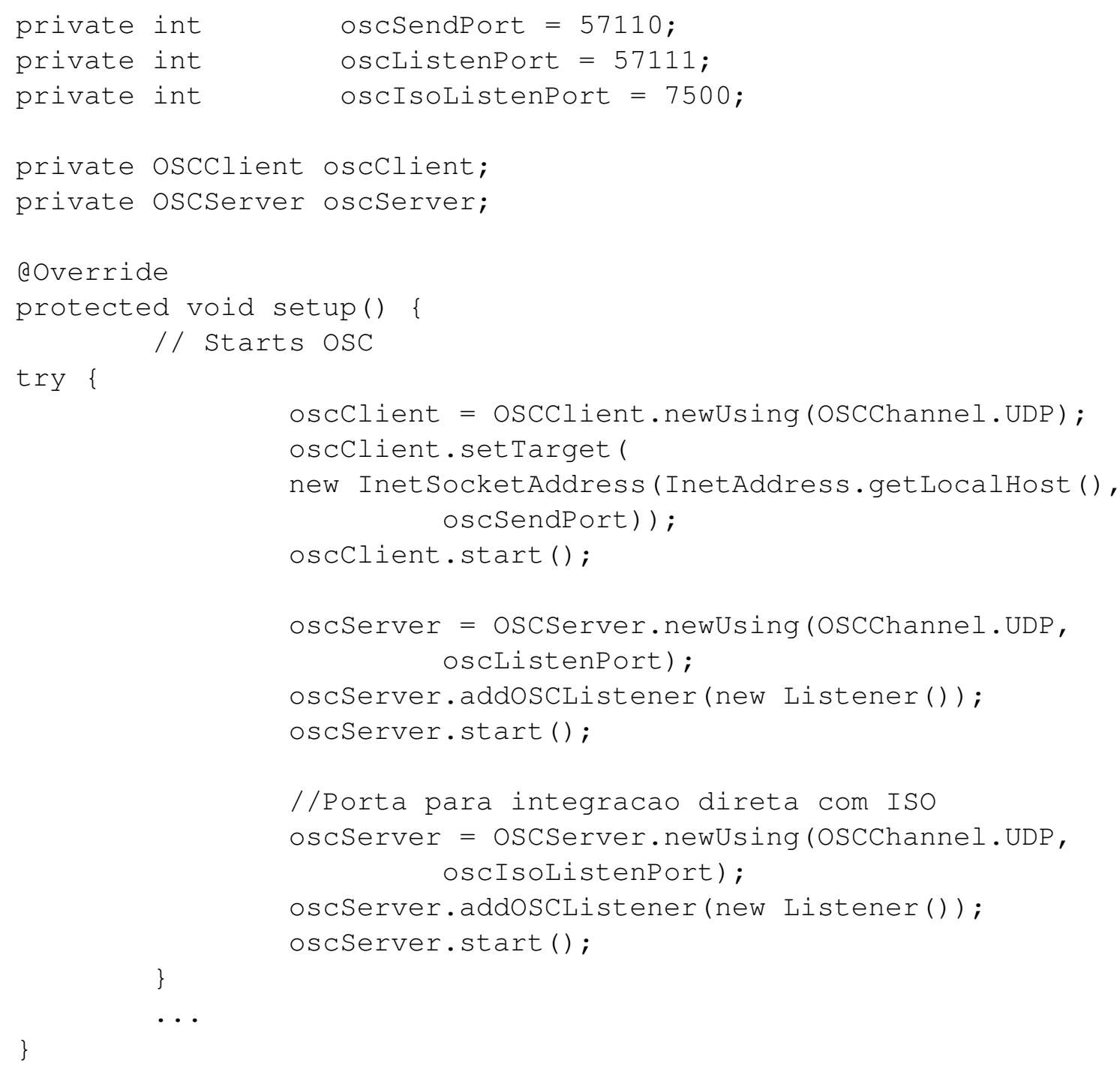

Figura 3.12: Inicialização da classe RouterAgent de roteamento de comandos

Interação O raciocínio de movimentação descrito na classe OscMovementReasoning consegue capturar posições do ISO e encaminhar os comandos pertinentes para o servidor de movimentação. Outra possibilidade de interação é a troca de tipo de movimentação, para isso configuramos mais de um enxame, ou conjunto de agentes, na simulação ISO e mudamos o enxame considerado ativo, assim se o usuário do ISO configura três enxames com movimentações diferentes e customizadas, no raciocínio podemos mudar para o enxame escolhido a partir de um comando. Na aplicação do piano preparado essa instrução podia ser dada a partir da interface ControlOSC para mudar de movimentação, ou omitir as informações vindas do ISO Swarms. A variedade de comportamentos de movimentação assim como outros parâmetros configuráveis do ISO, como tempo de intervalo de envio, quantidade de agentes por enxame e superposição de comportamentos, enriquecem as possibilidades de aplicação no contexto dos agentes no ENSEMBLE.

\subsubsection{Processamento de áudio}

O processamento de áudio dentro do ENSEMBLE é um dos focos para atender requsitos composicionais dos usuários da ferramenta. Os raciocínios do agente podem processar áudio e utilizar o resultado na tomada de decisões, ou propagar o resultado no mundo virtual. Em geral, os possíveis 


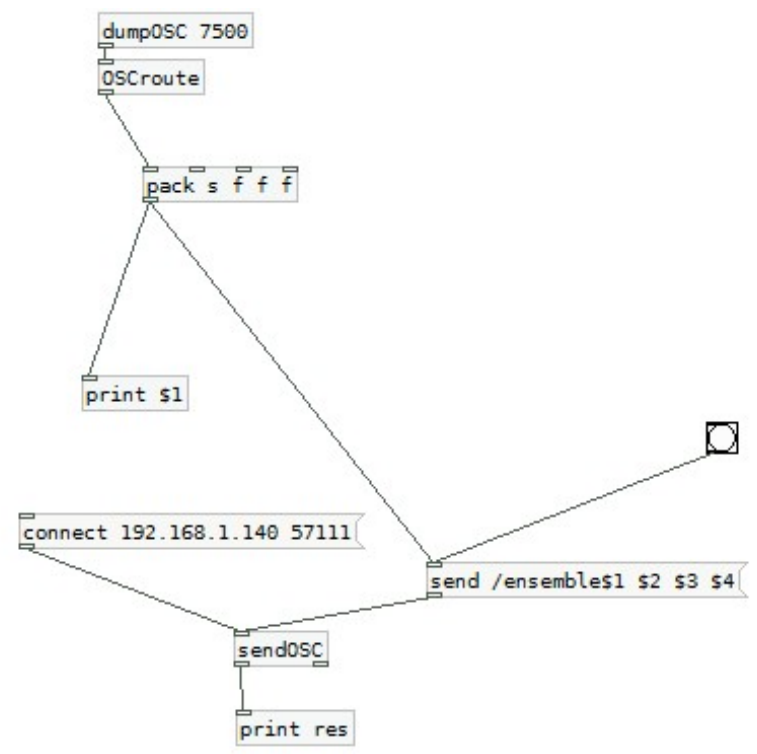

Figura 3.13: Patch de Roteamento de Mensagens OSC - ISO Swarm

interessados já têm experiência na área de sistemas interativos ou trabalham com ambientes como Pd e Max e, portanto, já possuem algum conhecimento dos processos de análise e efeitos existentes, e podem solicitar aqueles que sejam úteis para lograr determinados resultados.

Para alcançar o objetivo de processar áudio no ambiente do ENSEMBLE temos que compatibilizar algum recurso, seja uma biblioteca ou algoritmo, com a linguagem JAVA. Propomos algumas alternativas para isso, uma alternativa é a utilização de um software intermediário (host) para usar plug-ins no formato VST; outra alternativa explorada foi o desenvolvimento próprio de algoritmos de processamento e análise assim como a utilização de APIs de processamento de áudio que já foram escritas na mesma linguagem de programação que o ENSEMBLE.

Plug-ins O uso de plug-ins como método de processar o áudio em tempo real é muito comum nos ambientes de gravação e de mixagem e muitas ferramentas têm compatibilidade com formatos como o VST da Steinberg ou LADSPA para Linux, porém, não é trivial o uso desses efeitos no ambiente Java. Usando o host JVST ${ }^{10}$ podemos chamar plug-ins desde um ambiente Java. Partindo de um projeto base existente no repositório do ENSEMBLE foi criada a classe VstProcessReasoning, um raciocínio que permite chamar um determinado plug-in e processar um bloco de áudio informando os parâmetros desejados.

Uma limitação muito clara desse mecanismo foi a falta de padronização na implementação dos plug-ins; assim, eles dependem muitas vezes da interface gráfica para validar informações importantes de execução, como os valores máximos e mínimos dos parâmetros envolvidos. Outro ponto vinculado com as interfaces gráficas é o desrespeito de mecanismos básicos da definição de um plug-in VST, como são os presets ou programas e as saídas; nesse sentido todos os plug-ins de análise testados forneciam os resultados visualmente ou gravando arquivos externos; essa última modalidade é comum no caso de presets e parâmetros de entrada armazenados em arquivos de texto ou XML, reduzindo muito o número de VSTs compatíveis com o nosso host intermediário. Outra condicionante é a compatibilidade de determinado plug-in em relação ao sistema operacional, sendo que muitas vezes os plug-ins gratuitos existem apenas para uma determinada plataforma.

\footnotetext{
${ }^{10}$ http: / /jvst.sourceforge.net
} 
Com esse cenário o raciocínio descrito na classe VstProcessReasoning conta com algumas configurações de efeitos testados, disponíveis como elementos do ENSEMBLE. Para ilustrar o funcionamento dessa classe apresentamos um exemplo de carga e configuração default de um plug-in VST na figura 3.14, nesse exemplo é carregado o arquivo DLL informado, que deve ter sido compilado para a plataforma Windows. No código também temos a configuração de três parâmetros que controlam o efeito de distorção, essas configurações condicionais foram acrescentadas para alguns exemplos de plug-ins gratuitos previamente testados. Como podemos observar as escalas nos paramêtros são arbitrárias, assim como a informação sobre o número e significado de cada paramêtro.

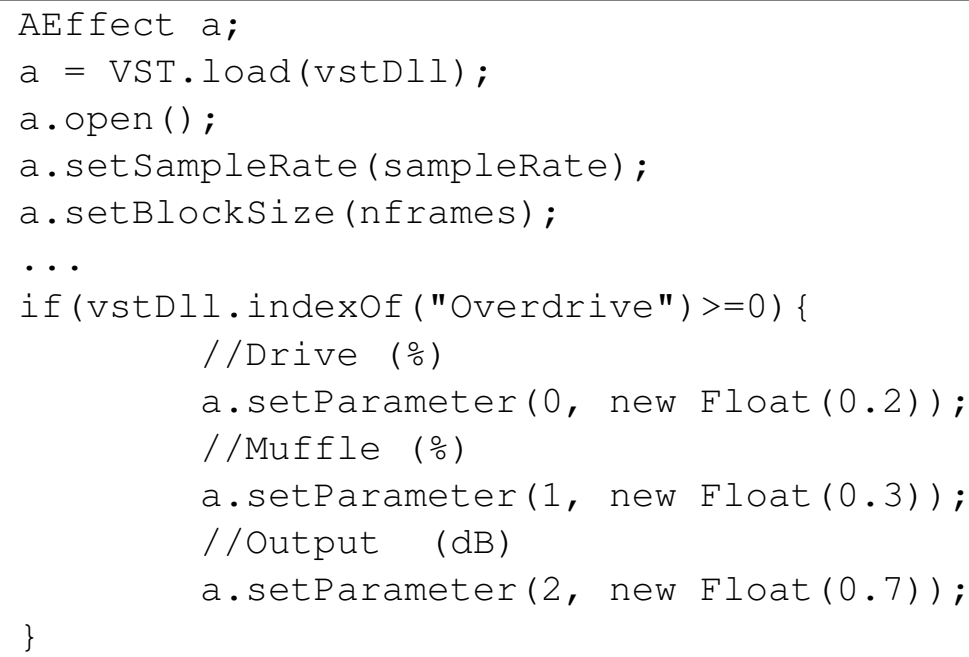

Figura 3.14: Exemplo da carga e configuração de um plug-in VST

Novos Processamentos Se por um lado partimos do princípio do reaproveitamento de recursos disponíveis, foi necessário implementar alguns algoritmos de processamento de áudio para atender algumas necessidades das nossas aplicações musicais. Esses novos recursos agregam valor ao arcabouço e ilustram a possibilidade de implementar algoritmos de processamento de áudio diretamente no ambiente Java. Apresentamos os filtros e o mecanismo de reconhecimento de picos incluídos na presente implementação.

Filtros Um filtro passa-baixas e um filtro passa-altas foram desenvolvidos para uso no ENSEMBLE, no contexto dos raciocínios de agentes musicais. Os filtros do tipo Butterworth[But30] são de segunda ordem com 2 polos e dois zeros e recebem como parâmetro uma frequência de corte. A implementação se encontra na classe FilterProcessing que disponibiliza os métodos para processar blocos de áudio informando o tamanho do bloco e a taxa de amostragem. Podemos ver um exemplo de uso de filtro passa-altas na figura 3.15, considerando HIGH_PASS_FREQ como a frequencia de corte do filtro, chunk_size como o tamanho do bloco e sampleRate como a taxa de amostragem. Esses processamentos são utilizados na aplicação do piano preparado e alteram o som propagado pelos agentes instrumentistas que aplicam um determinado filtro dependendo da região do mundo virtual onde eles se encontram.

Delay Um processamento de delay para entradas externas foi incluído no novo raciocínio JackInputDelayReasoning. O processamento inclui um tempo de atraso para entradas do sistema, especificamente vinculadas com um canal do servidor de áudio Jack. Nele os parâmetros de tempo de delay e ganho podem ser alterados em tempo de execução. Esse recurso foi utilizado na aplicação 


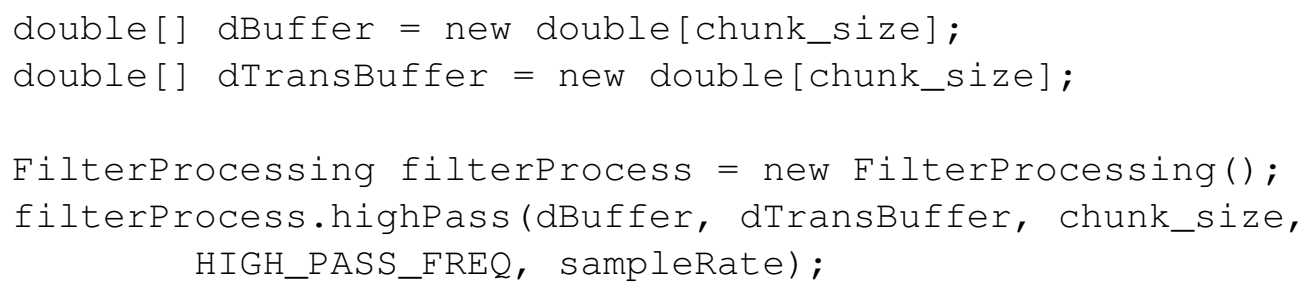

Figura 3.15: Exemplo do uso de um filtro - FilterProcessing

de delay espacializado mencionada anteriormente e detalhada na seção 4.2.

Rastreamento de picos Um algoritmo de Rastreamento de picos foi desenvolvido, que consiste em um analisador de amplitude que permite identificar picos no sinal. Pode ser utilizado para medidores VU ou para um controle de ganho automatizado. No nosso caso esse algoritmo tem o papel de analisar um sinal de entrada, seja captado pela propagação no mundo virtual ou diretamente de uma entrada externa do ENSEMBLE. A classe AnalysisProcessing possui no método peakFollower o algoritmo mencionado que é utilizado pelo raciocínio PeakReasoning, esse último faz chamadas informando blocos de áudio e compara o resultado com dois limiares configuráveis. Contamos as vezes que se identificam picos que superem os níveis configurados, quando o número de ocorrências dos picos superam um valor de tolerância informado, como mostra a tabela 3.6, o raciócinio cria um estímulo na forma de um comando enviado pelo servidor de mensagens. Esse raciocínio foi utilizado na aplicação de piano preparado com agentes instrumentistas; os estímulos identificados influenciam na escolha da reprodução de áudio e na movimentação do agente.

\begin{tabular}{|c|c|c|c|}
\hline Parâmetro & Nível & Tolerância & Resultado \\
\hline Nível 1 & Nível $2>$ Peak $>$ Nível 1 & Apresentado $n$ vezes & Estímulo 1 \\
\hline Nivel2 & Peak $>$ Nível 2 & Apresentado $n$ vezes & Estímulo 2 \\
\hline
\end{tabular}

Tabela 3.6: Estímulos no raciocínio de Peak Tracking

TarsosDSP O projeto TarsosDSP ${ }^{11}$ tem como premissa implementar reconhecimento de altura e outras funcionalidades voltadas ao áudio, inteiramente em Java, sem contar com nenhuma dependência externa. Podemos afirmar que esse projeto é uma exceção, já que existem várias bibliotecas livres que contam com processamentos digitais de áudio como o caso de Yaafe[MEF $\left.{ }^{+} 10\right]$ e Aubio[Bro06] para extração de informação do áudio, Soundtouch ${ }^{12}$ e Rubberband ${ }^{13}$ para mudar altura e/ou tempo, entre muitas outras, porém, essas implementações, escritas em $\mathrm{C}$ ou $\mathrm{C}++$, requerem uma interface para ser aproveitada na aplicação no ambiente Java.

Entre as características da ferramenta TarsosDSP vemos que a API impõe uma estrutura própria de cadeia de efeitos para executar mais de um processo numa mesma entrada, e considera JavaSound como principal interface com a placa de som; porém, usamos essa biblioteca para aproveitar seus algoritmos de reconhecimento de altura que podem ser executados isoladamente. A biblioteca inclui a implementação de detecção de altura por wavelets dinâmicas [LM05], algoritmo de Goertzel[GK58] e algoritmo McLeod[MW05].

\footnotetext{
${ }^{11}$ https://github.com/JorenSix/TarsosDSP/

${ }^{12}$ http://www.surina.net/soundtouch/

${ }^{13}$ http://breakfastquay.com/rubberband/
} 
A classe TarsosProcessing conta com funções que utilizam a API TarsosDSP e que são compatíveis como o mecanismo padrão de processamento do ENSEMBLE, aceitando blocos de áudio com uma taxa de amostragem específica.

O raciocínio PitchTrackingReasoning utilizado na aplicação de piano preparado utiliza essa classe para processar áudio e reagir de acordo às respostas obtidas das chamadas dos métodos da API, em relação à altura do sinal de entrada.

Memórias Auxiliares Originalmente o ENSEMBLE vincula estruturas de dados, as memórias de áudio, a atuadores. Assim com cada ciclo que um atuador de áudio precisa agir ele lê a sua memória e sabe o que deve reproduzir. Para permitir a inclusão de um ou vários processamentos de áudio incluímos estruturas intermediárias que estão vinculadas a um agente e podem ser manipuladas. Assim a entrada de um canal externo de áudio pode ser alterada e depois disponibilizada para o seu uso pelo agente.

Na figura 3.16 apresentamos um diagrama que resume os diferentes mecanismos de processamento de áudio apresentados nas últimas seções.

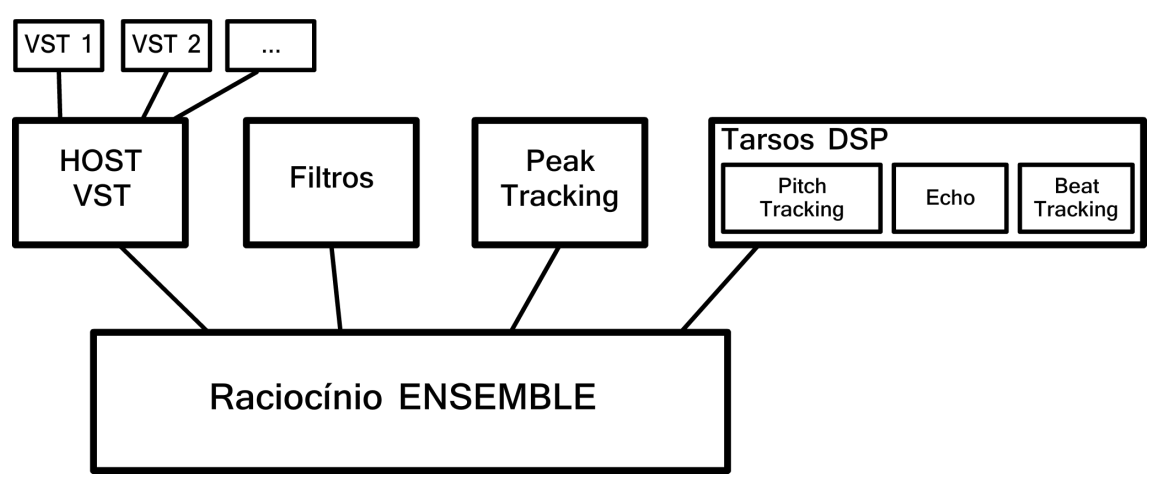

Figura 3.16: Diagrama de Processamentos de áudio com o ENSEMBLE

\subsection{Linguagem descritiva no Ensemble (EARScript)}

\subsubsection{Motivação}

Uma das limitações atuais do arcabouço é a necessidade de um conhecimento em programação para poder utilizar algumas funcionalidades avançadas ou customizadas nas aplicações. Isso acontece especialmente no caso de se desejar definir um roteiro de ações ou processos internos para uma instância específica de um agente. Descreveremos a seguir algumas estruturas sintáticas da linguagem EARScript, que consistem neste momento apenas em uma proposta teórica para a definição desta linguagem. A implementação de raciocínios de agentes para processar tais estruturas será objeto de trabalhos futuros

Na estrutura do projeto ENSEMBLE existe um conjunto de elementos prontos e documentados que permitem uma rápida introdução à utilização do arcabouço, na geração de um ambiente virtual, na definição de componentes de movimentação e na transmissão de áudio no ambiente virtual; esses exemplos abrangem alguns cenários típicos de uso, recorrentes na bibliografia que serviu de referência para montar esse arcabouço.

Além disso, na versão atual do arcabouço, existe um arquivo XML de configuração inicial, como parte do mencionado conjunto de recursos, que tem se mostrado importante para estruturar novas 
aplicações, ao ponto de se converter em parte do funcionamento padrão do arcabouço e até em um vínculo para monitorar o estado do ambiente virtual. Executando uma rotina da classe loader e passando esse arquivo XML como parâmetro podemos invocar e utilizar as classes já existentes, e montando tags XML podemos listar e carregar os tipos diferentes de agentes que vamos utilizar. Com o mesmo arquivo estabelecemos os valores dos parâmetros externos das classes, como alternativas de construção do ambiente virtual (por exemplo, determinamos se as posições no espaço são contínuas ou discretas, bem como a forma e tamanho do mundo virtual), ou diretórios de arquivos de áudio e outros recursos. Foi implementada uma interface gráfica a partir desse arquivo que constitui a primeira ferramenta visual genérica no contexto do projeto ENSEMBLE.

Queremos então resgatar o formato XML utilizado para a inicialização e propor uma alternativa para descrever o comportamento dentro de um agente definido. Seguindo esse exemplo do arquivo inicial observamos que seria relevante propor uma linguagem descritiva que complemente essa definição da aplicação, mantendo um olhar focado no interior do agente e seus raciocínios.

Esta linguagem descritiva esboçada na presente seção, poderia ser usada para construir algo equivalente a um roteiro parcial e interno de um agente, que determina como alguns comportamentos vão acontecer, isso detalhado ao nível de uma instância de um determinado tipo de agente, permitindo que vários indivíduos do mesmo tipo ajam de formas diferentes. Poderíamos, num exemplo particular, vincular o resultado desse tipo de linguagem a uma partitura, se for esse o objetivo da aplicação.

Idealmente, esta linguagem de script traria facilidade do uso permitindo ao compositor a especificação de comportamentos complexos sem a necessidade de programar em Java. Linguagens de script podem simplificar as tarefas de programação e no nosso contexto a execução de raciocínios. Assim, é interessante que a especificação de atividades, movimentações e atos comunicativos esteja separada da programação que define a arquitetura do agente e dos seus raciocínios. Desta forma não precisamos reprogramar elementos já existentes.

Esse tipo de problema já foi abordado anteriormente, especificamente na referência da linguagem STEP [HEV05] para roteiros de agentes com corpos antropomórficos. A linguagem STEP trata posições e gestos corporais assim como atos comunicativos, baseando-se na semântica formal da lógica dinâmica descrita por Harel [Har84], e foi usada na ferramenta DLP [Eli92], que implementa agentes inteligentes em três dimensões. STEP inicialmente foi proposta com uma sintaxe semelhante àquela da linguagem Prolog.

Uma evolução dessa linguagem, chamada XSTEP [HEV03] e baseada em XML, também foi considerada na análise de base para a nossa linguagem; porém, alguns elementos desta última mostravam-se muito específicos para a movimentação de corpos, considerando apenas os problemas de descrição temporal, de referência de partes corporais e de direção de movimentos nas suas instruções. As estruturas do nosso script XML também foram modeladas com a intenção de serem semelhantes às estruturas dos XMLs já utilizados no ambiente do arcabouço ENSEMBLE. Propomos assim a linguagem EARScript (Ensemble Agent Reasoning Script), com elementos que serão descritos a seguir, como parte dos trabalhos futuros. É importante ressaltar que esta descrição tenta abranger todas as funcionalidades desejadas numa linguagem desse tipo para o ambiente ENSEMBLE, porém, apenas algumas instruções ilustrativas foram descritas de forma detalhada, fazendo referência à implementação do ENSEMBLE. A escolha dessas instruções se deriva das aplicações musicais desenvolvidas durante a pesquisa. 


\subsubsection{Escopo}

Como parte do presente trabalho sugerimos um escopo e estrutura para a linguagem EARScript. Para a definição do escopo da linguagem devemos considerar que as possíveis ações vão depender dos raciocínios específicos e servidores de eventos disponíveis, mas esta deve ser suficientemente geral para que a sua estrutura funcione para novos tipos de servidores de eventos. Também é indispensável pensar na interação com outros elementos do sistema, como os estados internos dos agentes e a representação do mundo perceptível para eles; nessa categoria encontramos informações como a posição atual do agente ou sua memória sonora, dados da sua base de conhecimento e também características do mundo virtual, como por exemplo o tamanho do ambiente, a velocidade do som no mundo virtual ou a idade máxima permitida no ciclo de vida de um agente.

Com o propósito de ilustrar a sua descrição consideramos a movimentação e a transmissão de som que possuem servidores de eventos já implementados.

\subsubsection{Princípios do STEP aplicados ao EARScript}

Reforçando a idéia de que uma linguagem de script para agentes inteligentes deve providenciar interoperabilidade entre os diferentes agentes e componentes do mundo virtual e ter toda a capacidade de formular comportamentos com facilidade de uso [HEV05], a linguagem STEP apresenta alguns princípios para alcançar esses objetivos. Mostramos a seguir como esses princípios se encaixam na linguagem aqui proposta.

\section{Conveniência}

A linguagem deve ocultar as dificuldades técnicas (como problemas geométricos, ou de processamento de áudio), para que os usuários-alvo possam usá-la de uma forma natural. Poderíamos por exemplo descrever uma posição como "Center" ao invés de $(50,50,0)$, ou uma velocidade como "Fast" ao invés de 0.5. Para facilitar essa formulação de instruções precisamos definir essas expressões naturais dentro do contexto do sistema, e mais especificamente no contexto do servidor de eventos.

Uma seção para esse propósito foi localizada no início do script EARScript. Para que essa solução seja prática propomos que essa definição seja feita uma única vez pelos criadores de um novo servidor de evento, e que possa apenas ser atualizada por usuários interessados. O exemplo a seguir mostra como se pode formular esses valores predefinidos:

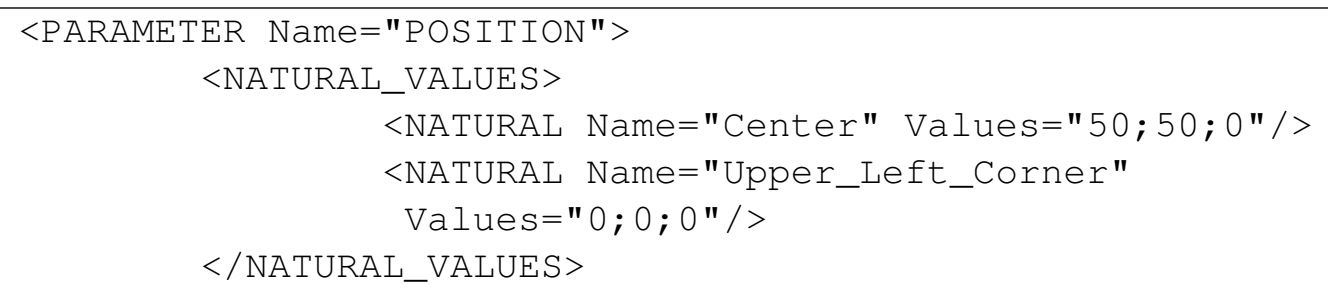

Figura 3.17: Exemplo da Definição de um Valor em linguagem natural no EARScript

\section{Semântica composta}

É necessário especificar ações compostas de componentes já existentes. Consideramos as possibilidades SEQ para sequências, PAR para eventos paralelos, CHOICE para alternativas (escolhida por sorteio com probabilidades iguais entre as opções) e REPEAT para repetições. A seguir estão 
alguns exemplos de comandos codificados em XML.

A figura 3.18 mostra como uma sequência de instruções pode ser formada.

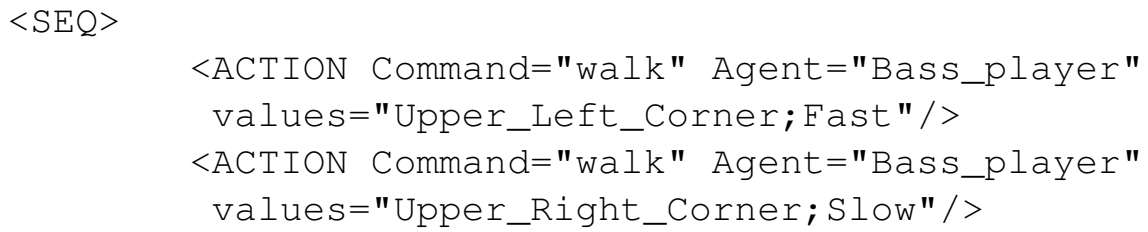

Figura 3.18: Exemplo de sequência de instruções no EARScript

Na figura 3.19 temos um exemplo do comando para ações em paralelo:

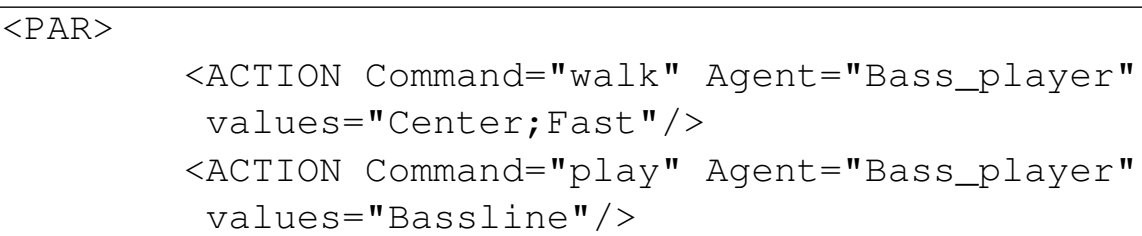

Figura 3.19: Exemplo de instruções em paralelo no EARScript

Para uma alternativa entre duas ações temos um exemplo na figura 3.20.

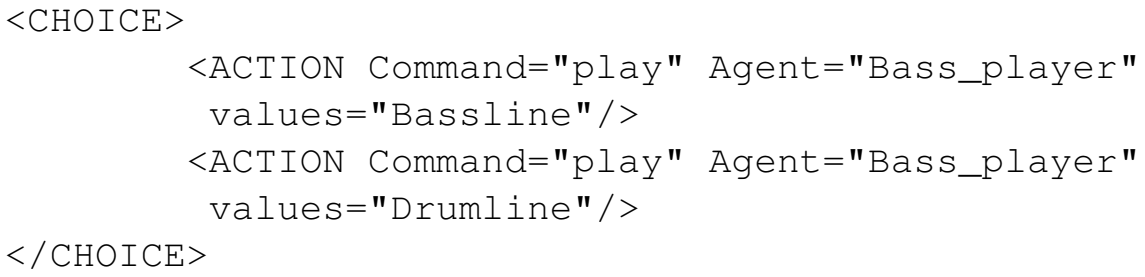

Figura 3.20: Exemplo de escolha aleatória de instruções no EARScript

No caso de repetição precisamos de um parâmetro que indique o número de vezes a executar conforme ilustra a figura 3.21.

$<$ REPEAT Times="2">

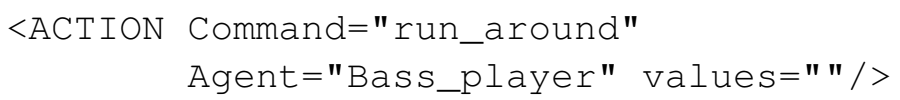

Figura 3.21: Exemplo de repetição simples de instruções no EARScript

\section{Redefinição}

As ações descritas no script devem poder ser definidas a partir de outras ações já explicitadas; estas ações serão identificadas pelo nome e poderão ser reutilizadas. Temos um exemplo na figura 3.22. 


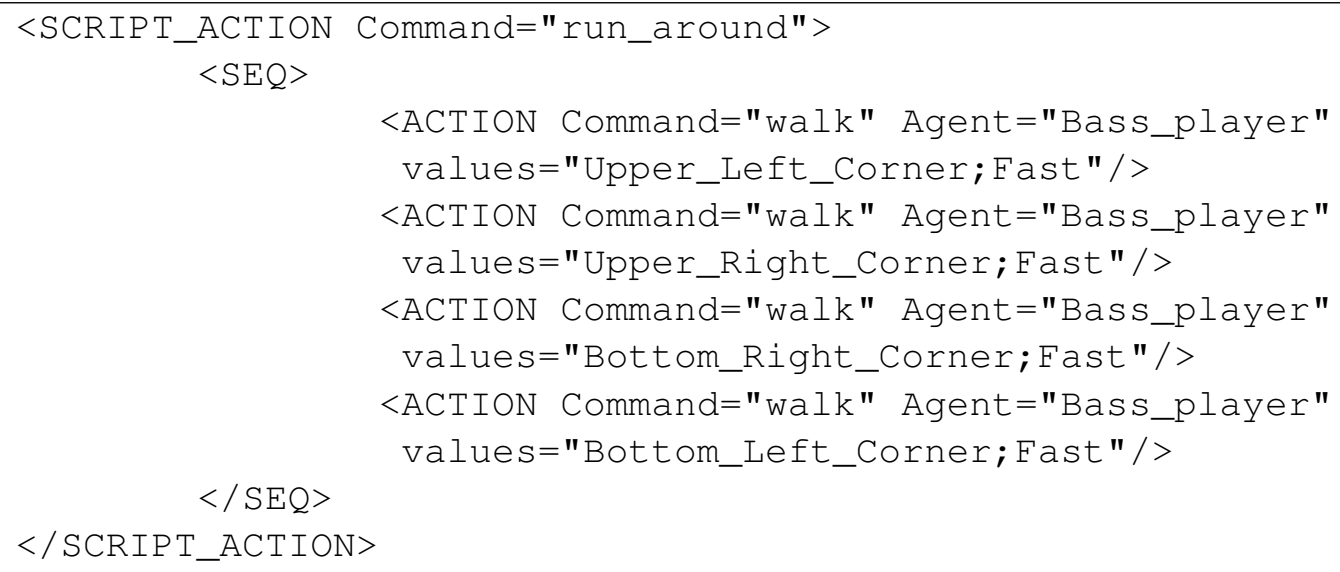

Figura 3.22: Exemplo de Redefinição de instruções no EARScript

\section{Parametrização}

As ações de script devem se adaptar a varias situações; utilizando parâmetros permitiremos que instruções semelhantes sejam usadas com valores diferentes e assim produzam resultados diferentes.

Incluímos também valores default que permitam facilitar as chamadas e evitar erros de sintaxe. Os parâmetros possíveis para cada ação básica, assim como os valores default, são definidos numa seção inicial do script. Temos um exemplo de definição de parâmetros na figura 3.23

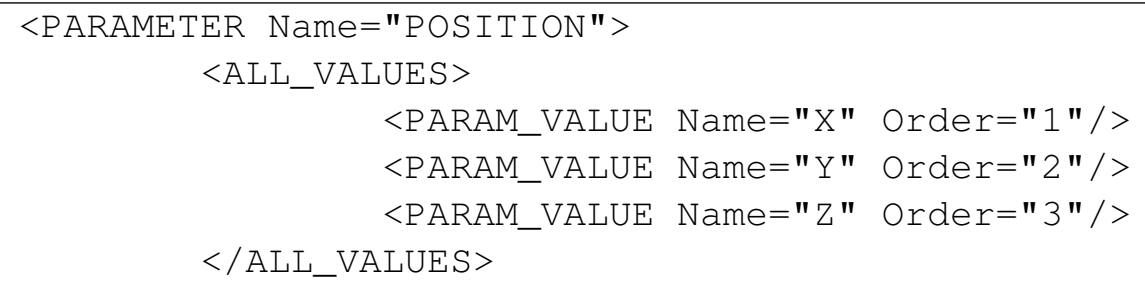

Figura 3.23: Exemplo de Definição de parâmetros no EARScript

\section{Interação}

As ações de script devem poder interagir com as percepções que o agente tem do mundo, permitindo assim ao script decidir se deve continuar executando uma ação ou se deve mudar seu comportamento. Esse tipo de interação é possível com a utilização de operadores de um outro nível, como se apresenta em Harel [Har84]. Na linguagem STEP esse nível superior se representa por sentenças de uma meta-linguagem utilizada para criar estados mentais nos agentes antropomórficos; em nossa linguagem utilizaremos o termo "meta" para nos referirmos aos elementos desse outro nível.

Consideramos os operadores: "TEST" para conferir a veracidade de uma sentença sobre o estado do agente ou do mundo, o operador "SET" para executar alguma mudança nesses estados e um operador condicional na forma de um IF, THEN e ELSE.

Aqui um exemplo de cada operador nas figuras $3.24,3.25,3.26$ 


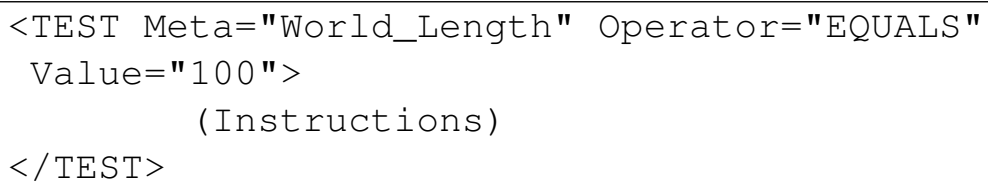

Figura 3.24: Exemplo do Operador TEST no EARScript

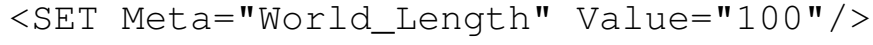

Figura 3.25: Exemplo do Operador SET no EARScript

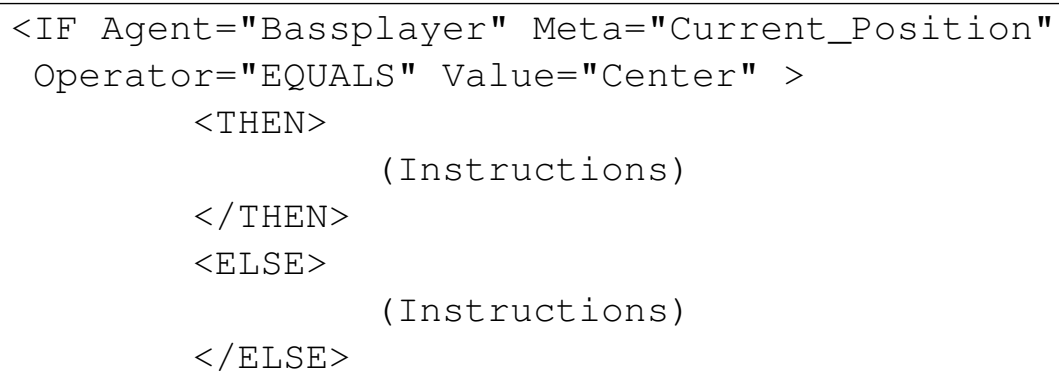

Figura 3.26: Exemplo do Operador IF no EARScript

\subsubsection{Estrutura da linguagem}

Para estabelecer o conjunto de operações de exemplo consideramos o conjunto de ações utilizadas para a interação com o Servidor de Eventos de movimentação e eventos de áudio. A seguir, mostramos a estrutura do XML da linguagem EARScript, para definição de ações de raciocínios no arcabouço ENSEMBLE com código ilustrativo para cada seção.

\section{Variáveis do Mundo virtual}

Nesta primeira seção definimos as variáveis que pertencem ao mundo virtual que podem ser utilizadas para interagir com as instruções de raciocínios como mostra a figura 3.27.

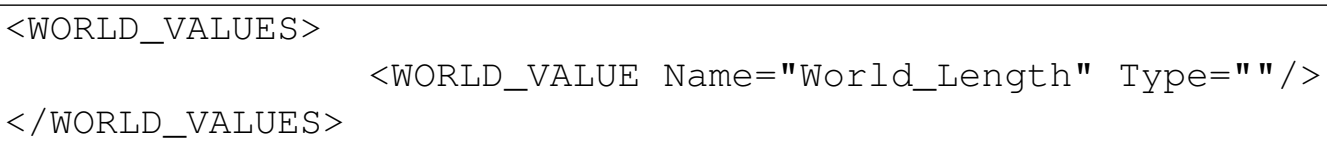

Figura 3.27: Exemplo de Definição de variável do Mundo Virtual

Definições de Servidores de eventos Nesta seção definimos que servidores de eventos serão considerados, informando as variáveis internas do agente que serão relevantes, os parâmetros e suas ações básicas do servidor.

Variáveis do Agente por Servidor de Eventos São as variáveis do estado interno do agente que vão poder ser avaliadas ou mudadas pelo script com o propósito de interagir com os raciocínios como mostra a figura 3.28 . 
$<$ STATE_VALUES $>$

$<$ STATE_VALUE Name="Current_Position" Type="POSITION" Scope="Agent"/> $</$ STATE_VALUES $>$

Figura 3.28: Exemplo de Definição da posição Atual de um Agente

Definições de parâmetros Como descrito anteriormente, nessa seção definimos os parâmetros possíveis para os servidores de eventos, seus componentes e os valores naturais que podem adotar. A figura 3.29 mostra o exemplo de definição de um parâmetro para descrever um arquivo de áudio referenciado pelo agente.

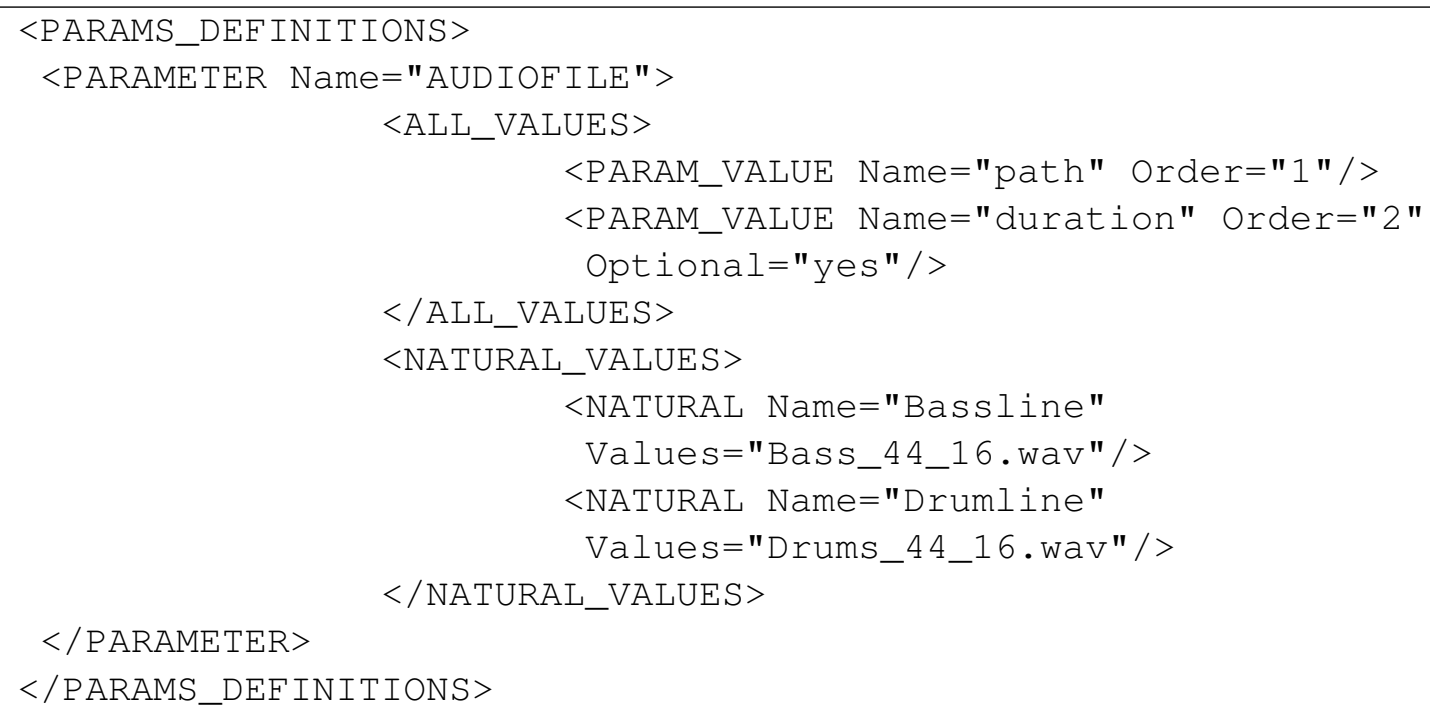

Figura 3.29: Exemplo da Seção de um parâmetro de Agente

Definições de Ações Básicas No servidor de movimentação implementado no arcabouço ENSEMBLE temos os comandos WALK, TURN, TRANSPORT, STOP e INFO. Essa lista claramente foi inspirada no trabalho Living Melodies de Dahlstedt e Nordahl [DN01] que também foi um estudo de caso para o arcabouço [Tho11].

Nesta seção temos a definição das ações básicas do servidor, fazendo referência aos parâmetros anteriormente definidos como mostra a figura 3.30 para um servidor de movimentação.

Definições de ações compostas Nesta seção se montam novas ações compostas que depois podem ser reaproveitadas. Elas estão formadas por um conjunto de instruções simples ou compostas como mostra a figura 3.22 .

Scripts Nesta seção se monta o roteiro que de fato vai ser executado para o contexto da aplicação, sendo que esta é a única seção que deve ser criada a partir do zero, já que as anteriores podem ser reaproveitadas.

No exemplo da figura 3.31 o agente é transportado ao centro do ambiente virtual, escolhe e reproduz um arquivo de áudio, enquanto dá duas voltas no ambiente, para depois retornar ao ponto de partida. 


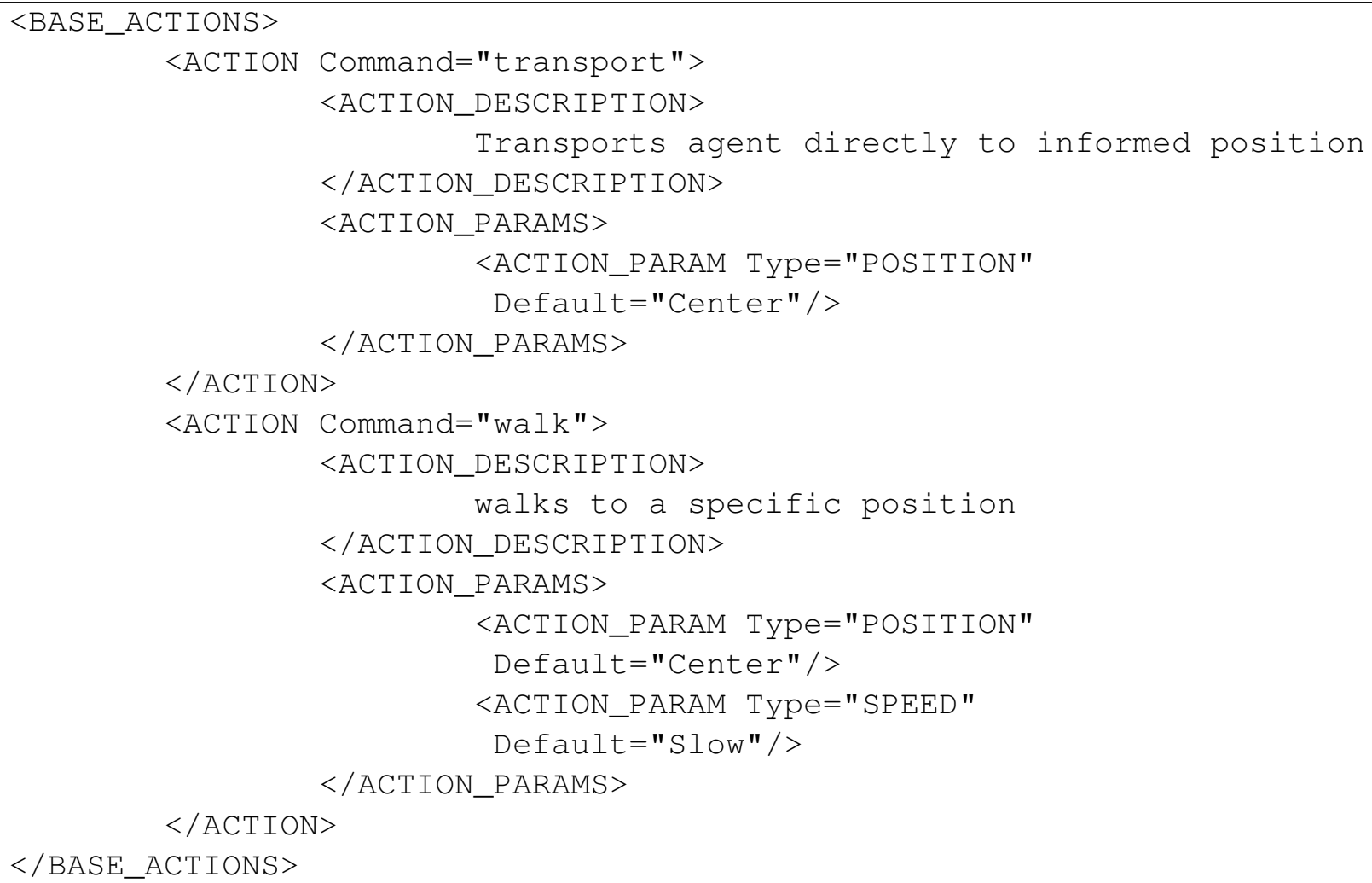

Figura 3.30: Exemplo da Seção de Ações básicas de um Servidor de Evento

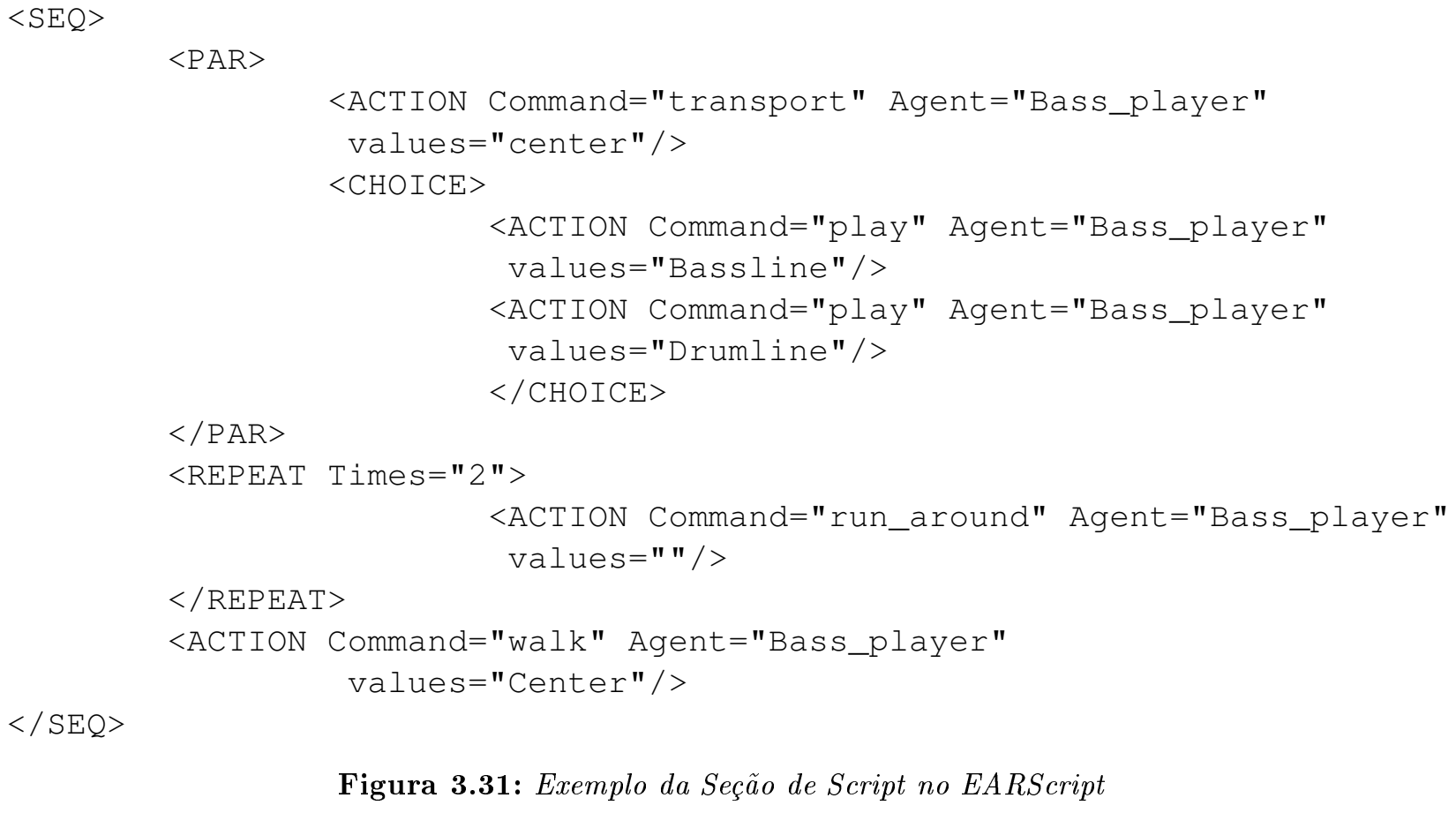

Figura 3.31: Exemplo da Seção de Script no EARScript

\subsubsection{Integração com o Arcabouço}

A linguagem de script pode ser utilizada em vários cenários, na inicialização do sistema, ou em tempo de execução dos sistemas musicais.

Para usar a linguagem como ferramenta de inicialização de comportamentos consideramos a integração mediante o arquivo XML de inicialização anteriormente mencionado, assim podemos 
incluir o raciocínio intérprete como parte dos raciocínios, informando como parâmetro o arquivo de instruções descritivas na linguagem EARScript.

Para ilustrar o uso da linguagem formulamos exemplos vinculados com as aplicações de Delay espacializado e de piano preparado com agentes multi-instrumentistas. A intenção foi aplicar alguns conceitos formulados na descrição da linguagem, aproximando o seu uso num cenário do ENSEMBLE com interesse performático.

\subsubsection{Discussão}

Continua sendo primordial manter a simplicidade da linguagem, e no caso um XML de estrutura simples, para que esse não seja um obstáculo para alguém iniciante em programação; ao mesmo tempo, isso pode servir de base para outras funcionalidades, como por exemplo uma GUI para elaborar essas instruções que tenha como resultado o script XML. No caso da linguagem XSTEP, existe uma interface gráfica baseada no editor de XML Xeena da IBM, porém os autores dessa iniciativa propõem ainda uma melhor alternativa de GUI como um trabalho futuro de pesquisa.

É importante observar que essa linguagem não poderá ser aproveitada diretamente por alguém completamente leigo, mas corresponde a um primeiro passo para ajudar no entendimento e manipulação do ENSEMBLE. 


\section{Capítulo 4}

\section{Aplicações e estudos de caso}

Neste capítulo vamos apresentar os estudos de caso desenvolvidos a partir da interação com músicos e a utilização das extensões e integrações implementadas para os arcabouços ENSEMBLE e ISO.

Uma diretiva principal do presente trabalho é aproximar o uso da ferramenta ENSEMBLE dos usuários vinculados diretamente com a atividade artística, que seriam os únicos capazes de validar o interesse estético e composicional dos arcabouços de sistemas multiagentes musicais. Nesse sentido os estudos de caso não podem ser apenas iniciativas técnicas. Portanto foi indispensável se aproximar de músicos para propor aplicações em conjunto com eles que sirvam como estudos de caso válidos para o arcabouço ENSEMBLE. Os estudos de caso são abordados sob duas perspectivas: uma perspectiva artística que enfoca a sequência das motivações e decisões composicionais, e uma perspectiva técnica no contexto do arcabouço ENSEMBLE. Pretendemos também abranger vários cenários diferentes de aplicações interativas, tanto para fins de performance como de composição, ou para a geração de material sonoro que poderá ser retrabalhado fora do sistema multiagentes.

Algumas características específicas da ferramenta complicaram essa tarefa já que os músicos e possíveis usuários abordados não estavam familiarizados com uma ferramenta sem uma interface gráfica de usuário voltada para a montagem da aplicação musical. Muitas vezes o usuário consegue explorar funcionalidades da ferramenta de uma forma intuitiva e visual, mas no caso do ENSEMBLE podia-se somente explicar as características do arcabouço e no máximo apresentar exemplos de código e de configurações. Na mesma linha, outros sistemas permitem interagir graficamente com os diferentes componentes, e escutar imediatamente o resultado das alterações realizadas, como no caso do Pd; isso no contexto do ENSEMBLE é apenas possível utilizando componentes prontos. A interface gráfica de usuário no ENSEMBLE permite principalmente acompanhar uma simulação e os componentes dela no mundo virtual. Daí a importância da mediação entre o compositor e o arcabouço, já que não podia ser formulada uma idéia musical no ENSEMBLE sem um conhecimento prévio dos arquivos de configuração e das potencialidades do sistema.

Propomos três casos de estudo com intuito estético: um gerador de material eletroacústico, um sistema performático com espacialização para um intérprete e uma aplicação baseada na técnicas de piano preparado que permite uma interação entre um músico e agentes multi-intrumentistas.

\subsection{Gerador de material eletroacústico}

Uma iniciativa que nasceu da aproximação do arcabouço com músicos interessados, através da disciplina Aspectos Tecnológicos da Música Atual no segundo semestre de 2009, foi a idéia de criar um gerador de material eletroacústico, que permita combinar entradas de áudio para experimentar com as técnicas de composição algorítmica e vida artificial, com o propósito de explorar as texturas 
sonoras, como resultado de vários agentes emitindo som num mesmo ambiente virtual. A proposta foi usar fragmentos de áudio criados com diversas técnicas de síntese, aplicar transformações e reproduzir esses novos fragmentos no mundo virtual, acrescentando-se características de vida artificial aos agentes musicais. O produto é o som gerado no ambiente e capturado em uma determinada posição, que pode ser salvo e analisado pelo compositor para posterior utilização em peças eletroacústicas.

A aplicação aproveita como referência os diferentes exemplos do arcabouço e contempla a utilização de repertório eletroacústico para os agentes; as regras de espacialização neste exemplo não precisam ser muito complexas já que o resultado se encaixa apenas numa imagem estéreo do mundo, captada por um agente ouvinte.

\subsubsection{Contexto composicional}

A intenção dos compositores consultados, Mario Del Nunzio e Claudio Vitale, era principalmente explorar modos de criação sonora através de um arcabouço computacional para sistemas multiagentes musicais. Cabe ressaltar que os músicos envolvidos têm experiência em música eletroacústica e familiaridade com algumas ferramentas de software para criação sonora, o que sem dúvida facilitou a inserção de técnicas de computação musical num processo criativo.

Inquietudes surgiram em debates entre os participantes do grupo envolvido em tal projeto durante o processo de definição das características relacionadas ao comportamento dos agentes no ambiente virtual. Em especial as discussões se focaram na noção de inteligência artificial nesses casos de aplicação para criação sonora, e em como essas técnicas poderiam fornecer resultados potencialmente diferentes em cada execução, e como essa diferença poderia ser satisfatória do ponto de vista artístico. Questionou-se principalmente como esses resultados se comparariam a aqueles dos aplicativos criados em diversos ambientes de software que permitem programação voltada à criação sonora, tais como Max/MSP, PureData, SuperCollider, entre outros.

Foi necessário e interessante expor também perante os compositores/usuários as vantagens e diferenciais que um arcabouço desse tipo pode oferecer em relação a ferramentas existentes que vêm sendo amplamente utilizadas. Os pontos mais relevantes são a capacidade de inserir características de vida artificial e assim comportamentos sociais nos agentes, a interatividade entre agentes computacionais e humanos e o aproveitamento da espacialização como fenômeno acústico, utilizando um mundo virtual. Outra forma de resumir as vantagens de uma ferramenta como o ENSEMBLE é a capacidade de reagir e mudar um cénario em tempo real.

Optou-se por utilizar como material sonoro inicial sons puramente eletrônicos, provenientes de síntese, com ou sem algum tipo de processamento sonoro posterior. Os sons têm em comum o fato de serem bastante ruidosos; alguns deles foram obtidos por síntese direta da forma de onda, e outros foram obtidos por síntese usando modulação de frequência. Foram criados 30 arquivos sonoros curtos, com durações aproximadamente entre $0.5 \mathrm{~s}$ e $5 \mathrm{~s}$.

Foi estabelecido como meta e como cenário ideal de experimentação um sistema com até 30 agentes independentes. Isso possibilitaria a obtenção de texturas complexas, bem como de grandes contrastes texturais; possibilitaria, ainda, o estabelecimento de relações sociais bastante distintas entre os agentes, de modo a favorecer situações sonoras ricas em detalhes e com diversas camadas simultâneas de acontecimentos em diversos níveis. Em etapas iniciais a experimentação foi feita com um número inferior de agentes, no caso apenas 4 agentes.

Foram pensadas maneiras de se estruturar cada um dos agentes. Inicialmente, definiu-se que cada um deles deveria ser constituído com um equilíbrio entre características individuais, exclusivas, e 
características compartilhadas com outros agentes; isso permitiria, por um lado, o estabelecimento da identidade própria do agente e, por outro, a comunicação e o estabelecimento de laços sociais entre os diversos agentes. Assim se estabeleceu um conjunto de características para os agentes categorizadas em repertório de fragmentos, processamentos ou transformações sonoras e movimentação do agente em relação ao ouvinte.

Na tabela 4.1 apresentamos um resumo das características da aplicação em relação ao arcabouço teórico tratado no capítulo 2 e às estruturas mencionadas no projeto ENSEMBLE.

\subsubsection{Agente Musical}

Consideramos dois tipos de agentes musicais para o sistema:

- Um agente musical gerador com o potencial de executar todas as variantes de processos sonoros em todos os fragmentos que fazem parte do repertorio base. Também poderá mostrar todos os comportamentos de movimentação e de outras tarefas vinculadas com vida artificial.

- Um agente ouvinte que tem a responsabilidade de repassar através da interface de áudio o som total gerado no ambiente e captado em uma posição específica, para que possa ser utilizado/escutado pelo usuário.

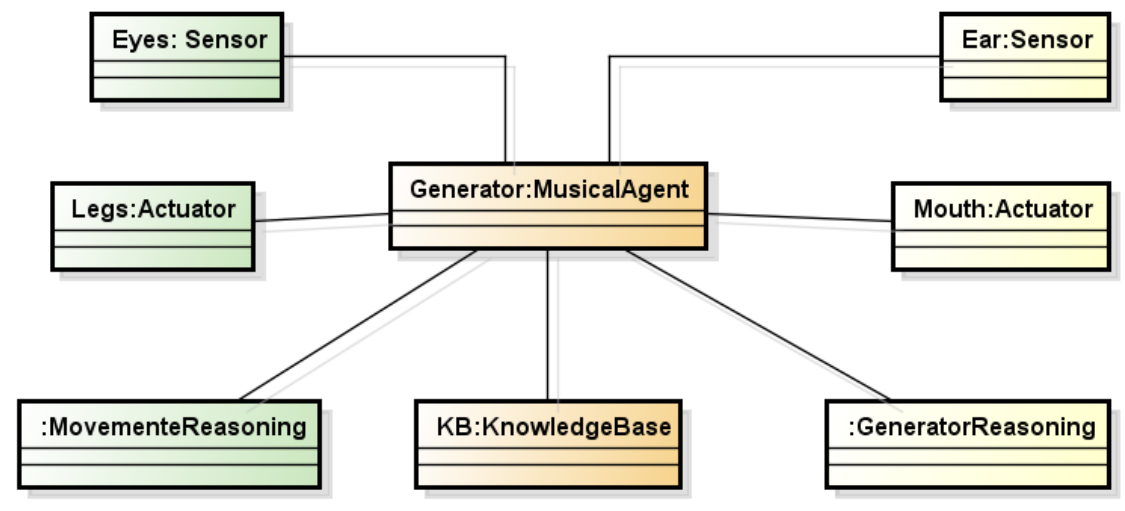

Figura 4.1: Diagrama de Objetos do Agente Gerador

Montamos a estrutura desses agentes tendo como base o estudo de caso Clapping Music [Tho11], e utilizando alguns componentes genéricos do arcabouço. Assim, para as funções sonoras, temos o sensor padrão ear e o atuador padrão mouth, enquanto que para as funções de movimentação temos o sensor padrão eyes e o atuador padrão legs. As figuras 4.1 e 4.2 mostram os diagramas de objetos dos dois tipos de agentes. Consideramos também que o agente ouvinte possui dois sensores sonoros, esquerdo e direito, com o propósito de viabilizar a reprodução em estéreo. Usamos também um raciocínio padrão para direcionar para a placa de som o som escutado pelo agente ouvinte, no caso o raciocínio PAOutputReasoning, que faz a interface com a biblioteca PortAudio.

\subsubsection{Ambiente virtual}

O Agente Ambiente na aplicação do gerador de material eletroacústico utiliza apenas componentes já existentes no arcabouço, tanto para a movimentação dos agentes como para a propagação 


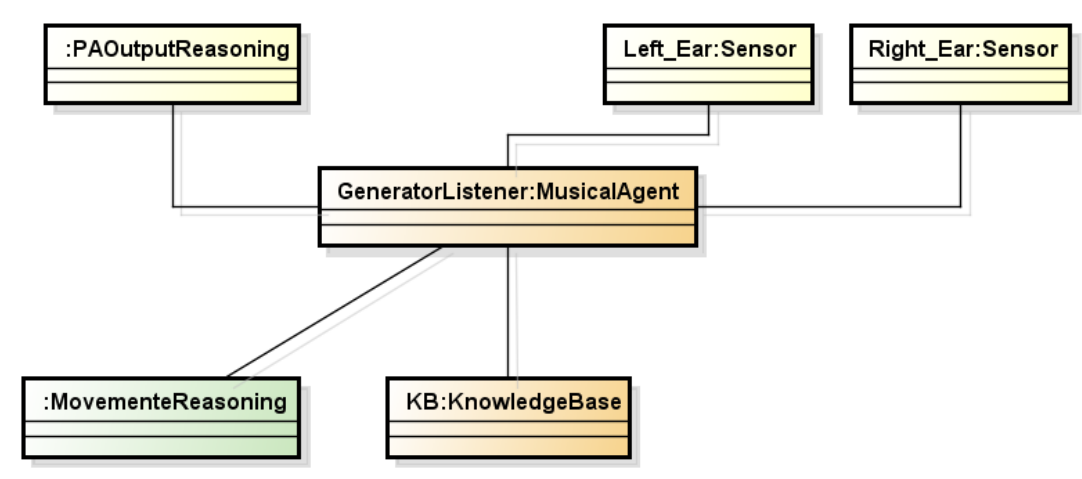

Figura 4.2: Diagrama de Objetos do Agente Ouvinte

sonora. O agente ambiente com os seus objetos é representado na figura 4.3.

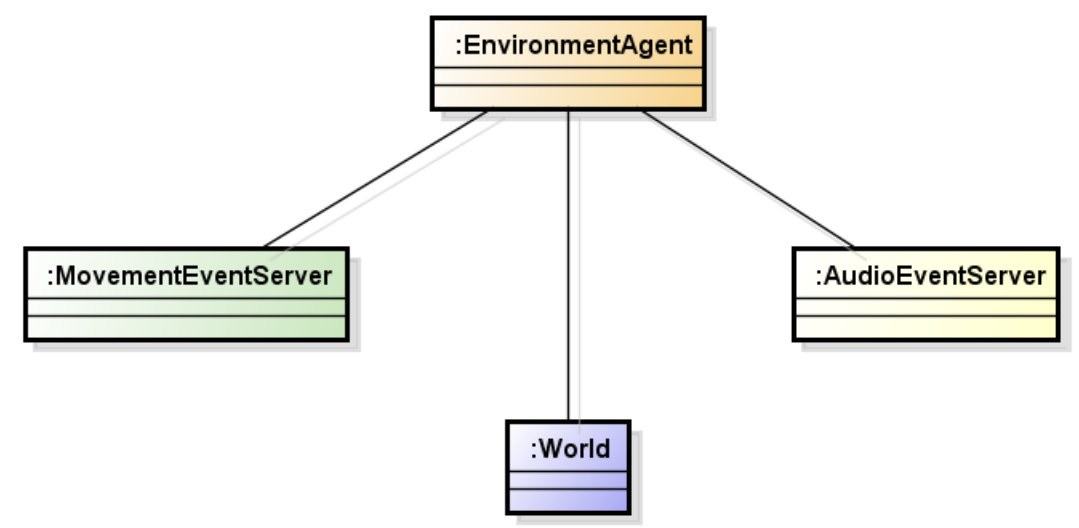

Figura 4.3: Diagrama de Objetos de um Agente Ambiente com Movimentação e Troca de Áudio

\subsubsection{Raciocínio}

Voltando a atenção ao que acontece no interior do agente musical vamos descrever mais detalhadamente os raciocínios dos agentes envolvidos.

$\mathrm{Na}$ aplicação aqui apresentada é interessante aplicar uma diversidade de efeitos nos segmentos de áudio para permitir a possibilidade de experimentação de texturas e a complexidade dos eventos que acontecem simultaneamente, sendo ideal que o processamento seja em tempo real, tanto para permitir uma adaptabilidade como para validar o desempenho do arcabouço nesses cenários.

$\mathrm{Na}$ etapa de estruturação desses raciocínios, os músicos envolvidos sugeriram diversas maneiras de estruturar cada um dos agentes. Inicialmente, com a intenção de que cada um deles seja constituído com um equilíbrio entre características individuais, exclusivas, e características divididas com outros agentes; isso permitiria, de um lado, o estabelecimento da identidade própria do agente e, por outro, a comunicação e o estabelecimento de laços sociais entre os diversos agentes. Para isso, foram definidas algumas características que servem de referência inicial, mas que não necessariamente restringem o escopo do gerador. Essas escolhas se resumem a seguir. 


\section{Repertório}

Cada instância do agente gerador será criada com um número de fragmentos sonoros. É uma decisão composicional que a distribuição de agentes com mesmo número de peças no repertório seja equilibrado, portanto esta característica será determinada por sorteio entre os valores menos frequentes da população atual.

O repertório é composto do conjunto de fragmentos de áudio produzidos e escolhidos, como descrito na seção 4.1.1. Um indivíduo terá um número determinado de fragmentos no seu repertório ou base de conhecimento, de 1 a 5 elementos, sendo esses os valores default desses parâmetros.

\section{Tipo de processamento sonoro}

Define os tipos de processamento que podem ser aplicados aos fragmentos que o agente gerador reproduz. Os processos mencionados inicialmente foram filtros de frequência, porém a intenção é acrescentar diferentes tipos de processamento de áudio. O ideal é que um agente possa possuir e combinar processamentos diferentes para a reprodução de cada fragmento. O filtro será aplicado a um determinado agente, de acordo com a combinação escolhida para a reprodução dos fragmentos. As opções são passa altos, passa baixos ou sem a aplicação de filtro.

\section{Tipo de movimentação}

Determina como um agente gerador vai se movimentar no mundo virtual. A movimentação do agente pode ser de um desses três tipos:

- Estática: O agente mantém uma única posição.

- Movimentação Unidirecional/Constante: O agente apenas se movimenta numa direção a velocidade constante (determinada por uma aceleração inicial).

- Irregular/Errante: Possui um padrão aleatório de movimentação no mundo, tanto a direção como a aceleração são obtidos por sorteio aleatório.

\section{Perfil de agente}

Considerando os aspectos sociais dos agentes definiu-se um perfil do agente que determina se as características musicais do agente mudam com o tempo, imitando outros agentes que ele encontra. Temos dois perfis de agentes geradores, aqueles fixos que não vão mudar seu comportamento durante a execução, e os agentes geradores mutáveis que têm como parte das suas características a assimilação de características dos outros agentes. Esse comportamento de imitação pode acontecer através da gravação de trechos do que é ouvido no ambiente pelo sensor do agente gerador, acrescentando esses novos fragmentos a seu repertório. Também a interação pode acontecer pelo reconhecimento das propriedades de um agente vizinho, para isso deve ser escolhido o mecanismo, seja a partir de eventos e sensores específicos ou a partir de uma análise do áudio escutado no ambiente.

\section{Ações}

O padrão de atividade determina as ações de movimentação e reprodução de áudio que o agente vai executar. As instruções podem descrever um ciclo ou uma sequência e devem corresponder às características já definidas para o agente. O número de instruções do padrão será sorteado aleatoriamente entre 10 e 30 , sendo esses os valores default desses parâmetros. 


\section{Considerações técnicas}

Consideramos uma classe GeneratorReasoning para encapsular o raciocínio do agente gerador. Nela devemos tratar os atuadores legs e mouth, instâncias da classe Actuator assim como os sensores ear e eyes, instâncias da classe Sensor. Também devemos considerar uma memória, do tipo Memory para cada um desses quatro elementos.

No método de inicialização init() vamos a preencher as características já presentes na base de conhecimento, definidos no XML de inicialização, e realizar os sorteios necessários para gerar as características do gerador e posteriormente seu padrão de ações. Para esse padrão de ações definimos uma estrutura para armazenar combinações de características como ação, fragmento e efeito.

Para manter uma distribuição uniforme do número de agentes presentes no mundo com quantidades semelhantes de fragmentos, podemos recuperar essa informação do agente ambiente.

O raciocínio poderá também implementar um ciclo de estados, indicando se o agente está tocando um fragmento, escutando ou ainda não foi inicializado.

Já no método needAction() do nosso raciocínio teremos rotinas diferentes dependendo do estado do agente. Assim caso o agente esteja esperando uma ação recuperamos a próxima operação da memória e mandamos executar. No caso de estar reproduzindo damos continuidade à tarefa até terminar o fragmento para depois indicar que o raciócinio do agente está esperando uma próxima instrução. No caso de uma pausa não executamos nenhuma operação até passar o tempo determinado de descanso.

Utilizaremos os processamentos de áudio tratados na seção 3.1.4 para a elaboração dessa implementação, já que estes recursos estão adaptados para o ambiente ENSEMBLE. Assim propomos incluir inicialmente filtros disponíveis na classe FilterProcessing.

\subsubsection{Discussão}

Desde o processo de formulação do gerador se questionou sobre os desdobramentos do projeto. A utilização de um sistema mais aberto, mas que atua isoladamente, deixa o compositor de certo modo distante da experimentação e essa quebra de paradigma exige uma adaptação.

A expectativa em torno dos resultados foi clara no sentido de não se esperar num primeiro estágio algo com valor artístico/estético, e sim continuar o processo de criação desenvolvendo idéias e confrontando as questões técnicas. Assim essa aplicação deve incluir ainda alguns mecanismos e processos sugeridos pelos músicos envolvidos. A isto somamos que o intuito do gerador é fornecer material base, sujeito a alterações para que possa se encaixar numa obra artística.

Tecnicamente será importante acrescentar transformações e processos que diversifiquem as texturas resultantes das rodadas da aplicação; de igual forma os processos sociais dão outra dimensão à geração de áudio.

\subsection{Espacialização de músicos com avatares no espaço virtual}

Entre as aplicações específicas mais interessantes de sistemas multiagentes musicais estão os sistemas generativos/improvisacionais, como chama Whalley [Wha09] ao conjunto de sistemas que se baseiam geralmente em processos, fundamentais no resultado sonoro, além de elementos de improvisação e interatividade. Uma performance improvisacional que utilize agentes para representar 
músicos externos ao sistema entra nessa categoria e é potencialmente interessante sob um ponto de vista artístico, já que pode fornecer um ingrediente a mais para formações que já trabalham com improvisação e computação musical, e portanto estão acostumadas com esse formato e à inclusão de um sistema interativo. Por outro lado o exemplo é muito ilustrativo para essa pesquisa, já que se explora um cenário com agentes avatares controlados por músicos humanos, com foco na espacialização.

A partir de contatos com a pianista Michelle Agnes que trabalha com improvisação, levantamos um cenário básico para montar uma performance interativa utilizando uma aplicação no arcabouço ENSEMBLE, focando no raciocínio interno do agente e em como esse último poderia materializar comportamentos de valor composicional. A aplicação propõe um cenário de performance que considera um delay espacializado com um agente avatar que reproduz as entradas da pianista, que interage ao conseguir controlar alguns fatores do comportamento do agente.

\subsubsection{Interesse performático}

Um dos campos mais promissores no contexto do uso de agentes para sistemas musicais é justamente a performance interativa. Nesse contexto, foi abordado o tema de uma aplicação do arcabouço para um conjunto de improvisação que, tendo familiaridade com elementos tecnológicos, poderia usufruir das características dos agentes musicais como elemento de experimentação nas performances, utilizando os recursos interativos do sistema. Um dos diferenciais da utilização de agentes num mundo virtual com troca de áudio é a oportunidade de trabalhar com espacialização além do plano físico, tanto para simular recintos como para usar essa espacialização como um elemento da performance, permitindo que diversos parâmetros da simulação possam ser controlados pelos músicos em tempo real.

\subsubsection{Cenário}

A escolha de um efeito de atraso permite que a intérprete tenha um nível de interação com o agente como contraparte na performance. Esse atraso pode ser controlado na hora de execução utilizando uma interface do aplicativo ControlOSC executado num tablete que ficaria dentro da cauda do piano; nesse caso usamos especificamente a GUI do emulador de Monome como mencionado na seção 3.1.2. Um primeiro slider permite controlar o tempo de delay enquanto um segundo slider controla o ganho da saída da aplicação do ENSEMBLE.

Outra requisição foi a possibilidade de desligar a saída do agente avatar com um gesto que não precise das mãos, no caso uma alternativa mais leve para um pedal de ligar ou desligar a saída. Uma pedaleira USB ou de outro tipo implicaria a presença de fios e a necessidade de ter o computador perto do instrumento, ou que dificulta a configuração em palco. Foi sugerida a utilização de mais um dispositivo móvel, um celular com o sistema operacional Android ou IOS no tornozelo da pianista, executando o aplicativo AndOSC, descrito na seção 3.1.2, e transmitindo via OSC a informação lida pelos acelerômetros; com isto um gesto do pé controla o switch solicitado. A configuração de sensibilidade do movimento pode ser alterada, para deixar o movimento mais suave ou mais longo e definido, e também existe um limite de tempo de descanso entre dois comandos desse switch para evitar estímulos repetidos e indesejados. A movimentação do agente avatar também pode ser configurada e alterada durante a execução da simulação. Consideramos a integração com a API ISO e recebemos posições via OSC que comandam a movimentação do nosso agente avatar e podemos mudar o comportamento da movimentação utilizando a matriz de botões presente na interface do aplicativo ControlOSC.

Na figura 4.4 podemos ver a montagem desse cenário combinando as diferentes interfaces de 
entrada, durante a execução da performance. Um diagrama da configuração utilizada para a performance é apresentada na figura 4.10 e os parâmetros controlados durante a performance estão detalhados na tabela 4.3 .

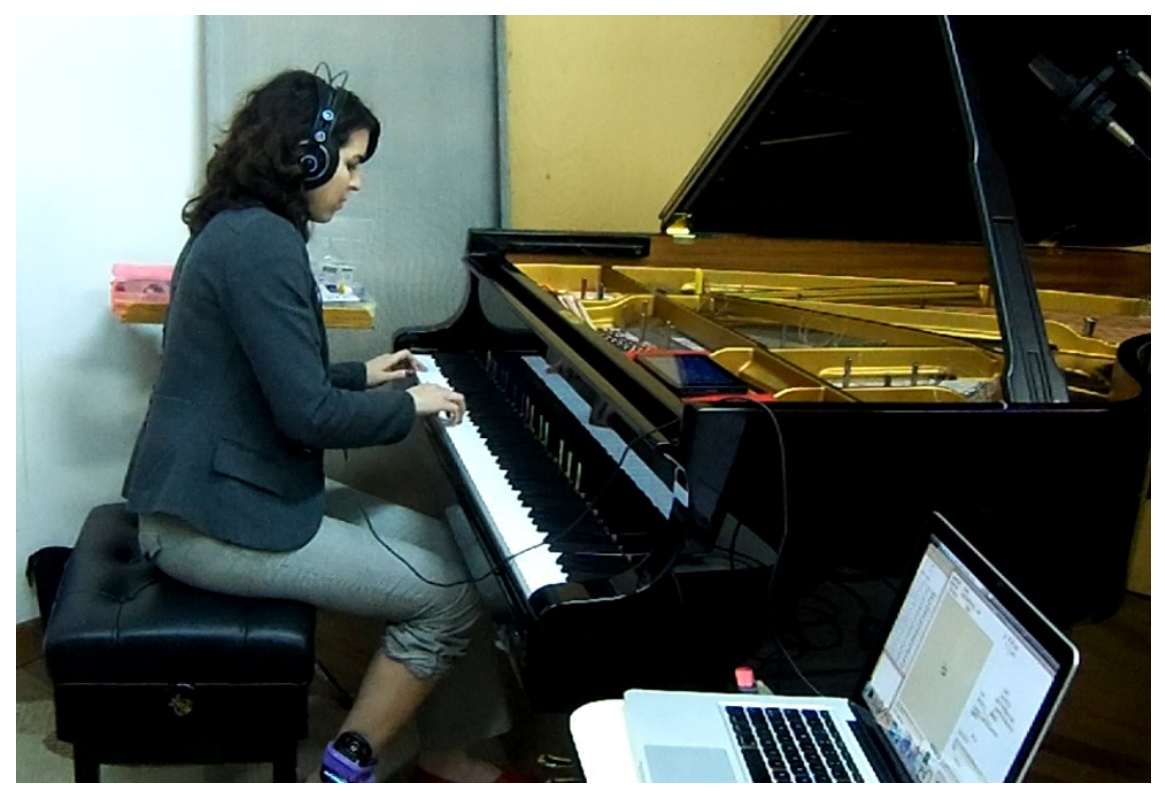

Figura 4.4: Imagem da execução do cenário de Delay Espacializado

\subsubsection{Agente Musical}

Nesta aplicação dois tipos de agentes musicais são considerados para o sistema:

- Um agente musical avatar que consegue receber áudio diretamente de uma fonte sonora externa; neste caso, de um músico que participa em tempo real durante a execução do sistema. Esse avatar terá a capacidade de se movimentar no espaço seguindo os comportamentos definidos pelo seu raciocínio de movimentação ou pelas instruções externas que um usuário envie durante a performance.

- Um agente ouvinte que tem a responsabilidade de repassar, através da interface de áudio, o som escutado na sua posição dentro do mundo virtual, que será reproduzido em um altofalante. A importância desse agente reside na capacidade de externalizar o resultado sonoro do mundo virtual; com esse propósito as distâncias entre os alto-falantes no mundo real, sejam dois, quatro ou mais instâncias, deverão corresponder às posições dos agentes ouvintes no mundo virtual.

Também nesse estudo de caso utilizamos principalmente componentes existentes no arcabouço para a estrutura desses agentes, e complementamos com componentes novos específicos para esse cenário. No caso do avatar, ele irá utilizar o raciocínio JackInputDelayReasoning que permite receber uma entrada de áudio, fazendo interface com o servidor de áudio Jack e incluindo o efeito de atraso desejado. Complementando as funções sonoras o agente avatar tem um sensor ear e um atuador mouth que possui a particularidade de considerar uma memória auxiliar de áudio, o que possibilita processamentos internos anteriores à difusão do som. Para dar suporte à movimentação temos o sensor eyes e o atuador legs. Para garantir a recepção de mensagens o agente possui um sensor de mensagens antenna. 


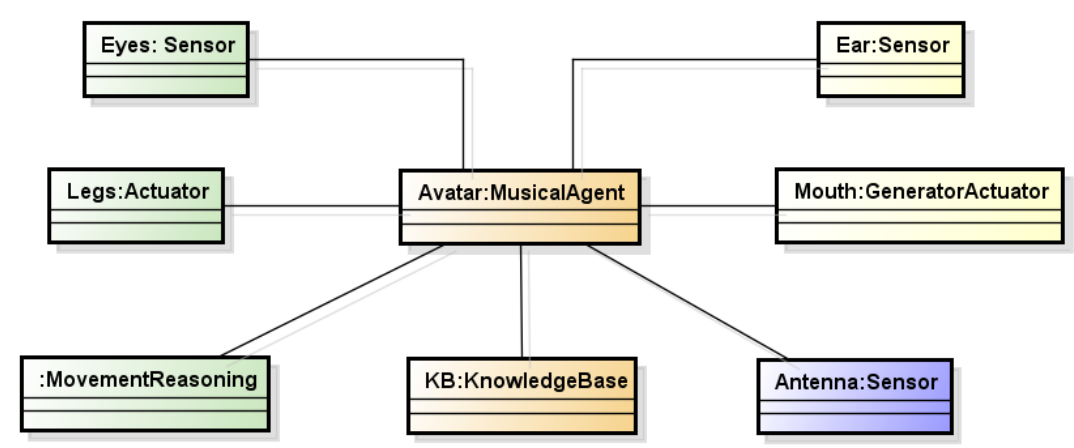

Figura 4.5: Diagrama de Objetos do Agente Avatar

As figuras 4.5 e 4.6 mostram os diagramas de objetos dos dois tipos de agentes. O agente ouvinte possui apenas um sensor sonoro com o propósito de reproduzir o que escuta a partir de um canal da interface de áudio. Usamos também um raciocínio padrão, na classe JACKOutputReasoning, para direcionar o som escutado por cada um desses agentes.

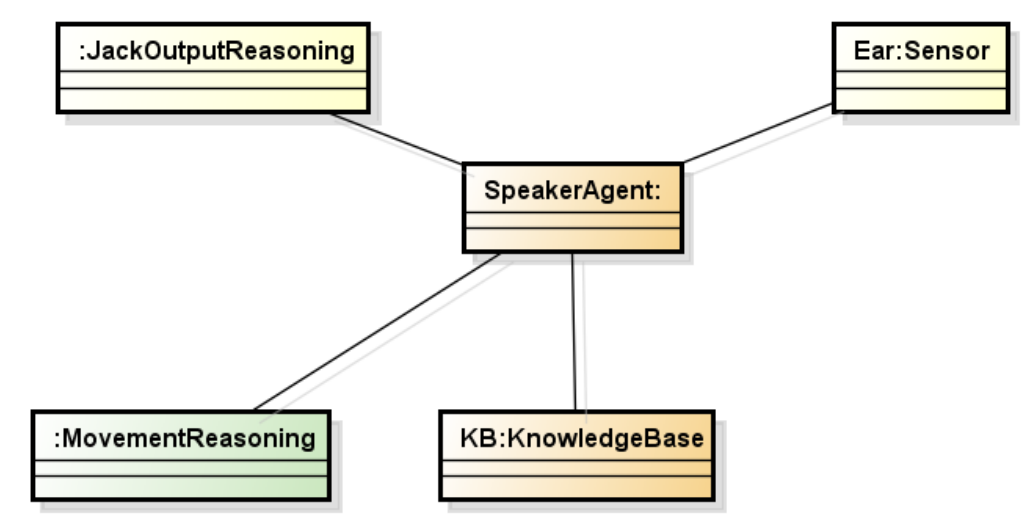

Figura 4.6: Diagrama de Objetos do Agente Alto-falante

\subsubsection{Ambiente virtual}

Aproveitamos a semelhança do mundo virtual necessário para essa aplicação com o mundo padrão apresentado por Thomaz [Tho11] em seu estudo de caso de transmissão de áudio em tempo real. Assim nosso ambiente utiliza apenas componentes já existentes no arcabouço, tanto para a movimentação dos agentes como para a propagação sonora. O agente Ambiente com os seus objetos é representado na figura 4.3.

Para os resultados estéticos dessa aplicação é muito importante definir o tamanho do mundo virtual e a correspondência com a sala ou ambiente real aonde se executará (e se escutará) o sistema.

\subsubsection{Raciocínio}

O raciocínio dos agentes nessa aplicação deverá permitir ao músico controlar ações dentro do mundo virtual. Considerando o foco da performance podemos tratar a movimentação dos avatares 
como sequências programáveis de trajetórias, mas que podem ser interrompidas ou mudadas em tempo de execução, priorizando sempre os comandos dos usuários humanos.

Assim o raciocínio JackInputDelayReasoning aplica um atraso no áudio antes de propagar o som através do atuador, sendo que esse atraso é definido por um parâmetro que pode ser mudado a partir de um comando específico, que pode ser enviado na forma de uma mensagem recebida pelo agente. De igual forma esse raciocínio entende o comando que muda o ganho, e no caso do switch ele para a emissão de som do agente avatar.

Em relação à movimentação dos agentes, o raciocínio PP_OscMovementReasoning interpreta as posições que chegam de um sistema externo como o ISO; na ausência de um sistema externo, a movimentação obedecerá as regras internas do ENSEMBLE.

\section{Considerações Técnicas}

Tecnicamente a arquitetura garante a facilidade de inclusão de outros comportamentos, tanto na movimentação e processamento de áudio como em outros domínios como ciclos de vida artificial e operações mais complexas.

O mecanismo para captar o movimento do pé da pianista considera uma ação composta em duas fases, uma extensão do pé e a volta dele a um estado de repouso. O celular se coloca de cabeça para baixo, portanto em repouso; com a perna perpendicular ao chão, temos uma aceleração nula no eixo X, que pode chegar a $-9.8 \mathrm{~m} / \mathrm{s}^{2}(-\mathrm{g})$ com a perna completamente paralela ao chão. Para caracterizar o estímulo, na primeira ação devemos chegar a uma aceleração no eixo X inferior ao parâmetro accSwitchLimit (por default é $-7 \mathrm{~m} / \mathrm{s}^{2}$ ) e na volta devemos identificar uma aceleração superior ao parâmetro accComeback (por default é $-0.5 \mathrm{~m} / \mathrm{s}^{2}$ ). Como terceiro fator temos o tempo de espera entre comandos que é um terceiro parâmetro com o nome restInterval (por default é $800 \mathrm{~ms}$ ).

Essas configurações estão presentes na figura 4.7, que mostra a definição do agente avatar no XML de inicialização. Também nessa figura vemos que é necessário configurar o canal de entrada de áudio para o agente no parâmetro mapping, que deve ser um nome válido registrado no servidor de áudio Jack.

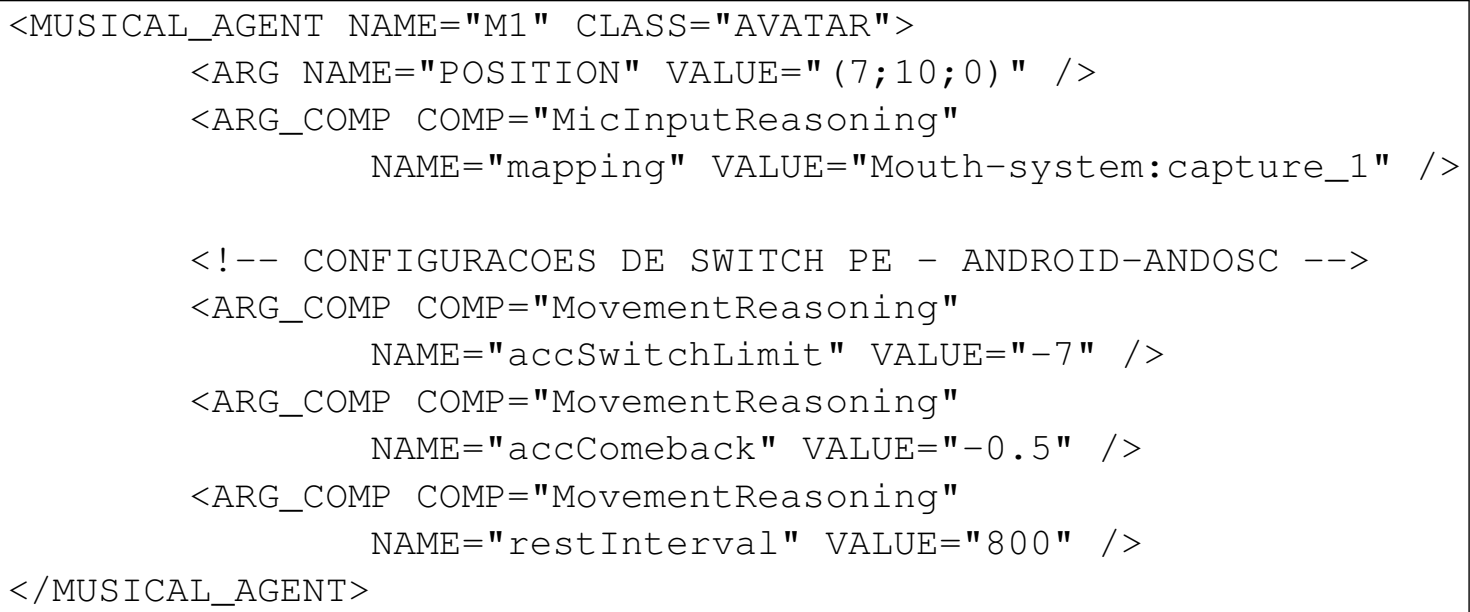

Figura 4.7: Definição do Agente Avatar no Delay Espacializado 


\subsection{Aplicação de Piano preparado}

O piano preparado pode ser definido como um piano de cauda onde objetos de materiais diferentes são introduzidos entre as cordas do piano, produzindo timbres diversos. Uma aplicação baseada nessa técnica de John Cage foi proposta no âmbito do projeto Mobile, com a participação da pianista Michelle Agnes; essa iniciativa foi desenvolvida utilizando o arcabouço ENSEMBLE em colaboração com a artista.

Trataremos nessa seção o contexto composicional dessa aplicação, descreveremos o cenário proposto e como participam os diferentes componentes do ENSEMBLE. Citaremos também as considerações técnicas relevantes da implementação e apresentaremos a montagem de estúdio para a gravação de algumas execuções da aplicação.

\subsubsection{Contexto composicional}

Costa [dC05] define o Piano preparado como um instrumento novo, que surge por invenção de John Cage na década de 1940. Assim como o piano resultou de modificações do cravo, o piano preparado teria surgido como uma nova vertente do piano. O termo "preparação" sugere que o instrumentista precisará de algum tempo antes da performance para preparar o piano, principalmente com a fixação dos objetos entre as cordas, processo este denominado de preparação fixa Cageana, para remeter a esse tipo de preparação onde os objetos são precisamente colocados antes da performance e só são retirados depois.

As origens do piano preparado vêm das técnicas do string piano (piano de cordas), desenvolvidas por Henry Cowell (1897-1965) em 1923. Esse termo se refere a um piano de cauda comum, onde as cordas são manipuladas diretamente com as mãos ou outros objetos. O compositor explora efeitos como o pinçamento de cordas individuais, o deslizamento de dedos e unhas nas cordas perpendicularmente enquanto um acorde é pressionado silenciosamente nas teclas, o abafamento das cordas, a produção de harmônicos naturais e artificiais ao abafar a corda em posições estratégicas enquanto toca, entre outros [BeCU06].

Cage foi aluno de Cowell por um ano na New School for Social Research, em Nova Iorque, e se fascinou pelos métodos inusitados do professor de extrair sons do piano. Em 1938, ante a impossibilidade de utilizar um grande conjunto de percussão, e limitando-se apenas a um piano, Cage lembrou-se dos métodos de utilização do string piano por Cowell,e procurou fazer com que o piano soasse como uma orquestra de percussão, inserindo objetos entre as cordas do instrumento, especificamente vedantes e parafusos [dC05]. Cage transformou o piano em um multiplicador de timbres e ruídos, fazendo com que cada região do instrumento produzisse um timbre diferente, possibilidade esta comparável à dos sintetizadores atuais de dividir (split) regiões do teclado com timbres diferentes [Wis89].

Com a intenção de combinar um sistema interativo com o piano preparado surgiu a possibilidade de criar uma aplicação que permita uma interação entre a pianista e uma contraparte de live electronics, no caso aproveitando as vantagens de utilizar um arcabouço como o ENSEMBLE que prioriza a troca de áudio e as capacidades de agentes inteligentes num âmbito musical.

\subsubsection{Cenário}

Num primeiro momento foi considerada a possibilidade de simular os efeitos sonoros provocados pelos distintos apetrechos instalados no piano, como por exemplo, abafadores, parafusos, arames entre outros e fazer deles agentes inteligentes; porém, isso significaria uma alta complexidade de 
processamento e síntese de áudio que dificilmente chegaria aos resultados tão ricos que o instrumento acústico consegue fornecer com a preparação. As técnicas utilizadas para instalar elementos no piano são muito depuradas e claramente são fruto de muitas tentativas e experiências sonoras que se convertem em boas práticas, tanto numa perspectiva de obter um determinado som como também num âmbito gestual e logístico.

A continuidade desse trabalho nos levou a formular um cenário que trabalhasse com áudio prégravado, com samples de uma qualidade considerada interessante para a artista e que pudessem representar atores adicionais na performance, como se fossem mais mãos dentro da cauda do piano. Assim os agentes seriam instrumentistas adicionais que existem num mundo virtual dentro do ENSEMBLE e que permitem chegar a resultados que não podem ser obtidos com a execução de uma única intérprete. Por exemplo, se uma região do piano conta com uma preparação específica seria impossível obter o som de uma preparação diferente na mesma corda ao mesmo tempo; também observamos a limitação de técnicas que precisam ser executadas com as duas mãos, como no caso da friç̧ão da corda do piano com um arame, segurado pelas pontas, que descreve um movimento de vai e volta e portanto, impedindo executar outro som junto com ele no contexto puramente acústico.

Esses agentes propostos reproduzem samples de técnicas de piano preparado categorizados pela artista. Contamos com aproximadamente 30 samples de técnicas de piano preparado, de diferentes durações e naturezas. Esses sons já foram escolhidos cuidadosamente para funcionar entre eles, e já foram utilizados pela pianista no contexto de um controlador de samples simples.

Por outro lado as entradas de áudio servem como estímulos para a movimentação e comportamento musical dos agentes virtuais. Esses estímulos considerados são derivados da amplitude e do pitch da entrada, e estão parametrizados para outorgar mais controle das execuções para a pianista. Contamos também com raciocínios internos que processam o áudio dentro do agente, incluindo filtros que poderão ser controlados pela intérprete e que dependem da posição do agente no mundo virtual.

Adicionamos como método de controle a possibilidade de enviar mensagens OSC, via rede, para mudar parâmetros e comportamentos dos agentes; a interface de um tablete touchscreen se aproxima da linguagem gestual na interpretação do piano preparado e facilita a configuração já que não precisa de fios adicionais.

Seguindo o padrão apresentado para os outros estudos de caso, na tabela 4.7 temos um resumo das definições para a aplicação no contexto do modelo teórico apresentado por Whalley [Wha09] e o arcabouço de Thomaz [Tho11].

\subsubsection{Agente Musical}

$\mathrm{Na}$ aplicação de piano preparado com agentes multi-instrumentistas consideramos dois tipos de agentes musicais para o sistema:

- Um agente musical instrumentista que habita o mundo e possui a característica de analisar o áudio de entrada em amplitude e altura, se comportando de acordo com esses estímulos. Os comportamentos de movimentação do agente serão definidos pelo raciocínio específico da aplicação, que contempla uma inicialização e vários comandos em tempo de execução. O agente poderá também ser silenciado e manipulado por uma interface externa.

- Um agente ouvinte que apenas é responsável por capturar o resultado do processamento sonoro na aplicação e repassar através da interface de áudio, espacializando o resultado de acordo 
com as dimensões do mundo virtual e a posição física dos alto-falantes.

O agente instrumentista pode escutar o som do ambiente, e mantém uma estrutura com componentes já existentes no arcabouço ENSEMBLE, além de vários raciocínios novos e atuador e sensor de mensagens como mostra a figura 4.8.

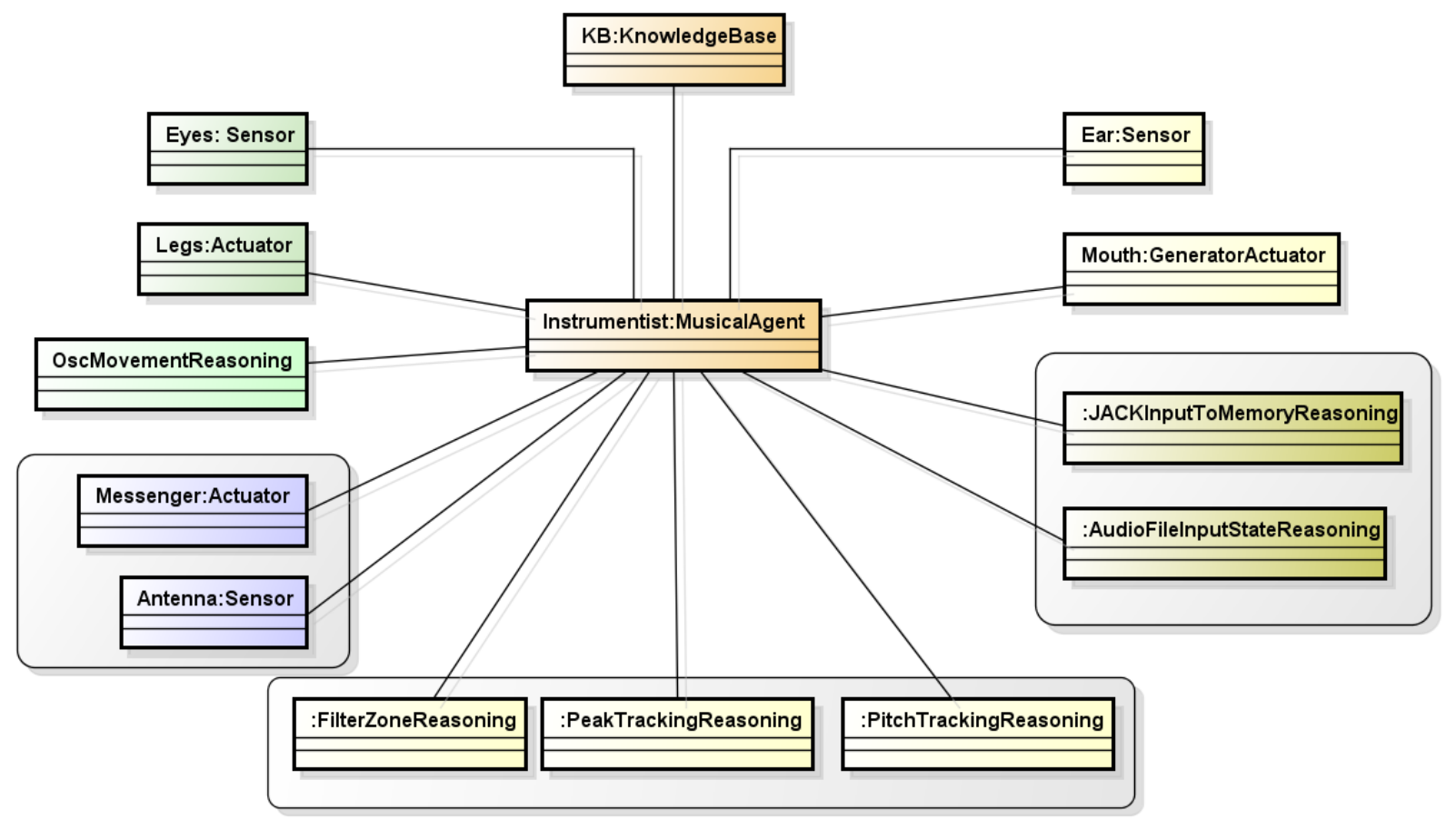

Figura 4.8: Diagrama de Objetos de um Agente Instrumentista

\section{Ambiente virtual}

O ambiente virtual desse cenário é idêntico ao ambiente do cenário de delay espacializado mencionado na seção 4.2.4. É importante considerar o número de agentes ouvintes utilizados para garantir a correspondência das distâncias entre os alto-falantes da configuração, sejam dois, quatro ou mais caixas de som utilizadas para ouvir o resultado.

\subsubsection{Raciocínio}

Existem vários raciocínios envolvidos na aplicação e o agente instrumentista está composto por alguns elementos que garantem a movimentação, a emissão de áudio e a troca de mensagens e comandos.

A movimentação é tratada pelo raciocínio OscMovementReasoning que permite a recepção de posições do ISO ou de outra aplicação externa. Quando não existem mensagens externas o agente pode manter uma trajetória fixa, determinada pelo XML de inicialização, ou pode receber mensagens internas para mudar de direção. Nesse caso essas mudanças se determinam com mensagens recebidas pelo sensor de mensagens do agente, mudando a direção do movimento e aplicando uma aceleração fixa e uma direção básica (acima, abaixo, direita ou esquerda). 
O áudio recebido como entrada pelo agente vem diretamente de uma fonte externa, um microfone que capta sons numa posição determinada da cauda do piano, e é recebido pelo raciocínio JACKInputToMemoryReasoning que salva numa memória auxiliar esse stream de dados para que possam ser analisados. Enquanto a saída de som e a interação com os samples acontece através do raciocínio AudioFileInputStateReasoning, que consegue reproduzir trechos de áudio e respeitar a escolha de categorias determinadas pelos comandos recebidos, mais uma vez, pelo sensor de mensagens do agente.

A tabela 4.4 mostra as condições para acionar esses comandos de movimentação e reprodução sonora.

Por outro lado, o raciocínio FilterZoneReasoning determina se o áudio a ser reproduzido terá a aplicação de um filtro como mencionado na seção 3.1.4, a escolha se determina por uma divisão em quadrantes do mundo virtual, assim como ilustrado na figura 4.9. Cada região terá a aplicação de um filtro passa-altas ou passa-baixas com uma frequência de corte que pode ser mudada pela intérprete na inicialização ou na hora da execução. Quando um agente instrumentista estiver na região central que tem forma de cruz, não se aplicará nenhum filtro.

Completando a participação dos raciocínios, o passo que garante a interação entre os atores da performance e a análise do áudio de entrada acontece pela combinação dos raciocínios PeakTrackingReasoning e PitchTrackingReasoning, que determinam se existem estímulos de picos ou de altura respectivamente como apresentamos na seção 3.1.4. Esses raciocínios têm como fonte de dados a memória auxiliar de áudio do agente, e emitem mensagens a partir do atuador Messenger do agente instrumentista.

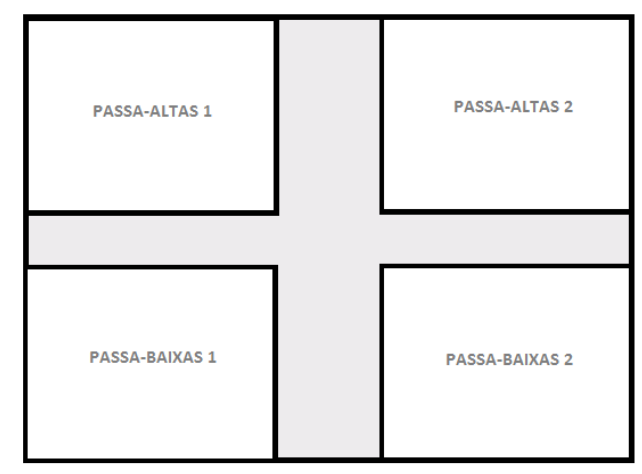

Figura 4.9: Diagrama da divisão por Quadrantes no Mundo Virtual da aplicação com Piano Preparado

\subsubsection{Considerações Técnicas}

No contexto dessa aplicação é importante apontar algumas características técnicas como a funções da interface gráfica utilizada para enviar as mensagens e as particularidades do XML de inicialização.

A interação no cenário de piano preparado pode se realizar utilizando o aplicativo ControlOSC como mencionado na seção 3.1.2, enquanto na tabela 4.5 apresentamos a configuração dos controles na interface gráfica criada para essa aplicação. Os mecanismos de interação da pianista incluem a manipulação em teclas, na cauda e nas interfaces móveis como podemos ver na figura 4.10.

Os parâmetros que determinam os limiares de altura e amplitude considerados para a simulação podem ser configurados diretamente na definição do XML de inicialização, como mostra a 


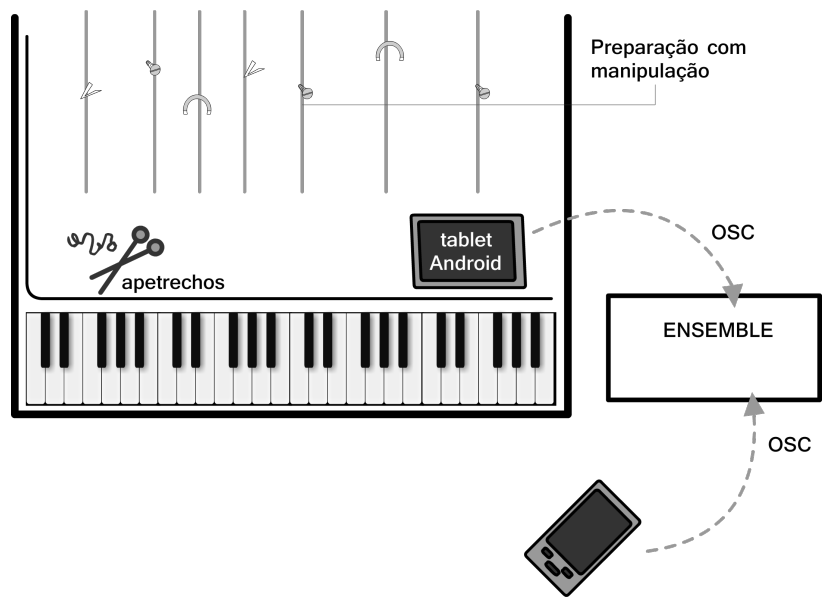

Figura 4.10: Diagrama de Interação com o Piano Preparado e Interfaces OSC - Cenário de Agentes Multiinstrumentistas

figura 4.11. Na mesma figura podemos ver os parâmetros da instância do raciocínio AudioFileInputStateReasoning, chamada FileInputReasoning, que permitem ligar ou desligar a inclusão de filtros assim como determinar o número máximo de samples executados depois de um único estímulo, seja relacionado à altura da entrada ou à amplitude.

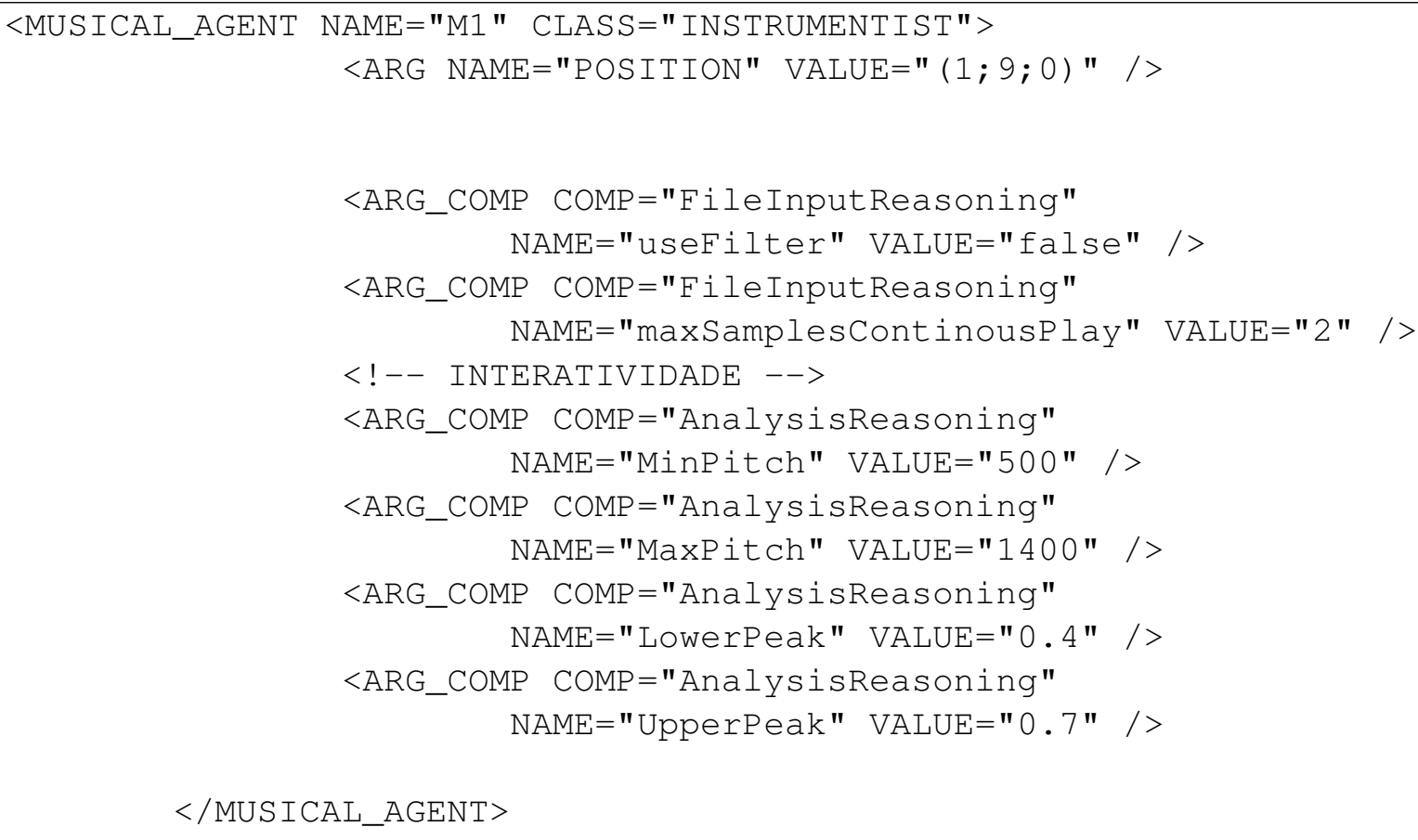

Figura 4.11: Definição do Agente Multi-intrumentista no cenário do Piano Preparado

Outra consideração relevante foi orientar a artista para poder executar e experimentar com o sistema independentemente; para isso foi criado um manual apresentado no apêndice C, que mostra os requisitos do sistema e os passos relevantes para conseguir testar as aplicações. Ficou claro que é muito difícil recriar as condições ideais de um estúdio em casa e que o processo como um todo, incluindo configuração de aplicativos móveis, rede e aplicação, não é triviail e sua realização seria difícil sem uma ajuda técnica. 


\subsubsection{Gravação}

Com o objetivo de ensaiar e registrar o resultado dessas aplicações musicais, tanto o cenário do delay especializado como o cenário apresentado nessa seção, foram montados no estúdio do LAMI - ECA - USP que possui um piano e o equipamento necessário para realizar essa tarefa.

A configuração no estúdio seguiu o esquema contemplado no apêndice B, tendo como objetivo registrar tanto as entradas acústicas do piano preparado como a saída do ENSEMBLE, para isso seguimos a configuração apresentada na figura 4.12. A configuração do notebook utilizado para executar o ENSEMBLE e da placa de som encarregada de entradas e saidas do sistema se apresentam na tabela 4.6. Para fins de acompanhamento visual do mundo virtual, o laptop ficou dentro da sala de gravação, já que um projetor seria barulhento demais, e seria captado pelos microfones do piano preparado. A figura 4.13 mostra a preparação do piano na performance.

Vídeos com as gravações realizadas nessas sessões estão disponíveis no site do grupo de Computação Musical - IME/USP ${ }^{1}$

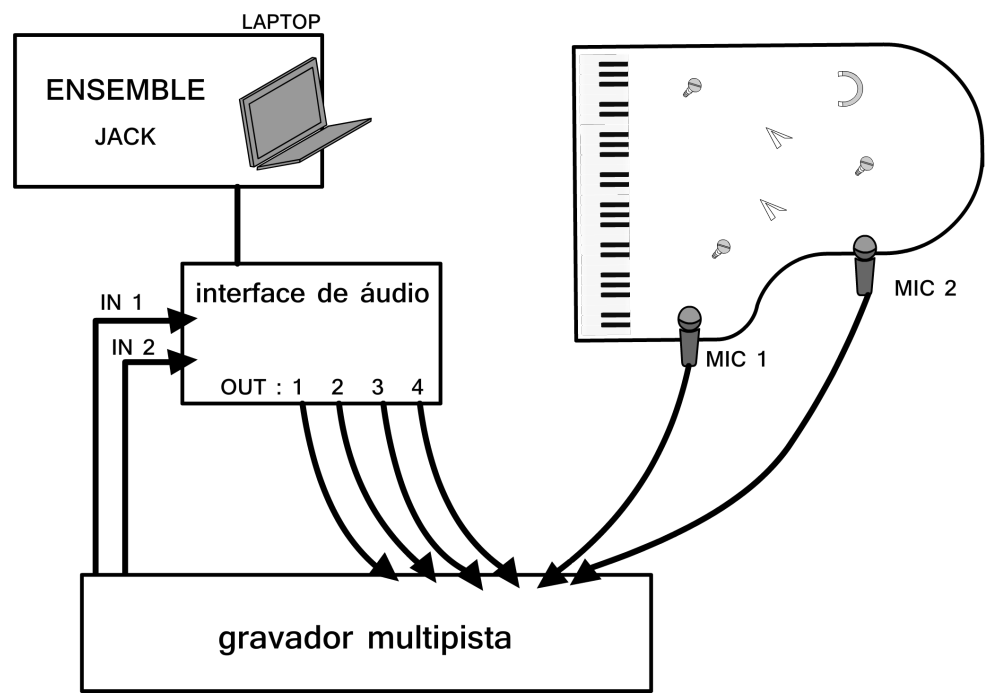

Figura 4.12: Esquema da Gravação dos cenários ENSEMBLE com o Piano Preparado

\footnotetext{
${ }^{1}$ http://compmus.ime.usp.br/
} 


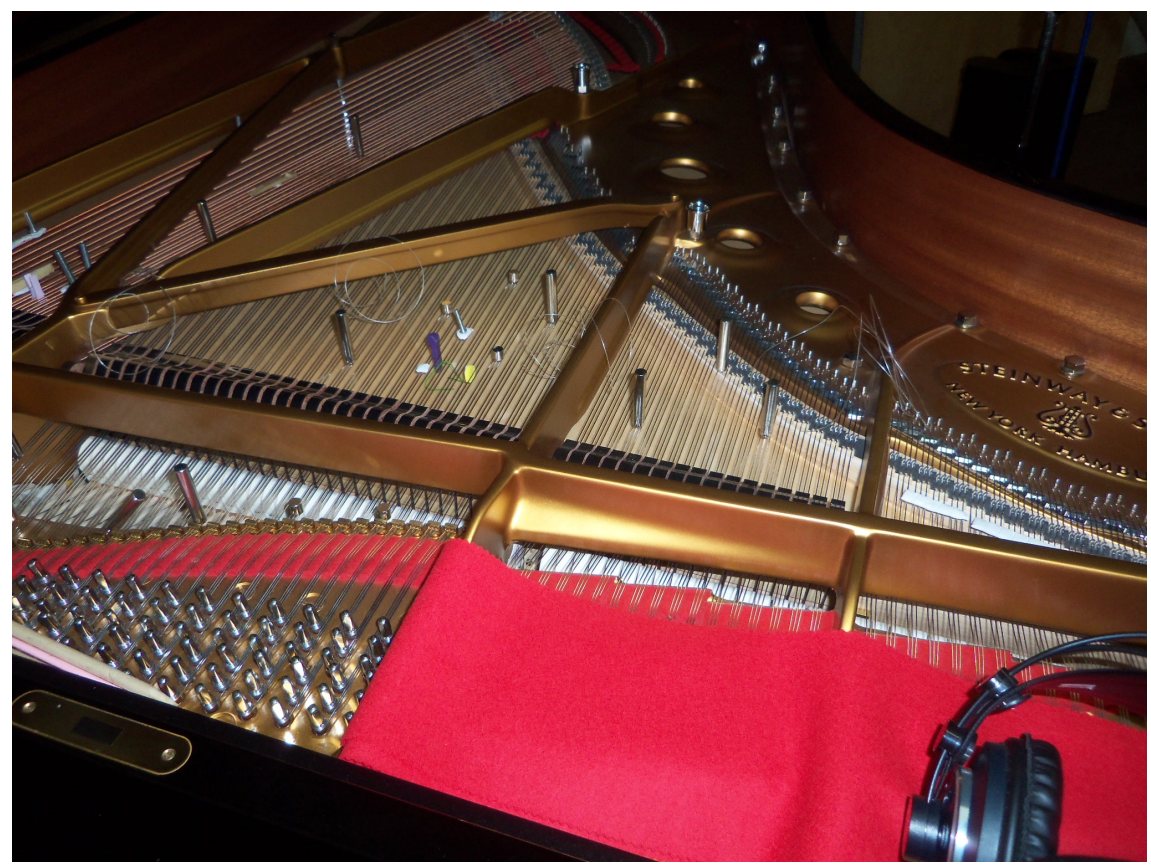

Figura 4.13: Preparação do Piano usada na Gravação 
Estrutura ou Formato do Resultado Sonoro

O gerador de material eletroacústico não estabelece uma estrutura musical ou de outro tipo para o resultado sonoro; é o processo da interação dos agentes que determina o som final.

\begin{tabular}{|c|c|}
\hline \multicolumn{2}{|r|}{ Comunicação e Bases de conhecimento } \\
\hline Codificação musical & $\begin{array}{l}\text { Um dos pontos importantes é trabalhar com o formato de } \\
\text { áudio, que também é o formato dos fragmentos que servem } \\
\text { como semente para as gerações de material sonoro. }\end{array}$ \\
\hline Elemento Comunicativo & $\begin{array}{l}\text { Considerando que o gerador é apenas uma instância inter- } \\
\text { mediária antes da peça musical final, não consideramos ne- } \\
\text { nhuma interação com outras disciplinas artísticas. }\end{array}$ \\
\hline Base de conhecimento & $\begin{array}{l}\text { Os agentes devem considerar uma base de conhecimento que } \\
\text { possua os fragmentos de áudio e também as operações de } \\
\text { vida artificial. }\end{array}$ \\
\hline \multicolumn{2}{|r|}{ Ambiente Virtual } \\
\hline Dimensão & $\begin{array}{l}\text { O mundo virtual considerado para essa aplicação é um es- } \\
\text { paço tridimensional. Um eixo principal é determinado para } \\
\text { posicionar o ouvinte do mundo. }\end{array}$ \\
\hline Estrutura & O espaço neste mundo é contínuo. \\
\hline Forma & $\begin{array}{l}\text { Trata se de um mundo cúbico com limite fixado na hora da } \\
\text { inicialização. }\end{array}$ \\
\hline \multicolumn{2}{|r|}{ Agente Musical } \\
\hline Movimentação & $\begin{array}{l}\text { Os agentes se movimentam pelo espaço de acordo a uma } \\
\text { trajetoria pré-definida ou aos comandos de movimentação } \\
\text { de um sistema externo como o ISO. }\end{array}$ \\
\hline Modelo de Raciocínio & O raciocínio dos agentes é somente reativo \\
\hline \multicolumn{2}{|r|}{ Atributos Principais } \\
\hline Autonomia & $\begin{array}{l}\text { Não existe participação musical nem extra-musical de usuá- } \\
\text { rios externos na hora da execução da aplicação, portanto o } \\
\text { comportamento dos agentes é totalmente independente. }\end{array}$ \\
\hline Cooperação & $\begin{array}{l}\text { Diferentemente de sistemas ecológicos ou principalmente } \\
\text { evolutivos, essa aplicação tem objetivos estéticos como a ex- } \\
\text { ploração de texturas sonoras e paralelismo de acontecimen- } \\
\text { tos, portanto a cooperação não é explicita. }\end{array}$ \\
\hline Aprendizado & $\begin{array}{l}\text { Atualmente não existe nenhum mecanismo de aprendizado } \\
\text { para o agente, que reproduz um comportamento padrão du- } \\
\text { rante a execução. }\end{array}$ \\
\hline \multicolumn{2}{|c|}{ Paradigma multiagentes } \\
\hline \multicolumn{2}{|c|}{$\begin{array}{l}\text { A aplicação não introduz interações com agentes humanos, apenas agentes computacionai } \\
\text { internos ao ambiente se envolvem no processo. Portanto, segundo a categorização simplifi- } \\
\text { cada de Whalley [Wha09], essa aplicação pertence ao tipo MAS (Sistemas multiagentes). }\end{array}$} \\
\hline \multicolumn{2}{|c|}{ Raciocínio do Agente } \\
\hline Utilização de áudio & $\begin{array}{l}\text { O áudio é utilizado como codificação musical única e as trans- } \\
\text { formações acontecem no tempo de execução. }\end{array}$ \\
\hline Composição Algorítmica & $\begin{array}{l}\text { Transformações semelhantes às transformações simbólicas } \\
\text { descritas na seção } 2.3 .2 \text { acontecem nessa aplicação, que busca } \\
\text { contemplar no uso desses métodos a utilização de áudio. Num } \\
\text { primeiro momento contamos com a aplicação de filtros. }\end{array}$ \\
\hline Performance & $\begin{array}{l}\text { Não se consideram características performáticas por estarem } \\
\text { fora do escopo da aplicação. }\end{array}$ \\
\hline
\end{tabular}

Tabela 4.1: Características no Desenho do Gerador de material eletroacústico 
Estrutura ou Formato do Resultado Sonoro

O sistema de espacialização com avatares musicais pretende dar suporte para a interação entre agentes controlados por humanos, no contexto de uma performance, portanto não se define uma estrutura musical a priori.

\begin{tabular}{|c|c|}
\hline \multicolumn{2}{|r|}{ Comunicação e Bases de conhecimento } \\
\hline Codificação musical & $\begin{array}{l}\text { A codificação musical é o áudio que chega ao sistema por entradas externas } \\
\text { em tempo real. }\end{array}$ \\
\hline Elemento Comunicativo & $\begin{array}{l}\text { O formato de performance interativa, e o intuito de usar a aplicação em apre- } \\
\text { sentações ao vivo, permitiria acrescentar elementos comunicativos com outras } \\
\text { disciplinas artísticas. }\end{array}$ \\
\hline Base de conhecimento & $\begin{array}{l}\text { Os agentes devem considerar uma base de conhecimento que armazene áu- } \\
\text { dio para os processos internos, assim como os padrões de movimentação, de } \\
\text { natureza simbólica. }\end{array}$ \\
\hline \multicolumn{2}{|r|}{ Ambiente Virtual } \\
\hline Dimensão & $\begin{array}{l}\text { O mundo virtual considerado é um espaço tridimensional; é um elemento-chave } \\
\text { para obter a espacialização como um atrativo performático. }\end{array}$ \\
\hline Estrutura & O espaço no mundo virtual é contínuo. \\
\hline Forma & $\begin{array}{l}\text { Trata se de um mundo cúbico com limite fixado na hora da inicialização. É im- } \\
\text { portante considerar que o tamanho do ambiente virtual pode ser um elemento } \\
\text { chave na experiência acústica da performance. Um arranjo de dois ou quatro } \\
\text { alto-falantes pode reproduzir o som do ambiente virtual para simular recintos } \\
\text { diferentes do recinto real usado pelos músicos. }\end{array}$ \\
\hline \multicolumn{2}{|r|}{ Agente Musical } \\
\hline Movimentação & $\begin{array}{l}\text { Os agentes se movimentam pelo espaço de acordo a uma trajetoria pré-definida } \\
\text { ou aos comandos de movimentação de um sistema externo como o ISO. }\end{array}$ \\
\hline Modelo de Raciocínio & $\begin{array}{l}\text { O raciocínio dos agentes numa primeira etapa da aplicação será somente rea- } \\
\text { tivo, já que o usuário humano terá grande controle sobre as decisões de emissão } \\
\text { sonora e outros elementos performáticos. }\end{array}$ \\
\hline \multicolumn{2}{|r|}{ Atributos Principais } \\
\hline Autonomia & $\begin{array}{l}\text { Os agentes contam com a participação direta de usuários na hora da execução } \\
\text { da aplicação, tanto para a emissão de som como para a execução de outras } \\
\text { tarefas como gravar som e reproduzir gravações. Apenas a movimentação do } \\
\text { agente poderá ter um nível considerável de autonomia, se desejado pelo usuário. } \\
\text { Portanto o comportamento dos agentes é muito dependente. }\end{array}$ \\
\hline Cooperação & Não existe cooperação entre os agentes. \\
\hline Aprendizado & $\begin{array}{l}\text { Os processos de gravação e reprodução mudam o conteúdo das bases de co- } \\
\text { nhecimento e podem eventualmente acrescentar elementos que satisfaçam o } \\
\text { performer, e portanto representem mecanismos de aprendizado relevantes para } \\
\text { a aplicação. }\end{array}$ \\
\hline \multicolumn{2}{|r|}{ Paradigma multiagentes } \\
\hline \multicolumn{2}{|c|}{$\begin{array}{l}\text { A aplicação contempla interações com agentes humanos; segundo Whalley [Wha09], pertence ao tipo } \\
\text { DAI (Inteligência Artificial Distribuída). }\end{array}$} \\
\hline \multicolumn{2}{|c|}{ Raciocínio do Agente } \\
\hline Utilização de áudio & $\begin{array}{l}\text { O áudio é utilizado como codificação musical única e os processos acontecem } \\
\text { no tempo de execução. }\end{array}$ \\
\hline $\begin{array}{l}\text { Composição Algorít- } \\
\text { mica }\end{array}$ & $\begin{array}{l}\text { Num primeiro momento apenas consideramos um processamento simples de } \\
\text { gravação do áudio escutado por um agente, e reprodução de áudio armazenado } \\
\text { na base de conhecimento. }\end{array}$ \\
\hline Performance & $\begin{array}{l}\text { É o foco dessa aplicação e portanto é uma prioridade que a aplicação viabilize } \\
\text { a participação de vários usuários simultâneos. }\end{array}$ \\
\hline
\end{tabular}

Tabela 4.2: Características no Desenho do Sistema de Espacialização com Avatares 


\begin{tabular}{|c|c|c|c|}
\hline Componente & Parâmetro & Aplicativo & Valores \\
\hline Slider 1 & Ganho & ControlOSC & {$[0-1]$} \\
\hline Slider 2 & Delay & ControlOSC & $200-1500 \mathrm{~ms}$ \\
\hline Grid & Movimentação & ControlOSC & {$[0-1]$ Aleatório } \\
& & & {$[2-3]$ Circular } \\
& & & {$[4-5]$ Velocidade crescente } \\
& & & {$[6-7]$ Imóvel } \\
\hline Acelerômetro & Switch ON/OFF & AndOSC & AccX $<-7$ (default) \\
\hline
\end{tabular}

Tabela 4.3: Paramêtros de Controle na aplicação Delay Espacializado

\begin{tabular}{|c|c|c|c|}
\hline Tipo de Análise & Condição & Direção & Reprodução \\
\hline Altura & $\geq$ Frequência Max & DIREITA & Longo \\
\hline Altura & $\leq$ Frequência Min & ESQUERDA & Curto \\
\hline Amplitude & $>$ Limite 1 e $<$ Limite 2 & DIREITA & Ressonante \\
\hline Amplitude & $>$ Limite 2 & BAIXO & Percussivo \\
\hline
\end{tabular}

Tabela 4.4: Condições de controle na aplicação Piano Preparado

\begin{tabular}{|c|c|c|}
\hline Componente & Parâmetro & Valores \\
\hline A1 & Switch ON/OFF Agente 1 & {$[0-1]$} \\
\hline A2 & Switch ON/OFF Agente 2 & {$[0-1]$} \\
\hline A3 & Switch ON/OFF Agente 3 & {$[0-1]$} \\
\hline Slider HP1 & Freq. Corte Passa Altas 1 & $400-1000 \mathrm{~Hz}$ \\
\hline Slider HP2 & Freq. Corte Passa Altas 2 & $400-1000 \mathrm{~Hz}$ \\
\hline Slider LP1 & Freq. Corte Passa Baixas 1 & $200-800 \mathrm{~Hz}$ \\
\hline Slider LP2 & Freq. Corte Passa Baixas 2 & $200-800 \mathrm{~Hz}$ \\
\hline Botão rnd & Movimentação & Aleatória \\
\hline Botão circ & Movimentação & Circular \\
\hline Botão fast & Movimentação & Velocidade alta \\
\hline Botão off & Movimentação & Estático \\
\hline
\end{tabular}

Tabela 4.5: Paramêtros de Controle na aplicação Piano Preparado - ControlOSC

\begin{tabular}{|c|c|}
\hline Modelo do Notebook & \\
\hline Processador & Intel Core 2 Duo $(2.0 \mathrm{GHz})$ \\
\hline Memória & $2 \mathrm{~GB}$ \\
\hline Sistema Operacional & OS X 10.6 "Snow Leopard" \\
\hline Modelo da Placa de som & M-Audio FastTrack Pro \\
\hline
\end{tabular}

Tabela 4.6: Configuração do Notebook utilizado na Gravação dos cenários 
Estrutura ou Formato do Resultado Sonoro

A aplicação do piano preparado tem como formato uma performance com piano que serve de entrada para o sistema interativo. Musicalmente não se define uma estrutura. Trata-se de uma aplicação com um resultado sonoro baseado em processo.

\begin{tabular}{|c|c|}
\hline \multicolumn{2}{|r|}{ Comunicação e Bases de conhecimento } \\
\hline Codificação musical & $\begin{array}{l}\text { A codificação musical é áudio, na entrada do sistema e nos processos } \\
\text { internos do sistema. }\end{array}$ \\
\hline Elemento Comunicativo & $\begin{array}{l}\text { Não se considera elementos comunicativos com outras disciplinas artís- } \\
\text { ticas. }\end{array}$ \\
\hline Base de conhecimento & $\begin{array}{l}\text { Os agentes devem considerar uma base de conhecimento que armazene } \\
\text { áudio e os elementos vinculados com vida artificial. }\end{array}$ \\
\hline \multicolumn{2}{|r|}{ Ambiente Virtual } \\
\hline Dimensão & $\begin{array}{l}\text { O mundo virtual considerado é bidimensional e a propagação do som } \\
\text { simula um ambiente real. }\end{array}$ \\
\hline Estrutura & O espaço no mundo será continuo. \\
\hline Forma & O mundo tem a forma de toro, com tamanho definido na inicialização. \\
\hline \multicolumn{2}{|r|}{ Agente Musical } \\
\hline Movimentação & $\begin{array}{l}\text { Os agentes se movimentam pelo espaço de acordo a estímulos de altura } \\
\text { e picos da entrada ou aos comandos de movimentação da intérprete. }\end{array}$ \\
\hline Modelo de Raciocínio & $\begin{array}{l}\text { O raciocínio dos agentes numa primeira etapa da aplicação será somente } \\
\text { reativo. }\end{array}$ \\
\hline \multicolumn{2}{|r|}{ Atributos Principais } \\
\hline Autonomia & $\begin{array}{l}\text { Os agentes instrumentistas são autônomos, já que reagem a estímulos do } \\
\text { ambiente e da entrada; apenas os comportamentos de movimentação e } \\
\text { emissão de som são controlados pelo usuário externo. }\end{array}$ \\
\hline Cooperação & $\begin{array}{l}\text { Um dos objetivos futuros é criar um modelo social mais complexo que } \\
\text { pode incluir cooperação e outros tipos de interação entre agentes. }\end{array}$ \\
\hline Aprendizado & $\begin{array}{l}\text { Num primeiro momento não se considera mecanismos de aprendizado } \\
\text { para os agentes instrumentistas do mundo virtual. }\end{array}$ \\
\hline \multicolumn{2}{|c|}{ Paradigma multiagentes } \\
\hline \multicolumn{2}{|c|}{$\begin{array}{l}\text { A aplicação contempla interações com agentes humanos, representados por agentes no ambiente. Por- } \\
\text { tanto, segundo a categorização simplificada de Whalley [Wha09], essa aplicação pertence ao tipo DAI } \\
\text { (Inteligência Artificial Distribuída). }\end{array}$} \\
\hline \multicolumn{2}{|c|}{ Raciocínio do Agente } \\
\hline Utilização de áudio & $\begin{array}{l}\text { Faz parte do escopo da aplicação desenvolver a comunicação por áudio. } \\
\text { O agente se movimenta a partir de estímulos sonoros, identificando as } \\
\text { frequências das notas executadas no piano. }\end{array}$ \\
\hline Composição Algorítmica & $\begin{array}{l}\text { Podemos considerar os filtros por frequência que o agente instrumentista } \\
\text { utiliza para alterar a entrada do sistema. A divisão por regiões e as } \\
\text { condições de estímulos são componentes algorítmicos da performance. }\end{array}$ \\
\hline Performance & $\begin{array}{l}\text { A intenção da aplicação é uma performance musical com piano prepa- } \\
\text { rado, e portanto pontos como o acompanhamento da situação do mundo } \\
\text { virtual são essenciais. }\end{array}$ \\
\hline
\end{tabular}

Tabela 4.7: Características no Desenho do Piano Preparado 


\section{Capítulo 5}

\section{Conclusões e trabalhos futuros}

Neste último capítulo apresentaremos algumas conclusões, considerações relevantes em relação ao presente trabalho, limitações técnicas e oportunidades para desenvolver trabalhos futuros com as ferramentas estudadas na área dos SMA Musicais.

Nesse trabalho conseguimos adaptar elementos existentes do ENSEMBLE para processar áudio, identificamos que os raciocínios são essenciais para implementar requisitos composicionais e que as interações entre eles e o resto dos componentes internos de um agente são importantes para alcançar o resultado desejado. Vemos que a independência dos raciocínios é relativa, já que precisamos de vários componentes para lograr montar um fluxo de processamento de áudio; da mesma forma devemos garantir que um agente possui os sensores e atuadores certos para que um raciocínio se comporte do jeito adequado.

O áudio foi utilizado nas aplicações como uma fonte de estímulos, seja para identificar picos ou altura e esse tipo de uso pode ser expandido a outras características do áudio que podem ser extraídas. Conseguimos também complementar a capacidade de comunicação entre os agentes, através de um servidor de mensagens que facilitou a integração com sistemas externos.

Realizamos a mediação entre o ENSEMBLE e os músicos interessados em duas oportunidades diferentes, e conseguimos montar cenários com motivação performática ou composicional. Observamos que na situação atual da ferramenta a manipulação não pode ser direta e encontramos dificuldade em captar o interesse de músicos acostumados a utilizar ambientes como Pd e Max. A familiaridade com as interfaces de usuário, que nesses casos são gráficas, e o conhecimento da gama recursos disponíveis é valorizada pelos músicos da área. Na mesma linha o nosso desenvolvimento cumpriu parcialmente com algumas exigências, pois não conseguimos fornecer efeitos um pouco mais complexos de processamento de áudio, como a mudança de altura ou a mudança de tempo de reprodução, principalmente porque seriam implementações custosas, sem garantia de obter um resultado equivalente às alternativas já existentes em outras plataformas. Assim, para cada recurso de processamento de áudio adicional, a plataforma Java exigia uma implementação nova, diferentemente dos ambientes de composição mencionados, que fornecem diversos recursos prontos para o processamento de áudio.

Em relação às novas interfaces de interação, especialmente as GUI em dispositivos móveis, observamos que elas ajudam na comunicação entre o intérprete e o sistema e são um interessante primeiro passo para permitir esse controle gestual dos parâmetros das aplicações. Apesar disso, no caso da aplicação do piano preparado, observamos que a intérprete não conseguia se sentir completamente a vontade com as interfaces e com o controle dos efeitos. Seria necessário experimentar em mais oportunidades e ajustar em mais iterações alguns parâmetros de controle e acrescentar mais processamentos de áudio, se identificados. Notamos que foi importante colocar algumas variáveis como parâmetros de controle dinâmico, que podem ser ajustados no momento do ensaio, mas em 
geral quando a mudança atinge a codificação de raciocínios, não é conveniente alterar código Java no momento da gravação ou performance.

Graças à participação do grupo de pesquisa de computação musical do IME, COMPMUS, e ao contato com participantes do projeto MOBILE, conseguimos discutir e divulgar o arcabouço ENSEMBLE durante o transcurso desse trabalho, porém, nos parece essencial manter o foco em colaborações com artistas para impulsar o projeto, seguindo o exemplo do projeto ISO e as suas colaborações multidisciplinares.

\subsection{Considerações}

Talvez um primeiro ponto a observar é a real necessidade que existe de criar vínculos entre os artistas e essas iniciativas de ferramentas, principalmente quando elas nascem como propostas técnicas. No caso do ENSEMBLE, a falta de uma interface gráfica intuitiva para a criação de aplicações dificulta o processo de experimentação; os usuários músicos não conseguem visualizar as potencialidades do arcabouço e como resultado podem ter dificuldade para explicar os processos desejados em termos de raciocínios do agente.

Nessa mesma linha é importante apontar para os potenciais usuários as semelhanças e diferenças entre uma aplicação multiagentes desenvolvida para o arcabouço e um trabalho realizado em CSound ou Pd, justificando assim porque o ENSEMBLE é interessante e inovador. Os pontos chaves são a adaptação em tempo real [Wha05], a espacialidade, a oportunidade de criar vínculos sociais complexos através de vida artificial e um novo paradigma de interatividade que deve continuar evoluindo.

Outro ponto tratado na presente pesquisa é a composição algorítmica, que se apresenta como um componente frequentemente usado, mas que não constitui um elemento central na produção musical eletroacústica ou nas performances interativas atuais. Identificamos que não existe um interesse tão grande de compositores que queiram formar peças apenas com esses elementos algorítmicos. Portanto devemos prever uma utilização de componentes algorítmicos como coadjuvantes na interação entre o músico e o sistema musical. Dessa forma, as técnicas de composição algorítmica devem estar contextualizadas na intenção de um compositor e não podem ser tratadas da mesma forma que os efeitos/processamentos de áudio; isso nos indica que desenvolver uma série de propostas de técnicas da literatura da composição algorítmica não terá a mesma utilidade do que dar um suporte personalizado ao compositor.

Como parte do resultado dessa pesquisa temos um conjunto de novos raciocínios que permitem o processamento de áudio internamente no agente; apesar de algumas limitações mencionadas, mostramos como o ENSEMBLE pode se aplicar em cenários com requisitos artísticos para performance ou para a geração de material eletroacústico. Em relação à linguagem de script proposta, EARScript, depois de várias tentativas de definição e protótipos descartáveis obtivemos uma definição clara quanto às principais características, operadores e sintaxe.

Constatamos também que os músicos interessados já possuem algum conhecimento de ferramentas de processamento de áudio; ambientes de construção de aplicativos musicais como o Pd, Max e Csound são cada vez mais populares, motivo pelo qual é importante questionar porque deveríamos acrescentar mais uma interface gráfica a essa gama já existente, ou qual seria a importância de que usuários leigos conseguissem rapidamente explorar um arcabouço de sistemas multiagentes musicais. Uma possível resposta é que o caminho futuro a ser percorrido pelo nosso projeto é justamente a convergência e integração com as ferramentas e plataformas já disponíveis. Os componentes visuais do PureData poderiam atender plenamente à falta de uma interface gráfica no ENSEMBLE. Uma 
convergência entre esses ambientes e o ENSEMBLE seria um objetivo válido de trabalhos futuros, talvez na forma externals e plug-ins ou de qualquer outro formato que integre o arcabouço às ferramentas já existentes.

Outra característica onservada em usuários potencialmente interessados no ENSEMBLE é a preferência pelo controle das condições das peças ou performances. Isso foi constatado a partir de vários levantamentos, como no caso do piano preparado, e tivemos como resultado a necessidade de fornecer novas interfaces, mais naturais e gestuais, ao ecossistema do arcabouço. A integração com aplicativos de dispositivos móveis baseados em sensores e telas tácteis abre uma gama de possibilidades, assim como a adoção de padrões para enviar e processar mensagens de controle.

\subsection{Limitações do Java para o Processamento de Áudio e Portabi- lidade}

Java é uma linguagem que apresenta a vantagem de ser independente de plataforma, porém, conta com algumas desvantagens que já foram identificadas no desenvolvimento do ENSEMBLE [Tho11]. Já haviam sido levantados pontos como a falta de controle no mecanismo de gerenciamento automático de memória do Java (Garbage Collector) que pode causar interrupções esporádicas em operações do arcabouço, a demora nas primeiras execuções devido à compilação em tempo de execução (Just-in-time Compilation) e a simplicidade da biblioteca JavaSound, que não serve como uma solução para aplicações de áudio profissionais.

Na presente pesquisa identificamos e tivemos que enfrentar outras dificuldades voltadas ao processamento de áudio em Java e ao uso das bibliotecas alternativas de som como o Jack Connection Kit e outras dependências.

O trabalho com processamento de efeitos de áudio para Java apresenta uma série de dificuldades, especialmente para processamento em tempo real. Dentre as limitações, achamos a ausência de bibliotecas realmente nativas, sem dependências, que atendam às necessidades básicas de processamento de áudio digital. A solução de incluir bibliotecas nativas com adaptadores como o Java Native Interface não é sempre viável, e muitas vezes o esforço não pode ser facilmente estimado.

Também constatamos a falta de uma integração eficiente da plataforma Java com os mecanismos de plug-ins de áudio, isso nos referindo aos mais populares padrões: LADSPA e VST. Para esse último padrão existe apenas uma iniciativa para a criação de plug-ins, mas não existe uma forma ideal para aproveitar os plug-ins existentes no ambiente Java, ou seja, não dispomos de um host completo e do suporte para Interfaces Gráficas. Nesta pesquisa conseguimos resultados limitados com a utilização de efeitos VST, sendo que cada caso deve ser avaliado e tratado individualmente, fazendo do Host JVST uma alternativa frágil em termos de diversidade de efeitos e robustez.

Há outros fatores que interferem na portabilidade do arcabouço que devemos considerar. A arquitetura definida para o ENSEMBLE é complexa e exige uma série de dependências que devem ser gerenciadas para garantir a compatibilidade com diferentes plataformas. Algumas vezes esse esforço de adaptação pode ser grande, como no caso de se adaptar projetos como Aubio ou LibXtract, bibliotecas usadas anteriormente, que dependem de várias outras bibliotecas de base referenciadas e que hoje encontram-se desatualizadas.

Na mesma linha, a arquitetura dos computadores, sejam 32 ou 64 bits, junto com a versão do sistema operacional, pode influenciar na disponibilidade de dependências como o Jack Connection Kit, o PureData ou inclusive uma versão compatível do Java. Por exemplo, o sistema OS X Leopard e anteriores não possuem uma versão de Java superior à 5 para a arquitetura 64 bits. Isso já seria 
um grave problema, e eliminaria a possibilidade de usar o ENSEMBLE; além desse ponto temos a exigência de usar a mesma arquitetura (32 ou 64bits) para a máquina virtual Java e para a instância do servidor de áudio Jack utilizado e não existem versões desse servidor de áudio na plataforma Mac para todas as arquiteturas.

Além disso, as divergências nas implementações do Jack e Pd em diferentes plataformas são também fatores relevantes, por exemplo, a interação entre os dois na plataforma Windows é muito limitada em relação às versões correspondentes em Linux; principalmente em termos de criação de canais virtuais do Jack no $\mathrm{Pd}$, a configuração padrão que aparece no Linux não aparece no outro sistema. Todos esses fatores mostram que o objetivo da portabilidade ainda não foi alcançado, e as dependências em relação a sistemas externos precisam ser revistas no contexto do desenvolvimento do ENSEMBLE.

\subsection{Trabalhos Futuros}

Resgatamos várias possibilidades para continuar o trabalho nesse projeto, tanto expansões mais técnicas assim como novas áreas e abordagens para o uso do ENSEMBLE.

Um trabalho que pode ser desenvolvido no contexto dessa pesquisa é a inclusão de outras técnicas de espacialização, como é o caso de modelos Head-Related Transfer Function (HRTF), que além de acrescentar valor como uma alternativa para a espacialização, poderia fomentar outras linhas de desenvolvimento para as aplicações com a ferramenta.

Também podemos considerar a possibilidade de interagir com projetos que surgiram com o propósito de padronizar elementos de espacialização, como é o caso do SpatDIF [BS11] que visa a criação colaborativa de um formato para descrever a informação de áudio espacial numa forma estruturada para atender a aplicações em tempo real.

Uma perspectiva interessante do projeto ENSEMBLE é diversificar a sua utilização em cenários que não sejam necessariamente sistemas interativos com intuito performático ou composições eletroacústicas. O mesmo contato com compositores, estudantes e professores da área, como no caso de participantes do projeto MOBILE ${ }^{1}$, apontaram outras possibilidades de uso da ferramenta. Dentre elas, o uso do ENSEMBLE em mixagem e jogos interativos ou aplicações a serem controladas pelos espectadores de uma performance.

O desenvolvimento de jogos interativos com avatares que consigam escutar uma versão espacializada do mundo virtual pode ser facilmente implementado com o arcabouço, que permite também extrapolar a realidade acústica, através de mudanças na propagação do som ou processamentos adicionais.

Mudar a experiência de uma apresentação ao vivo, individualizando a espacialização dos atores, pode ser uma interessante alternativa para o arcabouço, que seria controlado pela plateia em tempo real; diferentemente de composições ou performances que atendem a objetivos artísticos mais rigorosos, podemos valorizar o caráter lúdico dessas possibilidades.

Outra área de aplicação ainda inexplorada é o estúdio de gravação e mixagem, aproveitando o efeito de espacialização no ENSEMBLE que pode constituir num recurso a mais para interagir com o posicionamento de fontes sonoras a serem mixadas.

\footnotetext{
${ }^{1}$ http://www.cmu.eca.usp.br/mobile/
} 


\section{Apêndice A}

\section{Código da Interface do Piano Preparado - ControlOSC}

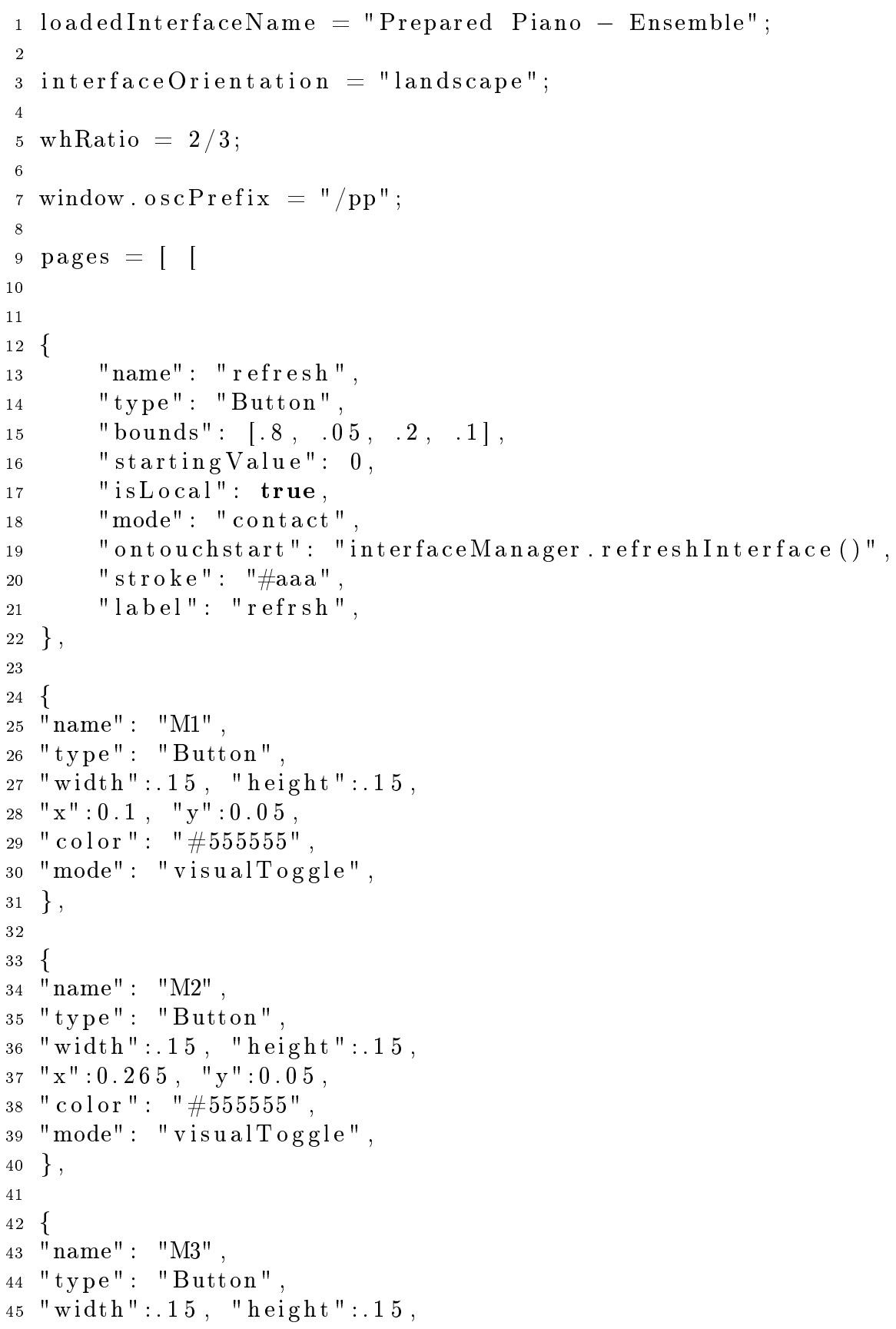




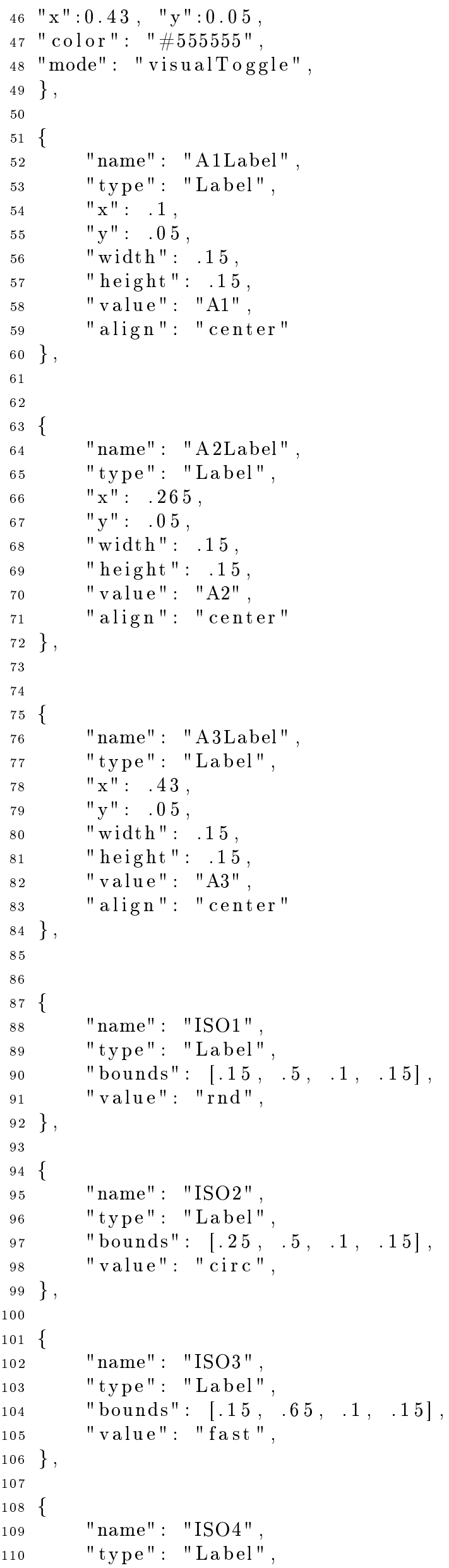




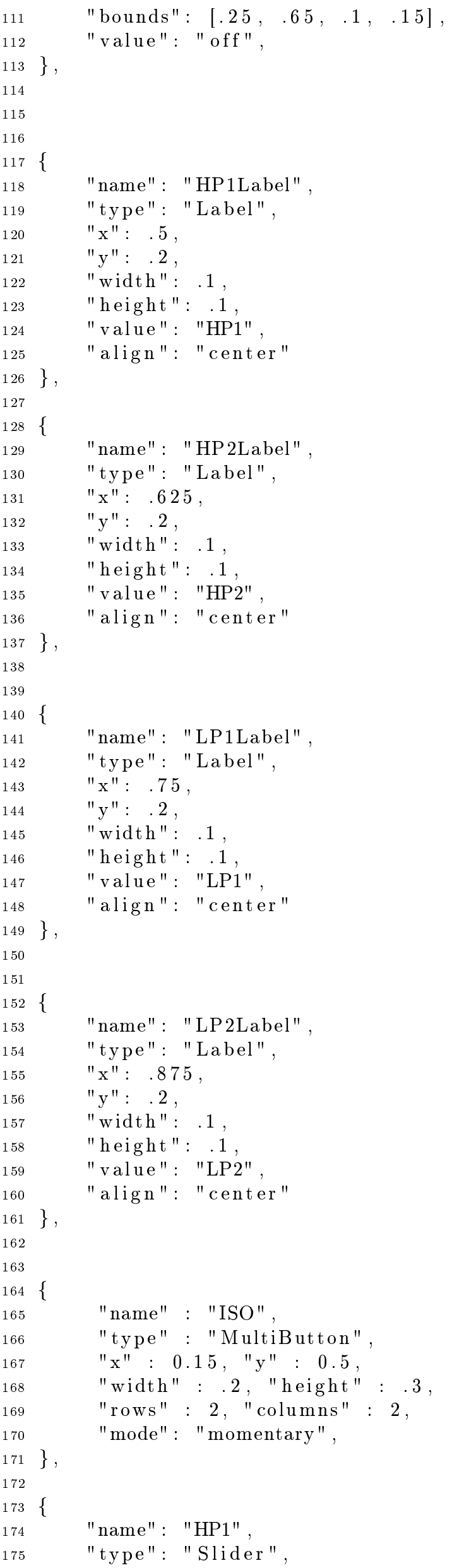




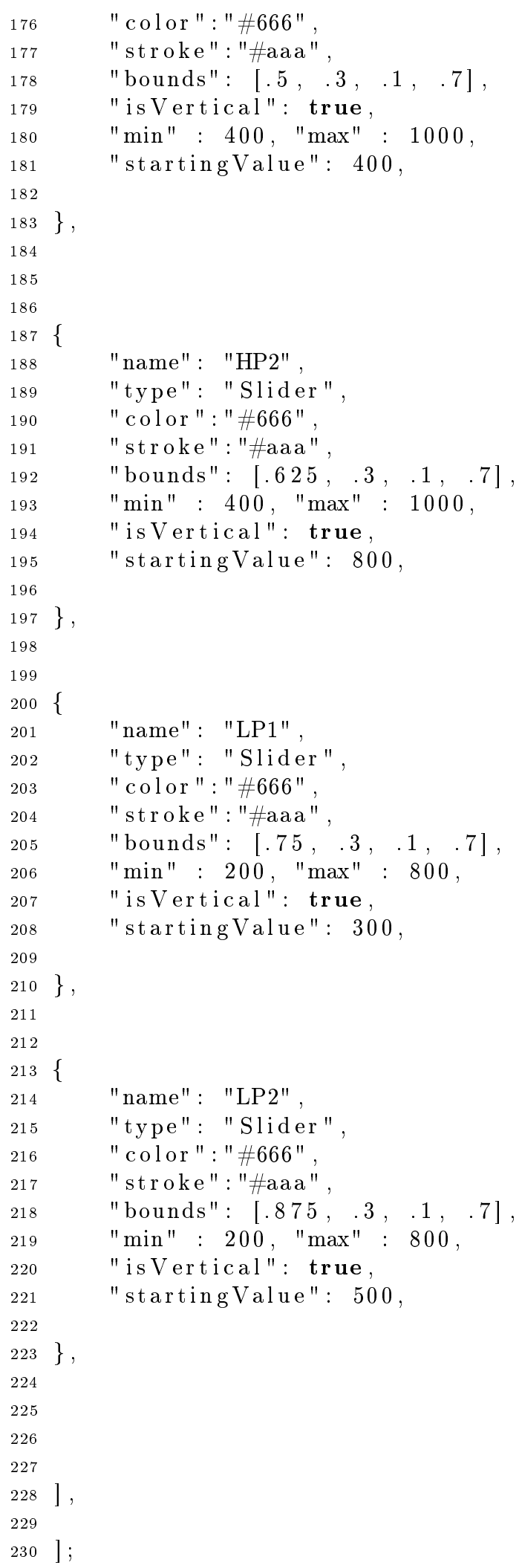


Apêndice B

Esquema de Gravação 


\section{Esquema de gravação Piano preparado - Ensemble}

Pianista: Michelle Agnes

\section{Objetivo}

O propósito dessa gravação foi registrar todo o material sonoro da performance, incluindo a captação do piano e as saídas do sistema. Capturamos em vídeo a performance e os elementos gestuais da interpretação.

Para essa performance foi necessário providenciar um retorno para a intérprete que interagiu com o sistema, esse retorno teve como intenção refletir a espacialização do som.

\section{Equipamento a ser instalado - utilizado}

\section{Placa de som}

Utilizamos uma placa FastTrack Pro da M-Audio com 2 entradas e 4 saidas de áudio. As entradas contam com canon ou p2, as saidas são 4 RCA ou duas P2 e duas RCA.

\section{Roteador wireless}

Foi instalada uma rede wifi para comunicar o sistema com as interfaces

Interface de entrada

Foram colocados dois dispositivos móveis com Android para manipular parâmetros do sistema Laptop e projetor

Uma visualização do mundo virtual foi projetada para acompanhamento da intérprete.

\section{Entradas}

Um ou Dois microfones para captar o piano preparado

\section{Retorno}

Fones permitiram à intérprete escutar o resultado do sistema e o retorno da captação do microfone do piano. 
Fluxo

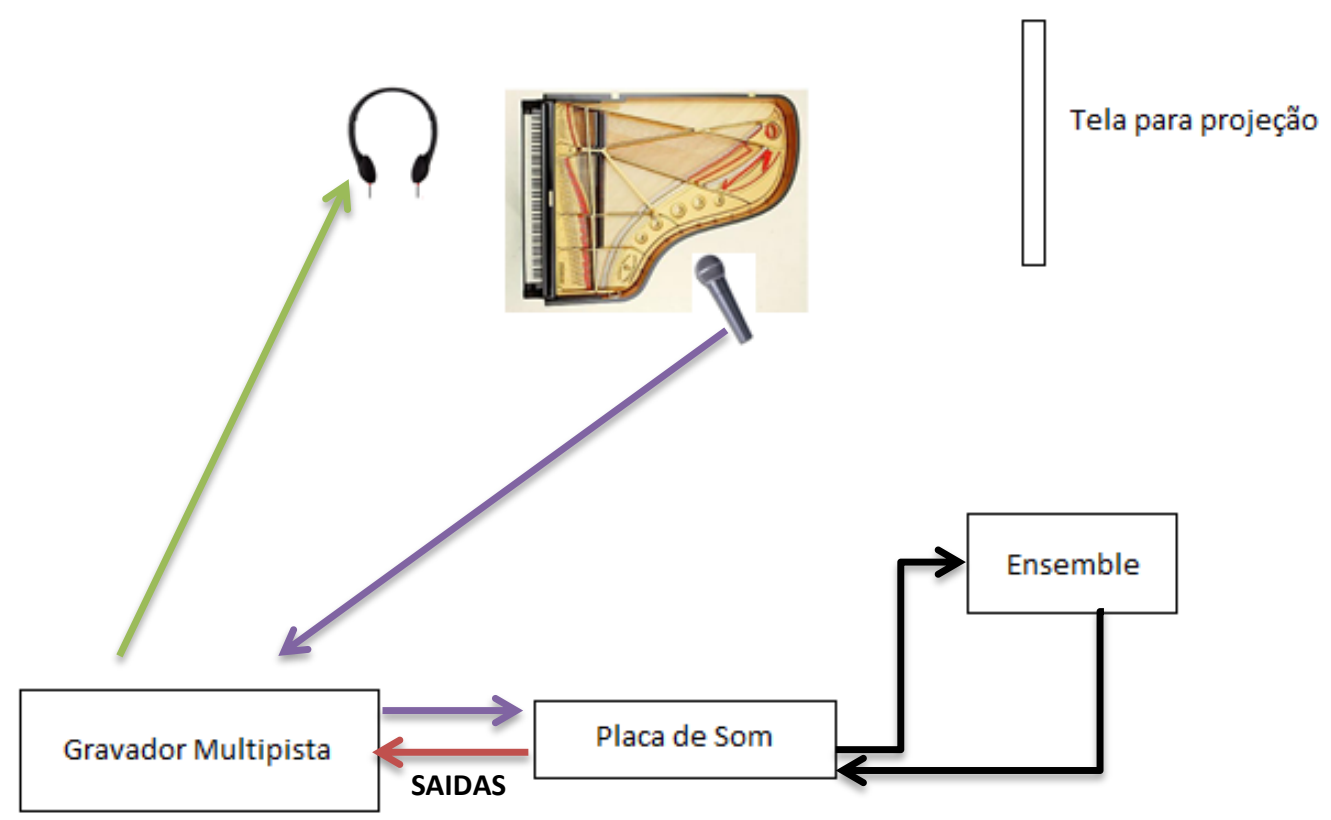

Pistas a serem gravadas

\begin{tabular}{|l|l|l|}
\hline Número & Nome da pista & Fonte \\
\hline 1 & Piano preparado & Microfone \\
\hline 2 & Saída Ensemble 1 & Saída 1 FastTrack Pro \\
\hline 3 & Saída Ensemble 2 & Saída 2 FastTrack Pro \\
\hline 4 & Saída Ensemble 3 & Saída 3 FastTrack Pro \\
\hline 5 & Saída Ensemble 4 & Saída 4 FastTrack Pro \\
\hline
\end{tabular}


APÊNDICE B 
Apêndice C

Manual de Uso da Aplicação 


\section{Manual de Uso do Ensemble com Piano Preparado}

\section{Conteúdo da Instalação}

- IDE - Ambiente de desenvolvimento Eclipse (www.eclipse.org/downloads/)

- External do pd para acompanhamento do mundo virtual (http://code.google.com/p/musicalagents/)

- Arquivos do projeto Ensemble (http://code.google.com/p/musicalagents/)

- Driver para placa FastTrack Pro

- ISO Flock - Simulação de enxames (http://swarms.cc/downloads/)

- Java 6

- Jack Connection Kit (http://jackaudio.org/download)

- Pd (http:puredata.info/downloads)

\section{Passos Para Usar}

Início

- Iniciar o JackPilot

- Start no Jack

- Iniciar o ISO Flock

- Abrir o arquivo xml de configuração do ISO Flock, se existir

- Abrir o Eclipse

- Escolher o workspace default do ENSEMBLE_WS2

\section{Visualização}

- Abrir o Pd

- Abrir o patch ensemble_gui.pd presente na pasta ensemble/pd/ no projeto ENSEMBLE

\section{Executar}

- No Eclipse Escolher Run> Run Configurations

- Escolher o cenário desejado

- Dar Run

- Confirmar a operação com o botão Proceed

\section{Características}

\section{Filtros}

Mundo de 10 unidades de distância por lado, com uma região em cruz central de 2 unidade de largura onde não se aplicam filtros. 
$\begin{array}{lcc}\text { UPPER_LEFT }=\text { HIGH_PASS } 1(\mathrm{HP} 1) & \text { Freq. } 400-1000 \mathrm{~Hz} & \text { Default } 400 \mathrm{~Hz} \\ \text { UPPER_RIGHT }=\text { HIGH_PASS } 2(\mathrm{HP} 2) & \text { Freq. } 400-1000 \mathrm{~Hz} & \text { Default } 800 \mathrm{~Hz} \\ \text { LOWER_LEFT }=\text { LOW_PASS } 1(\text { LP1) } & \text { Freq. } 200-800 \mathrm{~Hz} & \text { Default } 300 \mathrm{~Hz} \\ \text { LOWER_RIGHT = LOW_PASS } 2(\text { LP2) } & \text { Freq. } 200-800 \mathrm{~Hz} & \text { Default } 500 \mathrm{~Hz}\end{array}$

\section{Samples}

As categorias utilizadas na aplicação são:

- Longo

- Curtos

- Percussões

- Sinos

\section{Parâmetros de XML}

\section{Switch de pé}

Os parâmetros padrão estão nos XML.

- accSwitchLimit inclinação para ativar (apontando para baixo 0, perpendicular, chutando para a frente o máximo é -10) Default: -7

- accComeback inclinação para voltar da ativação, senão não permite usar de novo o switch. Corresponde ao movimento normal do pé voltando à posição normal (apontando para baixo 0, perpendicular, chutando para a frente o máximo e -10) Default: -0.5

- restlnterval Tempo entre um comando de on e um de off em ms. Default: $800 \mathrm{~ms}$

\section{Filtro}

useFilter Indica se deve usar os filtros na simulação ou não. (valores "true" ou "false") maxSamplesContinousPlay Indica o numero máximo de samples executados a partir de um estímulo.

\section{Pitch}

Valores que ativam a interatividade a partir de pitch tracking:

MinPitch Valor default $500 \mathrm{~Hz}$

MaxPitch Valor default $1400 \mathrm{~Hz}$

\section{Peak}

Valor do pico para ativar a interatividade.

LowerPeak valor default 0.4 (entre 0 e 1)

UpperPeak valor default 0.7 (entre 0 e 1)

\section{$\underline{\text { Condições }}$}


- Peak percebido $>$ LowerPeak = Estímulo 1

- Peak percebido < UpperPeak = Estímulo 2

\section{Uso do Android}

\section{AndOSC}

Usamos essa aplicação para ativar ou desativar a saída do agente avatar como switch ou pedal. Foi pensado em fixar o celular no tornozelo com a tela voltada para a parte externa e os botões para cima.

\section{ControlOSC}

Esse aplicativo conta com duas interfaces que vão ser usadas nos cenários do Ensemble com piano preparado.

Antes de escolher a interface é bom conferir que o destino (na aba destinations) tenha sido escolhido.

Para o delay espacializado usamos a interface Monome Emulation

Para a aplicação multi instrumentista usamos a interface Prepared piano - Ensemble. Quando não aparecem todos os elementos nessa tela, devemos dar refresh com o botão no canto superior direito da interface.

\section{Cenários}

Cenário 1 - Delay espacializado

Interfaces:

Switch -> aplicativo AndOSC

Interface -> aplicativo ControlOSC -> Interface Monome Emulation

Cenário 2 - Aplicação multi-instrumentista

Interfaces:

Interface -> aplicativo ControlOSC -> Interface Prepared piano - Ensemble

- config 1: 3 agentes com filtros ligados

- config 2: 3 agentes com filtros desligados

- config 3: 2 agentes com filtros desligados

- config 4: 2 agentes com filtros ligados 


\section{Referências Bibliográficas}

[AD02] G. Assayag e S. Dubnov. Universal prediction applied to stylistic music generation. Em Mathematics and music: a Diderot Mathematical Forum, páginas 147-159. Springer, 2002. 6

[Ame89] C. Ames. The markov process as a compositional model: a survey and tutorial. Leonardo, 22(2):175-187, 1989. 23

[BeCU06] C.C. Branco e M. em Composição-UNIRIO. O piano preparado e expandido no brasil. XVI Congresso da Associação Nacional de Pesquisa e Pós-graduação em Música (ANPPOM) Brasilia, 2006. 67

[Bey07] P. Beyls. Interaction and self-organisation in a society of musical agents. Em Proceedings of ECAL 2007 Workshop on Music and Artificial Life. Lisbon, Portugal, 2007. 5, 12

[Bil03] J.A. Biles. Genjam in perspective: a tentative taxonomy for ga music and art systems. Leonardo, 36(1):43-45, 2003. 25

[BNF07] D. Bisig, M. Neukom e J. Flury. Interactive swarm orchestra. Em Proceedings of the Generative Art Conference. Milano, Italy, 2007. 1, 14, 18, 27, 31

[BNF08] D. Bisig, M. Neukom e J. Flury. Interactive swarm orchestra, an artificial life approach to computer music. Em Proceedings of the International Computer Music Conference, Belfast, Ireland, 2008. 27, 31

[BPR99] F. Bellifemine, A. Poggi e G. Rimassa. Jade-a fipa-compliant agent framework. Em Proceedings of PAAM, volume 99, páginas 97-108, 1999. 28

[Bro06] P. Brossier. Automatic annotation of musical audio for interactive applications. Tese de Doutorado, 2006. 15, 46

[BS94] J. Bates e CARNEGIE-MELLON UNIV PITTSBURGH PA DEPT OF COMPUTER SCIENCE. The role of emotion in believable agents. Communications of the ACM, $37(7): 122-125,1994.9$

[BS11] J. Bresson e M. Schumacher. Representation and interchange of sound spatialization data for compositional applications. Em Proceedings of the International Computer Music Conference, Huddersfield, UK, 2011. 82

[BU09] D. Bisig e T. Unemi. Swarms on stage-swarm simulations for dance performance. Em the Proceedings of the Generative Art Conference. Milano, Italy, 2009. 31

[BU10] D. Bisig e T. Unemi. Cycles-blending natural and artificial properties in a generative artwork. Em the Proceedings of the Generative Art Conference. Milano, Italy, 2010. 31

[But30] S. Butterworth. On the theory of filter amplifiers. Wireless Engineer, 7:536-541, 1930. 45 
[Chr11] A.M. Christ. Bridging the mobile app gap. Sigma Journal Connectivity and the User Experience, página 27, 2011. 38

[Cop87] D. Cope. An expert system for computer-assisted composition. Computer Music Journal, 11(4):30-46, 1987. 26

[Cop93] D. Cope. Panel discussion. Em Proceedings of the International Computer Music Conference, 1993. 23

[Cro] D. Crockford. The application/json media type for javascript object notation (json), jul 2006. Relatório Técnico 4627. 38

[CVM08] L.L. Costalonga, R.M. Vicari e E.M. Miletto. Agent-based guitar performance simulation. Journal of the Brazilian Computer Society, 14(3):19-29, 2008. 3, 19, 21

[dC05] V.F. da Costa. Piano preparado: Composição com resultantes. ANPPOM Décimo Quinto Congresso, páginas 594-600, 2005. 67

[DFMS09] M. Delgado, W. Fajardo e M. Molina-Solana. Inmamusys: Intelligent multiagent music system. Expert Systems with Applications, 36(3):4574-4580, 2009. 4, 5, 8, 12

[DH03] P. Davis e T. Hohn. Jack audio connection kit. Em Proc. of the Linux Audio Developer Conference. ZKM Karlsruhe, 2003. 14

[DN01] P. Dahlstedt e M.G. Nordahl. Living melodies: Coevolution of sonic communication. Leonardo, 34(3):243-248, 2001. 4, 8, 10, 11, 12, 13, 19, 25, 53

[Eli92] A. Eliens. DLP: a language for distributed logic programming: design, semantics, and implementation. John Wiley \& Sons, Inc., 1992. 48

[EP09] A. Eigenfeldt e P. Pasquier. A realtime generative music system using autonomous melody, harmony, and rhythm agents. Em 12th Generative Art Conference GA2009, páginas $67-76,2009$. 4

[EP11] A. Eigenfeldt e P. Pasquier. A sonic eco-system of self-organising musical agents. Applications of Evolutionary Computation, páginas 283-292, 2011. 4, 11, 12, 13, 19, 22

$\left[\right.$ FTS $^{+}$05] R.R.A. Faria, L.F. Thomaz, L. Soares, B.T. Santos, M.K. Zuffo e J.A. Zuffo. Audienceaudio immersion experiences in the caverna digital. Em Proceedings of the 10th Brazilian Symposium on Computer Music, Belo Horizonte, Minas Gerais, Brazil, páginas 106117, 2005. 14

[GB91] PM Gibson e JA Byrne. Neurogen, musical composition using genetic algorithms and cooperating neural networks. Em Proceedings of the Second International Conference on Artificial Neural Networks, páginas 309-313. IET, 1991. 26

[GK58] G. Goertzel e M.H. Kalos. Monte carlo methods in transport problems. Progress in nuclear energy, 2:315-369, 1958. 46

[GMJ05] M. Gimenes, E.R. Miranda e C. Johnson. A memetic approach to the evolution of rhythms in a society of software agents. Em Proceedings of the 10th Brazilian Symposium on Computer Music (SBCM), 2005. 18

[GMJ06] M. Gimenes, E.R. Miranda e C. Johnson. The development of musical styles in a society of software agents. Em Proceedings of the International Conference on Music Perception and Cognition, páginas 204-208, 2006. 4

[Gor98] R. Gordon. Java native interface. Prentince Hall PTR, 1998. 14, 15 
[Gut92] M. Gutknecht. The postmodern mind: hybrid models of cognition. Connection science, 4(3):339-364, 1992. 26

[Har84] D. Harel. Dynamic logic, handbook of philosophical logic, vol. ii, d, 1984. 48, 51

[HB03] E.H. Hagen e G.A. Bryant. Music and dance as a coalition signaling system. Human Nature, 14(1):21-51, 2003. 20

[HEV03] Z. Huang, A. Eliens e C. Visser. Xstep a markup language for embodied agents. Em Proceedings of the 16th International Conference on Computer Animation and Social Agents (CASA 2003), IEEE Computer Society Press, páginas 105-110, 2003. 48

[HEV05] Z. Huang, A. Eliëns e C. Visser. Step: a scripting language for embodied agents. Life-like Characters, Tools, Affective Functions and Applications, 2005. 17, 48, 49

[HI58] L. Hiller e L. Isaacson. Musical composition with a high-speed digital computer. Journal of the Audio Engineering Society, 6(3):154-160, 1958. 1, 26

[Hol75] J.H. Holland. Adaptation in natural and artificial systems. The University of Michigan Press, Ann Arbor, 1975. 24

[Jac95] B.L. Jacob. Composing with genetic algorithms. Em Proceedings of the 1995 International Computer Music Conference, páginas 452-455, 1995. 25

[Jar00] H. Jarvelainen. Algorithmic musical composition. Seminar on content creation, Telecommunications software and multimedia laboratory, Helsinki University of Technology, 2000. 23,26

[Jen00] N.R. Jennings. On agent-based software engineering. Artificial intelligence, 117(2):277296, 2000. 9

[JS01] P.N. Juslin e J. Sloboda. Music and emotion: Introduction. Oxford: Oxford University Press, 2001. 20

[Lan97] C.G. Langton. Artificial life: An overview. The MIT Press, 1997. 13

[Lew00] G.E. Lewis. Too many notes: Computers, complexity and culture in voyager. Leonardo Music Journal, páginas 33-39, 2000. 26

[LM05] E. Larson e R. Maddox. Real-time time-domain pitch tracking using wavelets. Proceedings of the University of Illinois at Urbana Champaign Research Experience for Undergraduates Program, 2005. 46

[LMBL07] S.R. Livingstone, R. Mühlberger, A.R. Brown e A. Loch. Controlling musical emotionality: An affective computational architecture for influencing musical emotions. Digital Creativity, 18(1):43-53, 2007. 5

[McC01] J. McCormack. Eden: An evolutionary sonic ecosystem. Advances in Artificial Life, 1:133-142, 2001. 4, 8, 10, 11, 12, 14, 19, 25

$\left[\mathrm{MEF}^{+} 10\right]$ B. Mathieu, S. Essid, T. Fillon, J. Prado e G. Richard. Yaafe, an easy to use and efficient audio feature extraction software. Em 11th ISMIR conference, Utrecht, Netherlands, páginas 441-446, 2010. 46

[MH03] J. Mandelis e P. Husbands. Musical interaction with artificial life forms: Sound synthesis and performance mappings. Contemporary Music Review, 22(3):69-77, 2003. 13

[Mi192] D. Mills. Network time protocol (version 3) specification, implementation and analysis. Relatório técnico, 1992. 17 
[Mir02] E.R. Miranda. Emergent sound repertoires in virtual societies. Computer Music Journal, 26(2):77-90, 2002. 4

[Mir03a] E.R. Miranda. On the evolution of music in a society of self-taught digital creatures. Digital Creativity, 14(1):29-42, 2003. 4

[Mir03b] E.R. Miranda. On the music of emergent behavior: what can evolutionary computation bring to the musician? Leonardo, 36(1):55-59, 2003. 4

[MMH99] K. McAlpine, E. Miranda e S. Hoggar. Making music with algorithms: A case-study system. Computer Music Journal, 23(2):19-30, 1999. 4

[MMZG00] A. Moroni, J. Manzolli, F.V. Zuben e R. Gudwin. Vox populi: An interactive evolutionary system for algorithmic music composition. Leonardo Music Journal, 10:49-54, 2000. 4

[MRSE06] D. Murray-Rust, A. Smaill e M. Edwards. Mama: An architecture for interactive musical agents. Em Proceeding of the 2006 conference on ECAI 2006: 17th European Conference on Artificial Intelligence August 29-September 1, 2006, Riva del Garda, Italy, páginas 36-40. IOS Press, 2006. 4

[MT03] E.R. Miranda e P.M. Todd. A-life and musical composition: A brief survey. Em IX Brazilian Symposium on Computer Music, 2003. 13

[MW05] P. McLeod e G. Wyvill. A smarter way to find pitch. Em Proceedings of International Computer Music Conference, ICMC, 2005. 46

[NOK94] T. Nakatani, H.G. Okuno e T. Kawabata. Auditory stream segregation in auditory scene analysis with a multi-agent system. Em PROCEEDINGS OF THE NATIONAL CONFERENCE ON ARTIFICIAL INTELLIGENCE, páginas 100-100. JOHN WILEY \& SONS LTD, 1994. 22

[NTN02] M. Numao, S. Takagi e K. Nakamura. Constructive adaptive user interfaces-composing music based on human feelings. Em PROCEEDINGS OF THE NATIONAL CONFERENCE ON ARTIFICIAL INTELLIGENCE, páginas 193-198. Menlo Park, CA; Cambridge, MA; London; AAAI Press; MIT Press; 1999, 2002. 5, 6

[Nwa96] H.S. Nwana. Software agents: An overview. The Knowledge Engineering Review, 11(03):205-244, 1996. 21, 22

[Puc96] M. Puckette. Pure data: another integrated computer music environment. Proceedings of the Second Intercollege Computer Music Concerts, páginas 37-41, 1996. 3

[PW99] G. Papadopoulos e G. Wiggins. Ai methods for algorithmic composition: A survey, a critical view and future prospects. Em AISB Symposium on Musical Creativity, páginas 110-117, 1999. 23, 25

[Rei03] L.P. Reis. Coordination in Multi-Agent Systems: Applications in University Management and Robotic Soccer. Tese de Doutorado, PhD. Thesis, Univ. Porto, 2003. 7, 8, 11, 12

[RNC ${ }^{+}$95] S.J. Russell, P. Norvig, J.F. Canny, J.M. Malik e D.D. Edwards. Artificial intelligence: a modern approach. Prentice hall Englewood Cliffs, NJ, 1995. 12

[Row92a] R. Rowe. Interactive music systems: machine listening and composing. MIT Press Cambridge, MA, USA, 1992. 23

[Row92b] R. Rowe. Machine listening and composing with cypher. Computer Music Journal, 16(1):43-63, 1992. 23 
[Row99] R. Rowe. The aesthetics of interactive music systems. Contemporary Music Review, 18(3):83-87, 1999. 23

[RW79] C. Roads e P. Wieneke. Grammars as representations for music. Computer Music Journal, 3(1):48-55, 1979. 26

[Sch99] E. Schubert. Measurement and time series analysis of emotion in music. Tese de Doutorado, University of New South Wales, 1999. 6

[Sch04] M. Scheutz. Useful roles of emotions in artificial agents: A case study from artificial life. Em Proceedings of the National Conference on Artificial Intelligence, páginas 4248. Menlo Park, CA; Cambridge, MA; London; AAAI Press; MIT Press; 1999, 2004. 11

[Sho93] Y. Shoham. Agent-oriented programming. Artificial intelligence, 60(1):51-92, 1993. 9

[Ste96] M. Steedman. The blues and the abstract truth: Music and mental models. Mental Models in Cognitive Science, páginas 305-318, 1996. 26

[Tho11] L. F. Thomaz. Um arcabouço para construção de sistemas multiagente musicais. Tese de Doutorado, USP, 2011. 1, 2, 4, 10, 11, 12, 13, 15, 17, 18, 21, 22, 27, 28, 29, 32, 53, $59,65,68,81$

[TIS ${ }^{+}$07] J. Tweedale, N. Ichalkaranje, C. Sioutis, B. Jarvis, A. Consoli e G. Phillips-Wren. Innovations in multi-agent systems. Journal of Network and Computer Applications, 30(3):1089-1115, 2007. 21

[TQ09] L.F. Thomaz e M. Queiroz. A framework for musical multiagent systems. Em Proc. Int. Conf. Sound and Music Computing, Porto, páginas 213-218, 2009. 1, 3, 9, 10, 13, 22

[TW99] P.M. Todd e G.M. Werner. Frankensteinian methods for evolutionary music composition. Musical networks: Parallel distributed perception and performance, páginas 313-339, 1999. 5, 10, 13, 21, 25, 26

[UK04] L.K. Ueda e F. Kon. Andante: Composition and performance with mobile musical agents. Em In Proceedings of the International Computer Music Conference 2004, 2004. 21

[VE90] B. Vercoe e D. Ellis. Real-time csound: Software synthesis with sensing and control. ICMC Glasgow, páginas 209-211, 1990. 3

[VZ03] F.J. Von Zuben. Computação evolutiva: uma abordagem pragmática. UNICAMP, Available on: < ftp://ftp. dca. fee. unicamp. br/pub/docs/vonzuben/tutorial/tutorialEC. $p d f>[$ Links], 2003. 23, 24

[Wei05] G. Weinberg. Interconnected musical networks: Toward a theoretical framework. Computer Music Journal, 29(2):23-39, 2005. 19

[WF97] M. Wright e A. Freed. Open sound control: A new protocol for communicating with sound synthesizers. páginas 101-104, 1997. 14, 36

[WFM03] M. Wright, A. Freed e A. Momeni. Opensound control: state of the art 2003. Em Proceedings of the 2003 conference on New interfaces for musical expression, páginas 153-160. National University of Singapore, 2003. 15

[Wha05] I. Whalley. Software agents and creating music/sound art: Frames, directions, and where to from here. Em Proceedings of International Computer Music Conference, páginas $691-5,2005$. 1, 9, 27, 80 
[Wha09] I. Whalley. Software agents in music and sound art research/creative work: current state and a possible direction. Organised Sound, 14(02):156-167, 2009. 3, 18, 19, 22, $26,62,68,74,75,77$

[Wis89] J.M. Wisnik. som e o sentido: uma outra história das músicas. Editora Companhia das Letras, 1989. 67

[WNV03] R.D. Wulfhorst, L. Nakayama e R.M. Vicari. A multiagent approach for musical interactive systems. Em Proceedings of the second international joint conference on Autonomous agents and multiagent systems, páginas 584-591. ACM, 2003. 4, 5

[Woo02] M. Wooldridge. An introduction to multi-agent systems. 2002. 2002. 7

[Xen92] I. Xenakis. Formalized Music: Thought and mathematics in composition. Pendragon Pr, 1992. 23

[Zic87] D. Zicarelli. M and jam factory. Computer Music Journal, 11(4):13-29, 1987. 23 